\author{
UNIVERSIDADE DE SÃO PAULO \\ ESCOLA DE ENGENHARIA DE SÃO CARLOS \\ DEPARTAMENTO DE ENGENHARIA DE ESTRUTURAS
}

LICIA CARVALHO COELHO

SOFTWARE PARA CÁLCULO DE FLUXO E PRESSÕES EM SILOS CILÍNDRICOS METÁLICOS PARA ARMAZENAMENTO DE PRODUTOS AGRÍCOLAS E INDUSTRIAIS

SÃO CARLOS 



\title{
SOFTWARE PARA CÁLCULO DE FLUXO E PRESSÕES EM SILOS CILÍNDRICOS METÁLICOS PARA ARMAZENAMENTO DE PRODUTOS AGRÍCOLAS E INDUSTRIAIS
}

\author{
VERSÃO CORRIGIDA \\ A versão original encontra-se na Escola de Engenharia de São Carlos
}

Texto apresentado à Escola de Engenharia de São Carlos, da Universidade de São Paulo, como parte dos requisitos necessários à obtenção do título de Mestre em Engenharia Civil (Engenharia de Estruturas).

Orientador: Prof. Titular Carlito Calil Júnior

São Carlos

2016 
AUTORIZO A REPRODUÇÃO TOTAL OU PARCIAL DESTE TRABALHO, POR QUALQUER MEIO ĊONVENCIONAL OU ELETRÔNICO, PARA FINS DE ESTUDO E PESQUISA, DESDE QUE CITADA A FONTE.

Coelho, Licia Carvalho

Software para cálculo de fluxo e pressões em silos cilindricos metálicos para armazenamento de produtos agricolas e industriais / Licia Carvalho Coelho; orientador Carlito Calil Junior. São Carlos, 2016.

Dissertação (Mestrado) - Programa de Pós-Graduação em Engenharia Civil (Engenharia de Estruturas) e Área de Concentração em Estruturas -- Escola de Engenharia de São Carlos da Universidade de São Paulo, 2016.

1. Silo. 2. Programa computacional. 3. Pressões. I. Titulo. 


\section{FOLHA DE JULGAMENTO}

Candidata: Engenheíra LICIA CARVALHO COELHO.

Título da dissertaçāo: "Software para cálculo de fluxo e pressōes em silos cilindricos metálicos para armazenamento de produtos agricolos $e$ industriais".

Data da detesa: 05/09/2016.

\section{Comissōo Julgadora:}

Prof. Titular Carlito Calil Juntar (Orlentador)

(Escola de Engenharia de Sá Carlos/EESC)

Prof. Dr. Andrés Balista Cheung

[Universidade Federal de Mato Grosso do Sul/LFMS]

Prof. Dr. Jose Wallace Barbosa do Nascimento \{Universidade Federal da Paraiba/UFPB\}

\section{Resultado:}

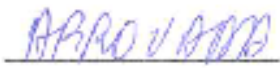

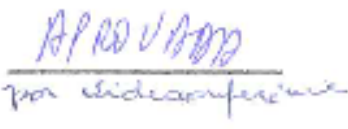

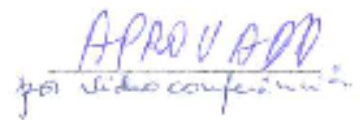

Coordenador do Programa de Pós-Graduaçāo em Engenheira Civil

[Engenhario de Estruturas):

Prof. Titular Humberto Breves Coda

Presidente da Comissāo de Pós-Graduaçōo:

Prof. Associado Luls Femando Costa Alberto 

Aos meus pais Antônio Luiz e Thais Elena, A minha irmã Tenile, Dedico. 



\section{AGRADECIMENTOS}

A minha família, pelos cuidados, pela compreensão e amor demonstrados.

À Escola de Engenharia de São Carlos pelos recursos e infraestrutura técnico-científica.

Ao meu orientador, Prof. Titular Carlito Calil Júnior, pela confiança e excelente orientação.

Ao corpo docente do Departamento de Engenharia de Estruturas, pelos conhecimentos transmitidos.

Ao técnico Dorival Piedade Neto, pela orientação na programação do software, sempre disposto a colaborar.

Ao Conselho Nacional de Desenvolvimento Científico e Tecnológico (CNPq) pela concessão de bolsa de mestrado.

Aos colegas de pós-graduação do Departamento de Estruturas, em especial os amigos de sala de estudos Paulo Vitor e Karolinne Coelho.

Aos Amigos do Laboratório de Madeira e Estruturas de Madeira (LaMEM) pelo companheirismo nesta jornada. 



\section{RESUMO}

COELHO, L. C. Software para cálculo de fluxo e pressões em silos cilíndricos metálicos para armazenamento de produtos agrícolas e industriais. 105 p. Dissertação de mestrado - Escola de Engenharia de São Carlos, Universidade de São Paulo, São Carlos, 2016.

Este trabalho apresenta o desenvolvimento e exemplos de aplicação de um software para cálculo de fluxo e pressões em silos cilíndricos metálicos de produtos agrícolas e industriais. As propriedades dos produtos a granel variam amplamente, e consequentemente suas pressões, tanto em grandeza e distribuição. Esses cálculos são importantes para prever picos de pressões imprevisíveis que podem causar sérios danos. O software está desenvolvido em linguagem Python com embasamento nas formulações do BS EN 1991-4 para silos esbeltos, medianamente esbeltos e baixos, com e sem excentricidades de carregamento e descarregamento, tremonhas cônicas, piramidais quadráticas, em forma de cunha ou de saída retangular dos tipos íngreme, rasa ou fundo plano. O programa é rápido, confiável, modular, estruturado e de fácil manuseio. A interface do software é simples para interação entre os dados fornecidos pelo usuário, tais como propriedades dos produtos armazenados, propriedades geométricas do silo e da tremonha, e os resultados obtidos das pressões e determinação do tipo de fluxo. São desenvolvidos exemplos de aplicação e análise dos resultados em silos cilíndricos metálicos de chapa corrugada muito comuns de uso em fazendas e cooperativas. Espera-se fornecer uma importante ferramenta para projetistas e desta forma criar projetos de silos mais eficientes, diminuindo falhas e colapsos.

Palavras-chave: Silo. Programa computacional. Pressões. 



\begin{abstract}
COELHO, L. C. Software to calculate pressure and flow in metal cylindrical silos for storage of agricultural and industrial products. 105 p. Dissertation (M. Sc. in Civil Engineering (Structures)) - School of Engineering of São Carlos, University of São Paulo, São Carlos, 2016.
\end{abstract}

This paper presents the development and application examples of software for calculation of pressures and flow in metal cylindrical silos of agricultural and industrial products. The properties of bulk materials vary widely, and consequently pressures, both in magnitude and distribution. These calculations are important to avoid peak unpredictable pressures that may cause serious damage. The software is developed in Python with grounding in the formulations of BS EN 1991-4 for silos slender, intermediate slenderness and squat, with and without loading and unloading eccentricities, conical and square pyramidal hoppers, wedge hoppers and hoppers of rectangular planform, shallow, steep or flat bottom. The program is fast, reliable, modular, structured and easy to handle. The software interface is simple for interaction between the data provided by the user, such as properties of stored products, geometric properties of the silo and hopper, and the results of the pressures and determining the type of flow. Are developed application examples and analysis of results in very common corrugated sheet metal cylindrical silos use in farms and cooperatives. It is expected to provide an important tool for designers and thus be more efficient silo designs, reducing failures and breakdowns.

Keywords: Silo. Computer program. Pressures. 



\section{LISTA DE FIGURAS}

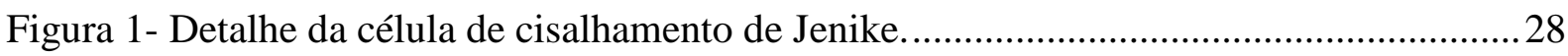

Figura 2 - Aparelho de cisalhamento de Jenike, vista superior e vista lateral........................ 29

Figura 3-Tipos de fluxo em silos com descarregamento concêntrico. .....................................30

Figura 4 - Tipos de fluxo em silos com descarregamento excêntrico.....................................30

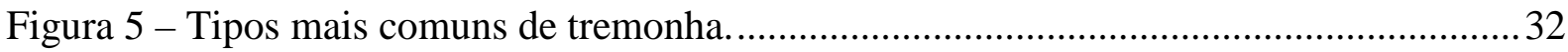

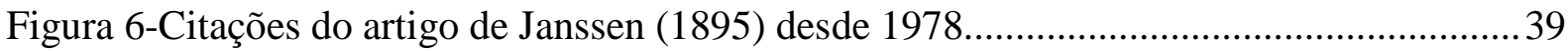

Figura 7 - Forças na camada elementar de altura dz adotada por Janssen(1895)................... 40

Figura 8-- Seção transversal com pressões excêntricas horizontais........................................44

Figura 9- Equilíbrio de forças que agem em uma camada infinitesimal da tremonha.............47

Figura 10- Formas de seção transversal. ........................................................................... 51

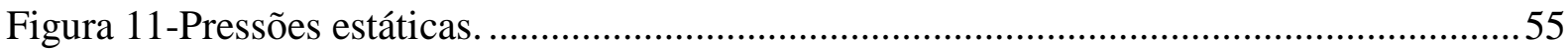

Figura 12- Diferença entre pressões em silos esbetos e medianamente esbelto/baixo.............56

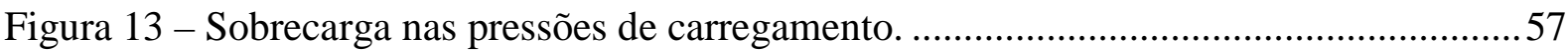

Figura 14-Componentes de pressões sobrecarga de carregamento. .......................................58

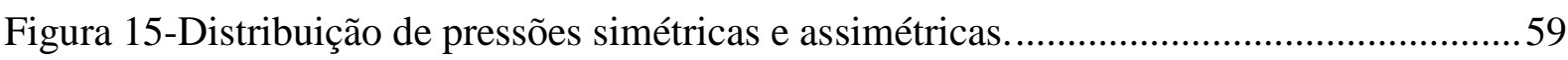

Figura 16- Sobrecarga nas pressões de descarregamento.....................................................62

Figura 17-Distribuição de pressões com descarregamento excêntrico.....................................63

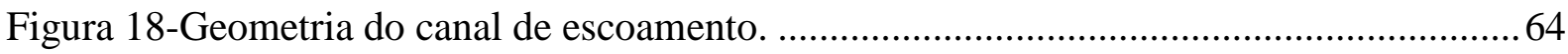

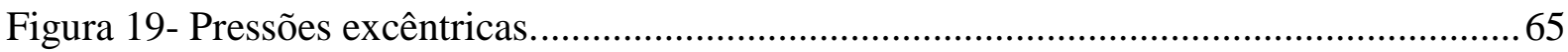

Figura 20 - Determinação do tipo de fluxo em tremonhas em forma de cunha........................66

Figura 21 - Determinação do tipo de fluxo em tremonhas cônicas e piramidais quadrada.....66

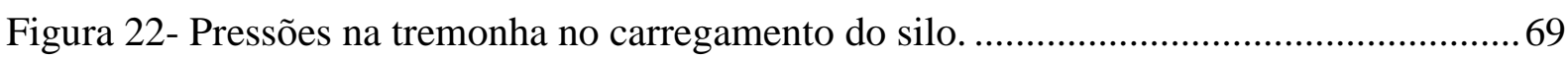

Figura 23- Pressões na tremonha no descarregamento do silo.............................................. 70

Figura 24- Interface programa "Pressões Silos Esbeltos 1.0”................................................ 72

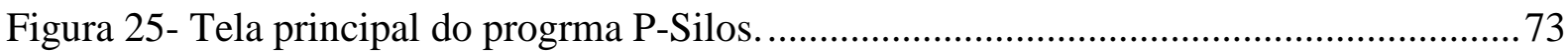

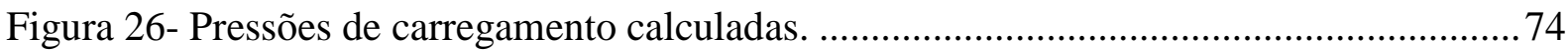

Figura 27- Pressões de descarregamento calculadas e visualização dos módulos disponíveis.74 Figura 28-Tela do módulo do P-Silos para determinação das propriedades dos produtos. ..... 75

Figura 29-Tela do módulo do P-Silos para traçado do Yield Locus. ....................................... 75

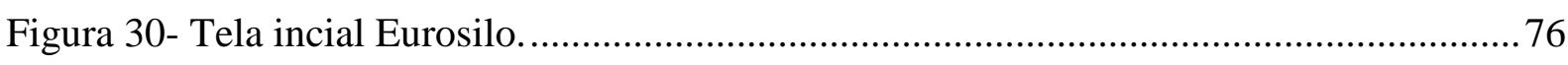

Figura 31-Tela do Eurosilo para cálculo da sobrecarga. .........................................................77

Figura 32-Tela do Eurosilo para cálculo das pressões excêntricas. .........................................77 
Figura 33-Tela auxiliar do programa Eurosilo para adicionar produto. 78

Figura 34-Tela auxiliar do Eurosilo para entrada de dados de paredes corrugadas................. 78

Figura 35-Tela auxiliar do Eurosilo entrada de dados de saída retangular............................. 79

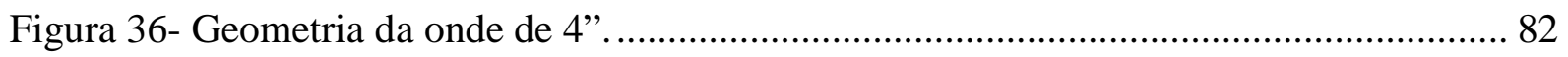

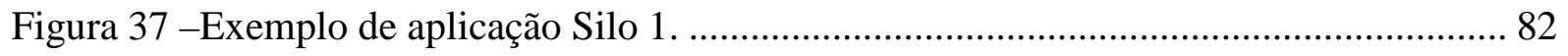

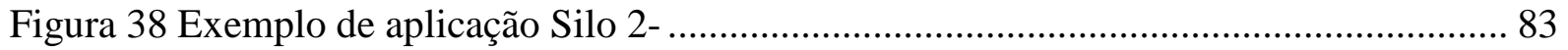

Figura 39- Excentricidades dos exemplos de aplicação Silos 3 e 4........................................ 84

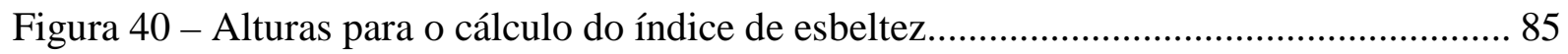

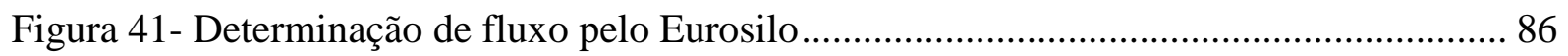

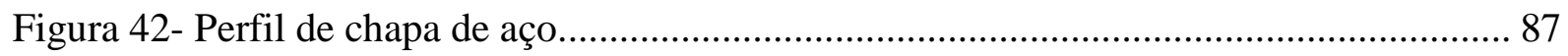

Figura 43 - Tela adicional para incluir valores dos comprimentos relativos da chapa

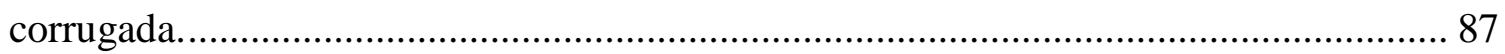

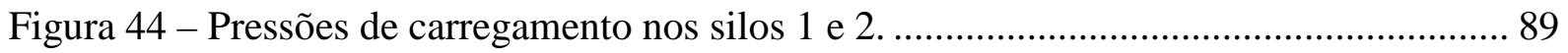

Figura 45- Pressões de descarregamento nos silos 1 e 2 2....................................................... 90

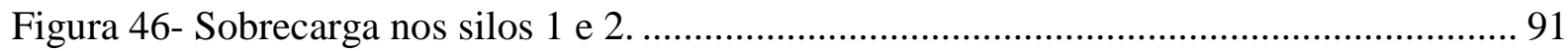

Figura 47-Pressões excêntricas nos Silos 1 e 2.................................................................... 92

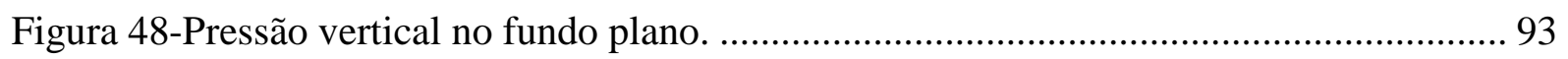

Figura 49- Pressões de carregamento na tremonha íngreme silo 1 e 2 ................................... 93

Figura 50- Pressões de descarregamento na tremonha íngreme silo 1 e $2 \ldots \ldots \ldots \ldots \ldots \ldots \ldots . . . . . . . . . . . . . .93$

Figura 51- Sobrecarga de carregamento e descarregamento nos Silos 3 e 4......................... 95

Figura 52-Pressões excêntricas horizontais nos Silos 3 e 4.................................................. 97

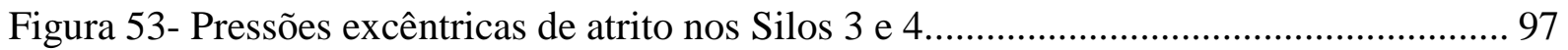




\section{LISTA DE TABELAS}

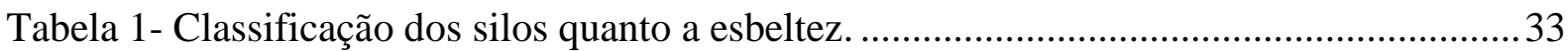

Tabela 2 - Valores médios de propriedades dos produtos...................................................52

Tabela 3- Valores de coeficiente de atrito da parede.............................................................53

Tabela 4-Valores inferior e superior das propriedades físicas. .............................................54

Tabela 5 - Valores para fatores de descarregamento em silos esbeltos.................................60

Tabela 6 - Valores para fatores de descarregamento em silos medianamente esbeltos. ..........60

Tabela 7- Valores para fator de sobrepressão no descarregamento.........................................61

Tabela 8-Expressões para cálculo de pressões excêntricas. ....................................................65

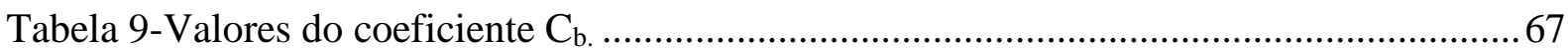

Tabela 10-Valor do coeficiente de atrito efetivo na tremonha. ..............................................68

Tabela 11 - Propriedades físicas do grão de soja.................................................................. 81

Tabela 12-Valores utilizados no cálculo do coeficiente de atrito efetivo................................87

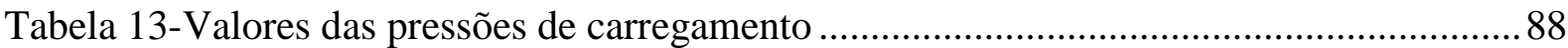

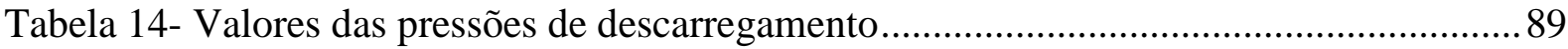

Tabela 15- Valores positivos das sobrecargas variando com a profundidade.........................90

Tabela 16- Valores de sobrecarga com variação circunferencial nos silos 1 e 2 ....................91

Tabela 17-Estudo das pressões na seção transversal de altura $\mathrm{z}=2,00$ metros. .......................92

Tabela 18- Sobrecarga de carregamento e descarregamento nos Silos 3 e 4..........................94

Tabela 19- Valores de sobrecarga com variação circunferencial nos silos 3 e 4....................95

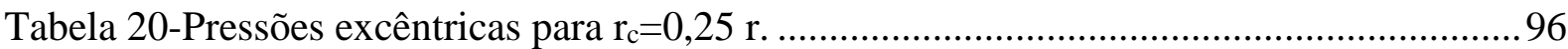

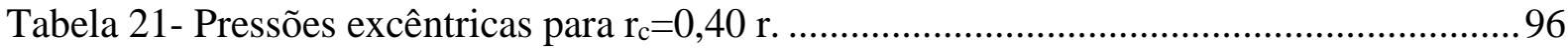

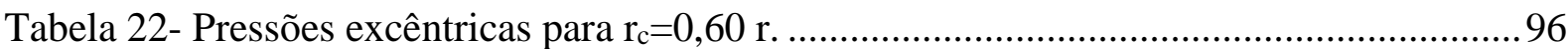





\section{LISTA DE QUADROS}

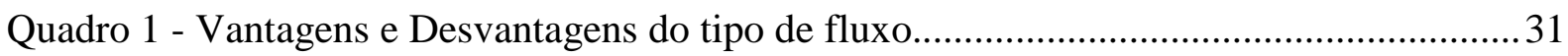

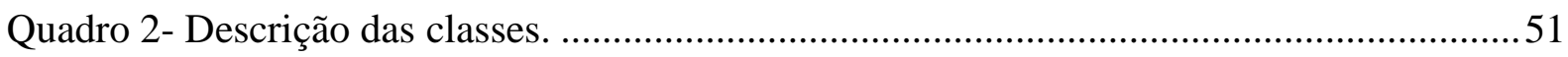





\section{LISTA DE SÍMBOLOS}

\section{Letras romanas}

$A_{c} \quad$ Área transversal do canal do fluxo

$A_{s} \quad$ Área do produto armazenado

$C_{p e} \quad$ Fator de sobrecarga no descarregamento

$C_{p o} \quad$ Fator de sobrecarga no carregamento

$\mathrm{C}_{\mathrm{op}} \quad$ Fator de sobrepressão

$\mathrm{d}_{\mathrm{c}} \quad$ Diâmetro do silo

$e_{c} \quad$ Excentricidade do canal de fluxo

$e_{f} \quad$ Excentricidade de carregamento

$h_{h} \quad$ Altura da tremonha

K Relação pressão horizontal e pressão vertical

$P_{h f} \quad$ Pressão horizontal de carregamento

$P_{p f} \quad$ Sobrecarga de carregamento

$P_{v f} \quad$ Pressão vertical de carregamento

$p_{\text {hce }} \quad$ Pressão horizontal no interior do canal de escoamento

$p_{h e} \quad$ Pressão horizontal de descarregamento

$p_{\text {hse }} \quad$ Pressão horizontal estática

$p_{n f} \quad$ Pressão normal na tremonha

$p_{v f t} \quad$ Pressão vertical na transição

$p_{w e} \quad$ Força de atrito no descarregamento

$p_{w f} \quad$ Pressão de atrito na parede no carregamento

$r_{c} \quad$ Raio do fluxo de escoamento

$U$ Perímetro da seção transversal do silo

Z Profundidade

\section{Letras gregas}

$\beta \quad$ Ângulo de inclinação da tremonha com a horizontal

$\gamma \quad$ Peso específico do produto armazenado

$\mu_{\text {eff }} \quad$ Coeficiente de atrito da parede efetivo

$\mu_{w} \quad$ Coeficiente de atrito da parede 
$\emptyset_{i} \quad$ Ângulo de atrito interno

$\emptyset_{\mathrm{im}} \quad$ Ângulo de atrito interno médio

$\emptyset_{r} \quad$ Ângulo de repouso do produto 


\section{LISTA DE SIGLAS E ABREVIATURAS}

ACI American Concrete Institute

ANSI American Nacional Standard Institute

AS Australian Standard

CEN Comitê Europeu de Normalização

CFBC Canadian Farm Building Code

CONAB Companhia Nacional de Abastecimento

DIN Deutsches Institute for Normung

EESC Escola de Engenharia de São Carlos

EM European Committee of Standardization

ISO International Organizations for Standardization

SET Departamento de Engenharia de Estruturas

USP Universidade de São Paulo 



\section{SUMÁRIO}

1. INTRODUÇÃ

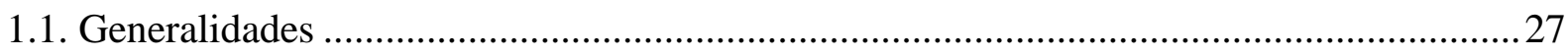

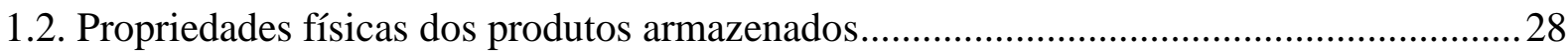

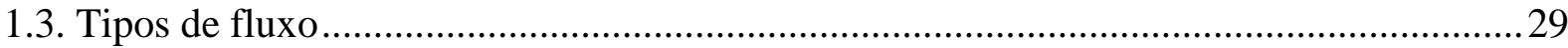

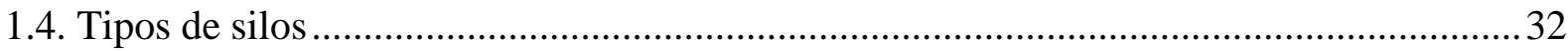

1.5. Estudos realizados na escola de engenharia de São Carlos (USP) ...................................33

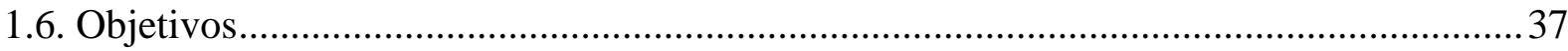

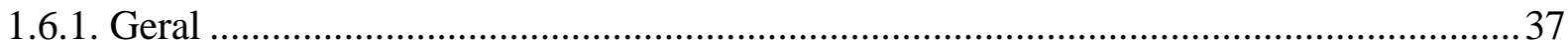

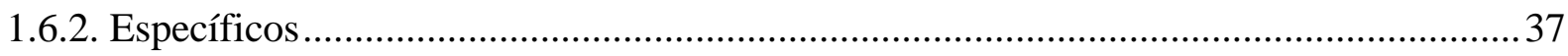

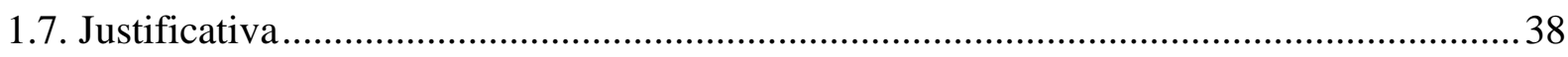

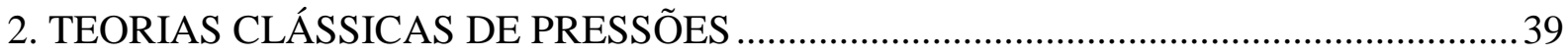

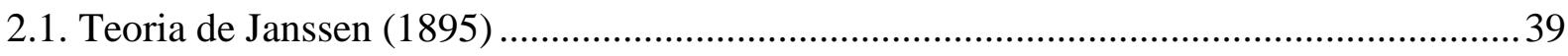

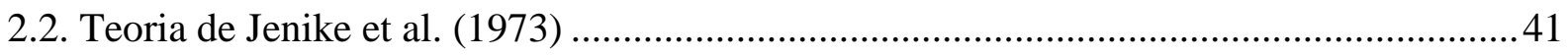

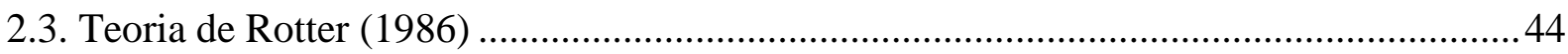

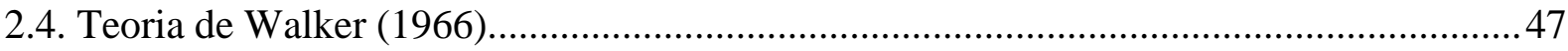

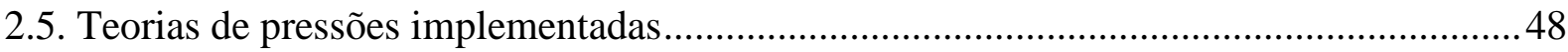

3. NORMAS ESTRANGEIRAS E RECOMENDAÇÕES DO EUROCODE .......................49

3.1. Documentos normativos em projetos de silos ...............................................................49

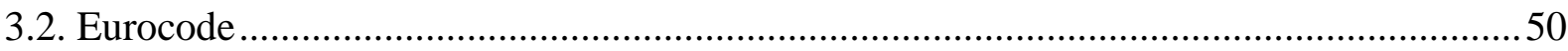



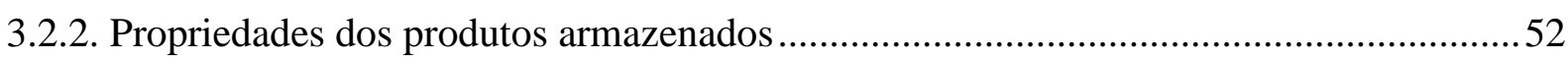

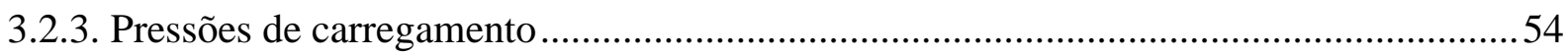

3.2.4. Sobrecarga nas pressões de carregamento................................................................56

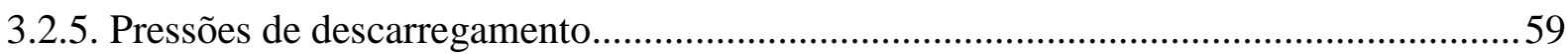

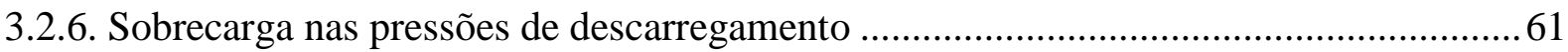

3.2.7. Pressões de descarregamento para silos circulares com grande excentricidade.............63 
3.2.8. Pressões no fundo do silo 66

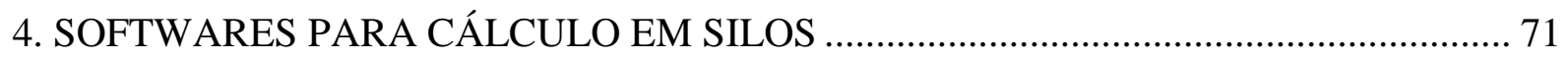

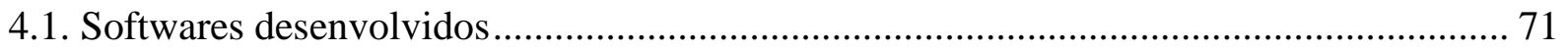

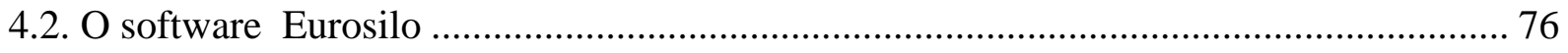

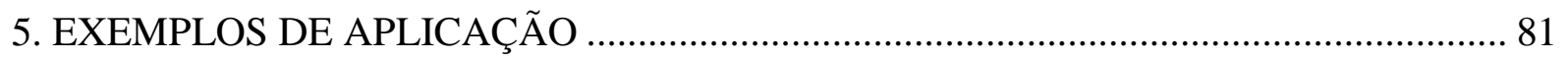

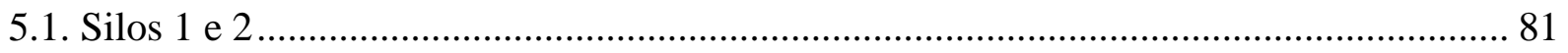

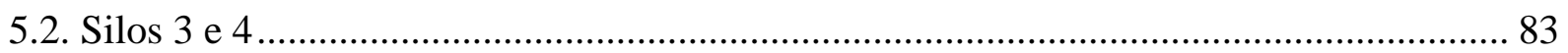

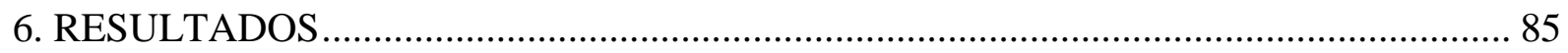

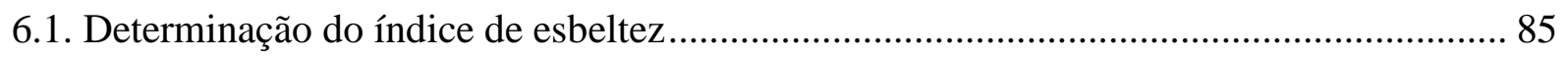

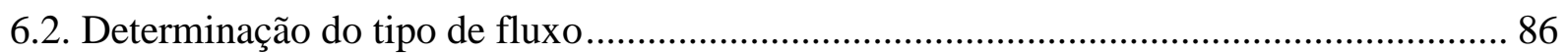

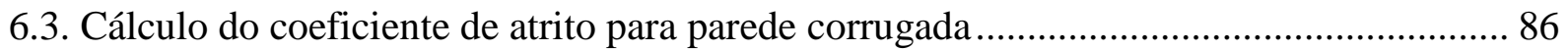

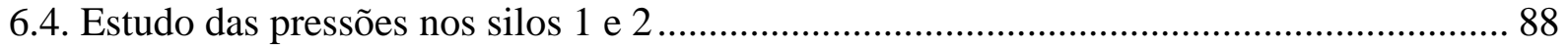

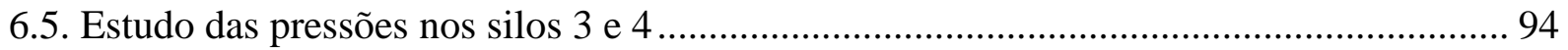

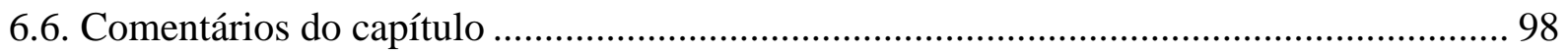

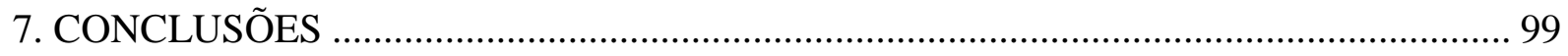

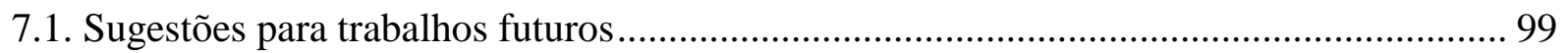

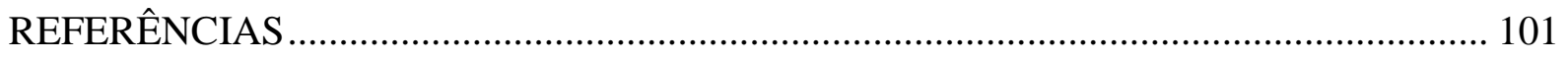




\section{INTRODUÇÃO}

\subsection{Generalidades}

Os silos são estruturas de armazenamento para produtos granulares ou pulverulentos a granel, utilizados largamente pela indústria e agricultura. O material comumente utilizado na construção de silos é o aço, formado por chapas metálicas corrugadas. Outros tipos de materiais também podem ser adotados, como concreto armado, argamassa armada, madeiras, fibras, plásticos, entre outros.

Possuem uma grande importância econômica para países que possuem grande produtividade agrícola. Entre eles está o Brasil, com abundantes recursos naturais como solo, água e incidência solar. A estimativa para a produção brasileira de grãos é de que alcance 189,3 milhões de toneladas na safra 2015/16 segundo a Companhia Nacional de Abastecimento (CONAB).

Para os projetos de novas unidades armazenadoras com segurança, economia e eficiência é essencial o correto conhecimento das máximas pressões capazes de atuar sobre as paredes do silo durante sua vida operacional.

Os produtos armazenados, ao contrário dos fluídos que possuem apenas o estado de tensão hidrostática com tensões tangenciais nulas, transmitem tensões tangenciais oriundas do atrito entre os grãos e as paredes. Portanto, uma abordagem baseada em fluídos para cálculo de pressões em silos está condenada a produzir valores irreais.

Apesar das teorias existentes no estudo de pressões em unidades armazenadoras, muitos parâmetros de cálculo ainda não foram corretamente determinados, principalmente quando se trata de pressões relacionadas com o descarregamento excêntrico, que produzem pressões não uniformes ao longo do perímetro do silo e da altura. 
Vale ressaltar que não existe norma brasileira que regulamenta, de forma específica, o dimensionamento de silos, por isso se optou nesta pesquisa por seguir as diretrizes do documento normativo BS EN 1991-4:2006: Silos e tanques.

\subsection{Propriedades físicas dos produtos armazenados}

A caracterização dos produtos armazenados é o ponto de partida para o projeto estrutural, pois as propriedades físicas influenciam as pressões atuantes e tipo de fluxo. As propriedades físicas mais relevantes neste estudo estão listadas a seguir:

- Peso específico do produto armazenado $(\gamma)$;

- $\quad$ Coeficiente de atrito da parede $(\mu)$;

- Ângulo de atrito interno $\left(\phi_{\mathrm{i}}\right)$;

- Ângulo de repouso do produto $\left(\phi_{\mathrm{r}}\right)$;

- Relação pressão horizontal e pressão vertical (K);

- Fator de sobrepressão $\left(\mathrm{C}_{\mathrm{op}}\right)$.

Jenike (1964) apresentou o método de cálculo de maior importância na determinação das propriedades, que utiliza o aparelho de cisalhamento de translação conhecido internacionalmente como “Jenike shear tester”, mostrado na Figura 1.

Figura 1- Detalhe da célula de cisalhamento de Jenike.

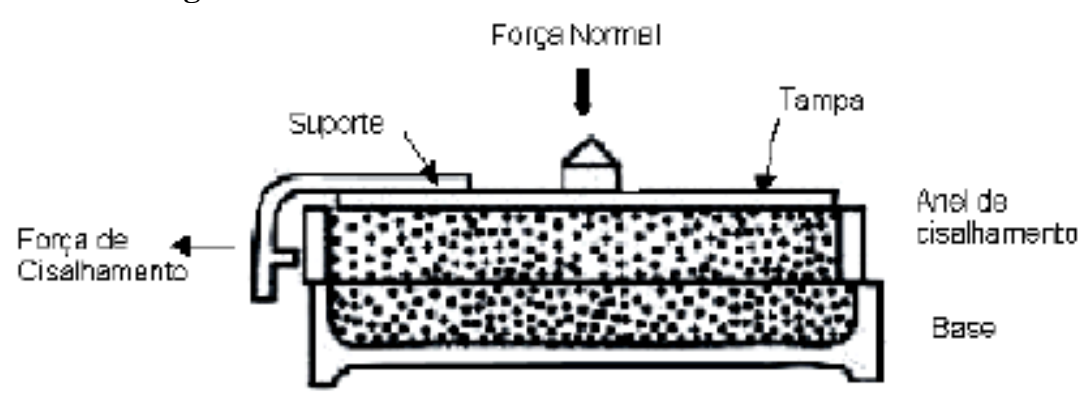

Fonte: MADRONA (2008) 
Este aparelho possui uma base cilíndrica fixa, um anel de cisalhamento, uma tampa e um pendural com massas para aplicação de uma força normal de compressão na tampa da célula de cisalhamento, mostradas na Figura 2.

Figura 2 - Aparelho de cisalhamento de Jenike, vista superior e vista lateral.

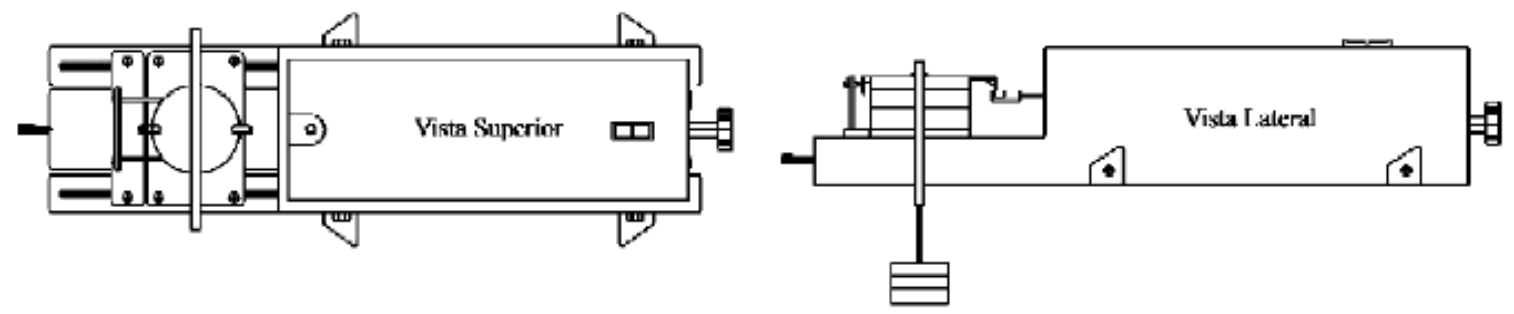

Fonte: MADRONA (2008)

$\mathrm{Na}$ lateral da tampa, encontra-se uma haste que desloca a parte superior da célula horizontalmente contra sua base que se mantém fixa. No momento do deslocamento, a força de cisalhamento é registrada.

Podem ser encontradas detalhadamente como são feitas as determinações das propriedades em função deste ensaio em Jenike (1964). Alguns documentos normativos sugerem valores de referência para as propriedades, entre eles o BS EN 1991-4:2006.

\subsection{Tipos de fluxo}

Segundo Calil Jr (1990), o tipo de fluxo determina a formação ou não de zonas de materiais sem movimento que também são chamadas de zonas estacionárias. Além de ocasionar a distribuição de pressões nas paredes verticais e no fundo do silo.

Quando o silo é descarregado por gravidade, dois tipos de fluxo podem ser observados: o fluxo de massa e o fluxo de funil. Benink (1989) descreveu o primeiro como sendo o fluxo onde todo o produto se movimenta, e o segundo quando nem todo o material se movimenta e existem zonas estagnadas de produtos. Há também o fluxo misto (intermediário), onde ocorrem os dois tipos de fluxo supracitados simultaneamente. O fluxo de massa é o ideal e 
deve ser adotado sempre que possível. Os tipos de fluxo podem ser vistos na Figura 3 em silos concêntricos e na Figura 4 em silos excêntricos.

Figura 3-Tipos de fluxo em silos com descarregamento concêntrico.

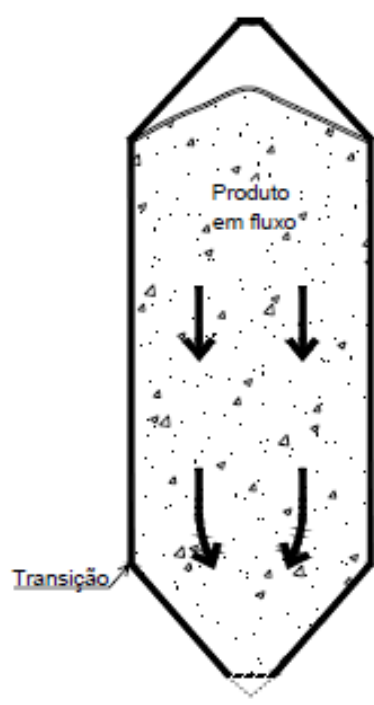

(a) Fluxo de mlassa

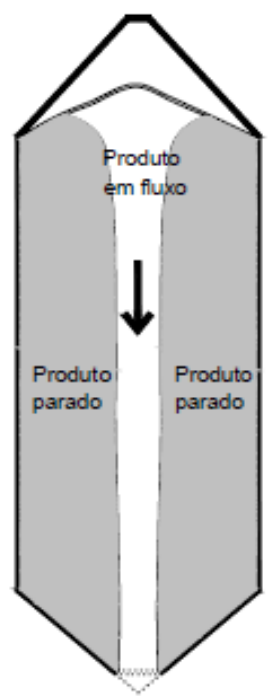

(b) Tubo interno paralelo

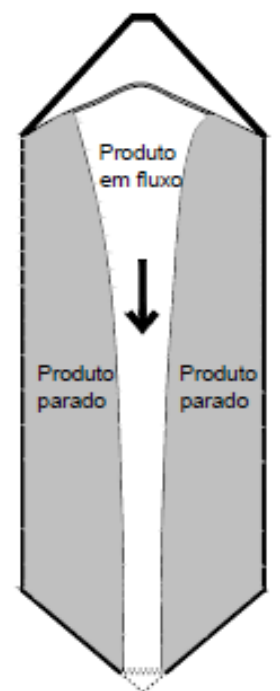

(c) Tubo intemo cônico

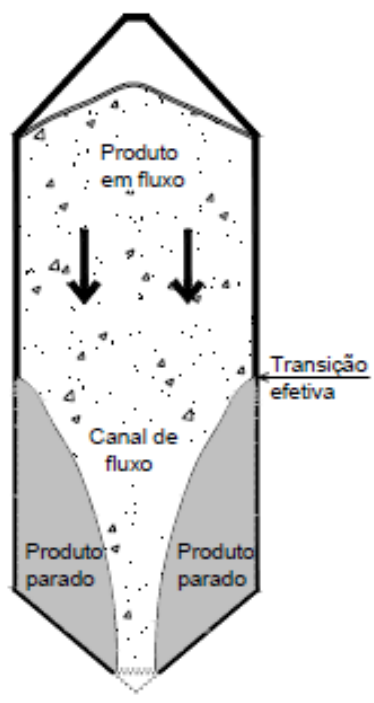

(d) Fluxo misto

Figura 4 - Tipos de fluxo em silos com descarregamento excêntrico.

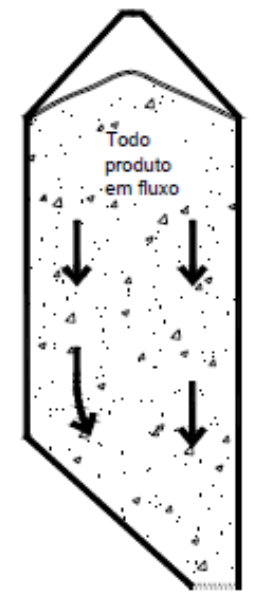

(a) Massa

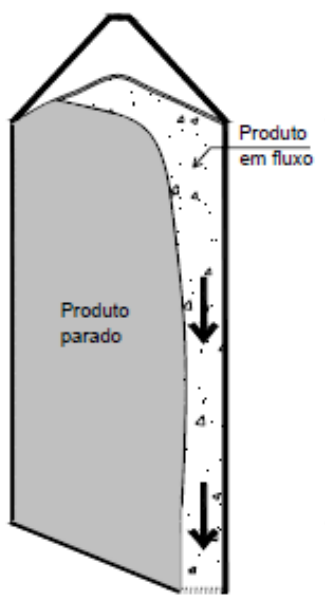

(b) Tubo paralelo

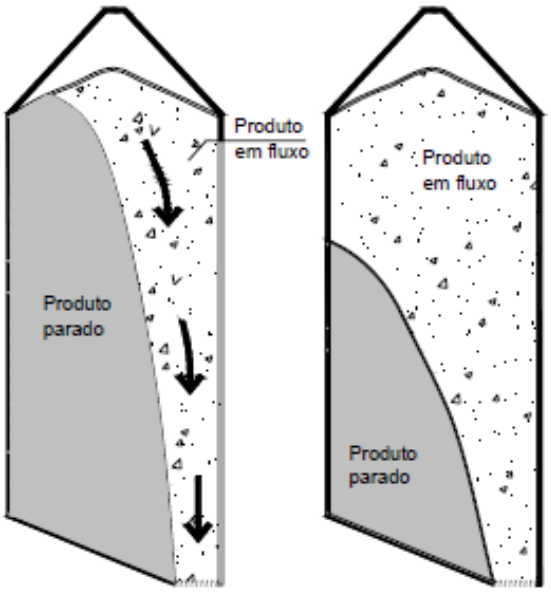

(c) Tubo inclinado

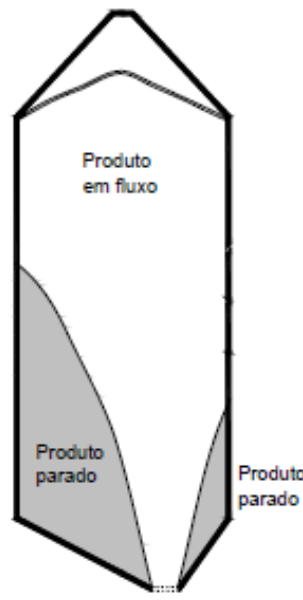

(e) Misto parcialmente

FLUXO DE FUNIL 
CALIL \& CHEUNG (2007) ressaltam que a saída excêntrica em silos com fluxo misto e em funil provocam carregamentos assimétricos que são problemáticos para silos metálicos devido à pequena espessura das paredes e que, mesmo para saída concêntricas, a transição efetiva pode não ocorrer na mesma altura em todo o perímetro.

A determinação do tipo de fluxo deve ser feita enquanto o silo está sendo projetado, ou quando são previstas mudanças em sua estrutura ou dos produtos a serem armazenados. As principais normas estrangeiras, DIN e Eurocode, apresentam gráficos para a determinação do tipo de fluxo para diferentes tipos de geometria de tremonha.

As vantagens e desvantagens no uso dos principais tipos de fluxo em um projeto estrutural, segundo CALIL \& CHEUNG (2007), estão mostrados no Quadro 1.

Quadro 1 - Vantagens e Desvantagens do tipo de fluxo.

\begin{tabular}{|c|c|c|c|}
\hline \multicolumn{2}{|c|}{ FLUXO DE MASSA } & \multicolumn{2}{|c|}{ FLUXO DE FUNIL } \\
\hline Vantagens & Desvantagens & Vantagens & Desvantagens \\
\hline Vazão regular & $\begin{array}{c}\text { Altas tensões na } \\
\text { transição da tremonha }\end{array}$ & $\begin{array}{l}\text { Menor altura da } \\
\text { tremonha }\end{array}$ & Flutuações na vazão \\
\hline $\begin{array}{l}\text { Efeitos de segregação radial } \\
\text { é reduzido, com a melhora } \\
\text { da homogeneidade }\end{array}$ & $\begin{array}{c}\text { Desgaste superficial da } \\
\text { parede }\end{array}$ & $\begin{array}{l}\text { Diminuição das } \\
\text { pressões dinâmicas na } \\
\text { região da tremonha }\end{array}$ & Segregação de sólidos \\
\hline $\begin{array}{c}\text { Campo de tensões mais } \\
\text { previsível }\end{array}$ & $\begin{array}{l}\text { São necessárias } \\
\text { tremonhas mais } \\
\text { inclinadas e lisas }\end{array}$ & $\begin{array}{c}\text { Menor desgaste } \\
\text { superficial da parede }\end{array}$ & $\begin{array}{c}\text { Efeitos de consolidação com } \\
\text { o tempo podem causar } \\
\text { obstruções no fluxo }\end{array}$ \\
\hline Toda capacidade é utilizada & $\begin{array}{l}\text { Maior energia de } \\
\text { elevação }\end{array}$ & & $\begin{array}{c}\text { Deterioração dos produtos } \\
\text { por causa da região } \\
\text { estagnada }\end{array}$ \\
\hline & $\begin{array}{l}\text { As partículas devem } \\
\text { resistir à queda livre de } \\
\text { alturas maiores }\end{array}$ & & $\begin{array}{c}\text { Redução da capacidade de } \\
\text { armazenagem }\end{array}$ \\
\hline $\begin{array}{l}\text { Maior capacidade de } \\
\text { armazenamento, pois não } \\
\text { possui regiões com produto } \\
\text { estagnado. }\end{array}$ & & & Formação de tubos \\
\hline & & & $\begin{array}{l}\text { Picos de pressões na região } \\
\text { de transição efetiva. }\end{array}$ \\
\hline
\end{tabular}

Fonte: CALIL \& CHEUNG (2007). 
Os fundos dos silos são classificados em função do seu ângulo de inclinação com a horizontal e são intituladas de fundo plano ou fundo inclinado. Este último é comumente chamado de tremonha. Existem variações nas geometrias dos fundos dos silos, mostrada na Figura 5.

Figura 5 - Tipos mais comuns de tremonha.
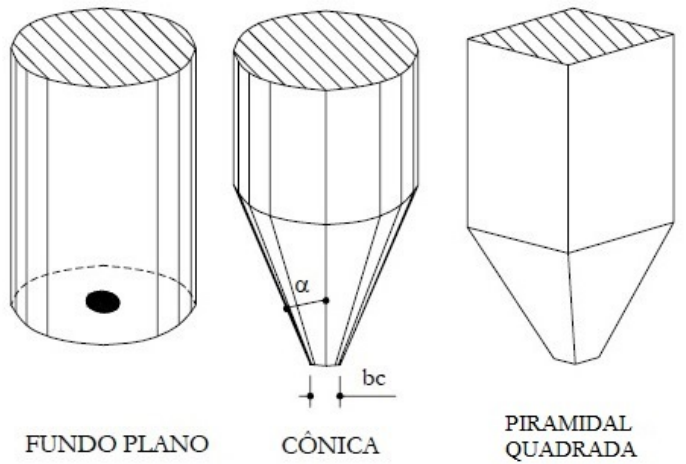

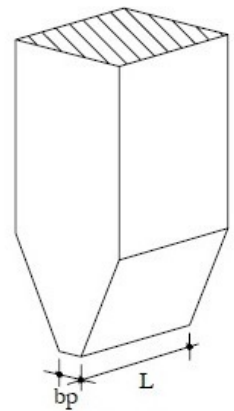

CUNHA

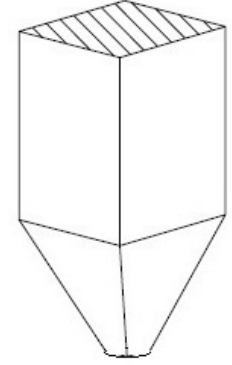

PIRAMIDAI

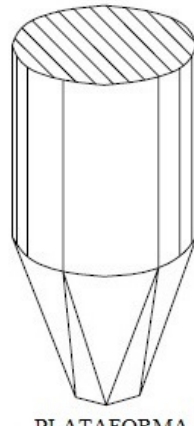

PLATAFORMA RETANGULAR

Fonte: Adaptado CHEUNG (2007)

\subsection{Tipos de silos}

Quanto ao sentido que se desenvolve a estrutura, os silos são classificados como verticais ou horizontais. Quando a dimensão longitudinal é preponderante sobre as outras dimensões, estes são chamados de silos horizontais, caso contrário são verticais.

No que diz respeito à classificação em relação ao solo, os silos construídos acima do nível do solo são chamados de silos elevados ou aéreos. Silos subterrâneos se localizam abaixo do nível do solo e os semissubterrâneos são um tipo intermediário entre os dois tipos anteriores.

No que se refere à estanqueidade, os silos que não permitem a troca de ar com o ambiente externo são chamados de herméticos, e os que permitem chamados de não-herméticos.

A geometria é um fator importante de classificação dos silos, a razão entre a altura $(\mathrm{H})$ e diâmetro (D) é chamado de índice de esbeltez. Na Tabela 1 são mostradas a classificação de algumas normas quanto à esbeltez. 
Tabela 1- Classificação dos silos quanto a esbeltez.

\begin{tabular}{|c|c|c|c|}
\hline \multirow{2}{*}{ NORMA } & \multicolumn{3}{|c|}{ CLASSIFICAÇÃO } \\
\hline & BAIXOS & $\begin{array}{c}\text { MEDIANAMENTE } \\
\text { ESBELTO }\end{array}$ & ESBELTO \\
\hline $\begin{array}{c}\text { Australiana } \\
\text { AS 3774:1996 }\end{array}$ & $\mathrm{H} / \mathrm{D}<1,0$ & $1,0 \leq \mathrm{H} / \mathrm{D}<3,0$ & $\mathrm{H} / \mathrm{D}>3,0$ \\
\hline $\begin{array}{c}\text { Europeias } \\
\text { BS EN 1991-4:2006 } \\
\text { DIN 1055-06:2005 }\end{array}$ & $0,4 \leq \mathrm{H} / \mathrm{D}<1,0$ & $1,0 \leq \mathrm{H} / \mathrm{D}<2,0$ & $H / D \geq 2,0$ \\
\hline $\begin{array}{l}\text { Americanas } \\
\text { ACI-313:199 } \\
\text { ANSI/ASAE } \\
\end{array}$ & $\mathrm{H} / \mathrm{D}<2,0$ & - & $\mathrm{H} / \mathrm{D} \geq 2,0$ \\
\hline $\begin{array}{l}\text { Canadense } \\
\text { CFBC:1983 }\end{array}$ & $\begin{array}{c}\mathrm{H} / \mathrm{D} \leq 1,0 \text { ou } \\
\mathrm{H} / \mathrm{D}<\tan ^{2}\left(\frac{\emptyset_{c}}{2}+\frac{\pi}{4}\right)\end{array}$ & - & $\begin{array}{c}\mathrm{H} / \mathrm{D}>1,0 \text { ou } \\
\mathrm{H} / \mathrm{D} \geq \tan ^{2}\left(\frac{\emptyset_{c}}{2}+\frac{\pi}{4}\right)\end{array}$ \\
\hline
\end{tabular}

Fonte: Adaptado CHEUNG (2007)

\subsection{Estudos realizados na escola de engenharia de São Carlos (USP)}

O Departamento de Engenharia de Estruturas (SET) da Escola de Engenharia de São Carlos (EESC), da Universidade de São Paulo (USP), possui uma linha de pesquisa com o intuito de aprimorar o conhecimento, comprovar as teorias existentes e desenvolver tecnologia própria na área de silos. Até o momento, foram desenvolvidos os seguintes trabalhos de Mestrado, Doutorado e Livre Docência:

CALIL (1978), em sua dissertação de Mestrado "Estudo dos Silos de Madeira a Nível de Fazendas”, propôs como alternativa para o pequeno produtor a construção de tais estruturas nas propriedades agrícolas, utilizando madeira tanto como material estrutural quanto de revestimento.

CALIL (1982), em sua tese de Doutorado "Sobrepresiones em las Paredes de los Silos para Almacenamiento de Productos Pulverulentos Cohesivos”, realizou estudos em modelos reduzidos, determinando os tipos de fluxo de produtos armazenados, a intensidade das pressões de carregamento e descarga para produtos granulares e para produtos pulverulentos. 
FORTES FILHO (1985), em sua dissertação de Mestrado "Uma Introdução ao Estudo dos Silos”, abordou a problemática dos silos de maneira ampla e suficientemente profunda para as aplicações correntes, apoiando-se em uma análise de estudos teóricos e experimentais realizados por diversos autores.

VAZ (1987), em sua dissertação de Mestrado "Silos Verticais de Madeira Compensada", apresentou uma proposta de silos de madeira compensada de seção hexagonal para o pequeno produtor.

COUTO (1989), em sua dissertação de Mestrado "Contribuição ao Estudo dos Silos de Argamassa Armada para o Armazenamento de Cereais", propôs uma metodologia de dosagem para argamassa armada, verificando sua viabilidade construtiva em dois silos protótipos cilíndricos.

ESTEVES JUNIOR (1989), em sua dissertação de Mestrado "Silos Metálicos de Chapa Corrugada", apresentou estudo teórico e experimental destas unidades com vistas à caracterização dos materiais e das ligações utilizadas, além de propor uma metodologia de ensaio para a avaliação dos componentes estruturais.

CALIL (1990), em sua tese de Livre-Docência "Recomendações de Fluxo e de Cargas para o Projeto de Silos Verticais", realizou o estudo das teorias e práticas que envolvem as várias fases de carregamento e fluxo de produtos armazenados, propondo recomendações para o armazenamento destes produtos em silos.

SILVA (1993) ${ }^{1}$, em sua tese de Doutorado "Estudo da Variabilidade de Pressões em Silos", estudou as pressões em silos sob o ponto de vista probabilístico, com ênfase na análise da variabilidade das propriedades dos produtos armazenados e na variabilidade das pressões.

MILANI (1993), em sua tese de Doutorado "Determinação das Propriedades de Produtos Armazenados para Projeto de Pressões e Fluxo em Silos", apresentou uma metodologia de ensaio para a determinação das propriedades de produtos armazenados, com base em estudos teóricos e experimentais utilizando o equipamento de translação "Jenike Shear Cell".

\footnotetext{
${ }^{1}$ Tese apresentada à Escola Politécnica da Universidade de São Paulo sob orientação do Prof. Dr. Carlito Calil Junior.
} 
FASSONI (1994), em sua dissertação de Mestrado "Sistema Construtivo Modular em Madeira para Silos Horizontais", apresentou uma proposta de projeto de silo horizontal de madeira utilizando peças maciças e chapas de compensado, com ênfase na pré-fabricação.

GOMES (1994), em sua dissertação de Mestrado "Silos para Armazenamento de Laranjas", propôs o projeto e detalhes construtivos de um silo-protótipo, utilizando madeiras de reflorestamento para o armazenamento de laranjas, tanto em fazendas como em indústrias.

MANFRIN (1994), em sua dissertação de Mestrado "Um Estudo dos Silos para Açúcar: Propriedades Físicas do Material Armazenado, Recomendações Construtivas, Normativas e Análise Estrutural”, analisou as condições ideais que o açúcar deve apresentar para uma adequada armazenagem, bem como avalia a distribuição dos esforços solicitantes a partir do confronto entre uma análise discreta, que trata a estrutura como um conjunto de pilares e vigas curvas, e de outra contínua, na qual a estrutura da parede é tratada como casca.

NASCIMENTO (1996), em sua tese de Doutorado "Estudo de Silos Prismáticos para Fábricas de Ração", desenvolveu um estudo teórico e experimental de painéis metálicos com conformação ziguezague horizontal, fornecendo subsídios técnicos para projetos de silos prismáticos metálicos para uso industrial.

ARAÚJO (1997), em sua tese de Doutorado "Estudo Teórico Experimental de Tremonhas Piramidais para Silos Metálicos Elevados", realizou estudos para a determinação dos esforços em tremonhas enrijecidas e não enrijecidas por modelo analítico, numérico e experimental, confrontando os métodos utilizados.

ANDRADE JÚNIOR. (1998), em sua dissertação de Mestrado “Análise Estrutural das Chapas Metálicas de Silos e de Reservatórios Cilíndricos”, procurou dispor conceitos claros e distintos do comportamento e dos fenômenos de perda de estabilidade do equilíbrio de reservatórios e silos metálicos, bem como estabelece configurações estruturais que apresentam maiores riscos à perda da estabilidade da estrutura e fornece relações de diâmetro/espessura e de diâmetro/altura em que é possível evitar os problemas advindos da perda de estabilidade do equilíbrio. 
GOMES (2000), em sua tese de doutorado "Estudo Teórico e Experimental das Ações em Silos Horizontais”, comparou resultados teóricos com os obtidos por meio de medições diretas das pressões em um modelo-piloto e um silo horizontal em escala real, com a relação entre as pressões horizontais e verticais, K. Com base nos resultados obtidos, propõe um novo método de cálculo fundamentado em um modelo empírico para a determinação das pressões horizontais nessas unidades.

FREITAS (2001), em sua tese de doutorado "Estudo teórico e experimental das pressões em silos cilíndricos de baixa relação altura/diâmetro e fundo plano”, realizou ensaios em um siloprotótipo e um silo-piloto. Com base nos resultados experimentais, propõe modelos empíricos para a determinação das pressões horizontais e verticais no fundo plano do silo para esse tipo de unidade armazenadora.

ANDRADE JÚNIOR. (2002), em sua tese de doutorado “Ação do Vento em Silos Cilíndricos de baixa relação altura/diâmetro", realizou estudos teóricos e experimentais em modelos aerodinâmicos e aero elásticos sobre as ações do vento em silos, determinando coeficientes aerodinâmicos no costado e na cobertura.

PALMA (2005), em sua dissertação de mestrado "Pressões e Fluxo em Silos Esbeltos $(\mathrm{H} / \mathrm{D} \geq 1,5)$ ", realizou estudos teóricos sobre teorias e normas vigentes sobre as pressões e fluxo em silos esbeltos.

CHEUNG (2007), em sua tese de doutorado “Modelo Estocástico de Pressões de Produtos Armazenados para a estimativa da confiabilidade estrutural de Silos Esbeltos” realizou um tratamento estocástico nas pressões dos silos verticais esbeltos com ênfase na estimativa da confiabilidade de silos verticais cilíndricos.

NASCIMENTO (2008), em sua dissertação de mestrado “A relação entre as Pressões horizontais e verticais em Silos Elevados: o parâmetro K” determinou experimentalmente a relação entre as pressões horizontais e verticais em um silo piloto vertical, cilíndrico, de fundo plano e realizou um estudo comparativo das principais recomendações propostas pelos especialistas e normas estrangeiras para o cálculo do K. 
MADRONA (2008), em sua dissertação de mestrado "Pressões em Silos Esbeltos com descarga excêntrica”, realizou um estudo teórico e numérico da distribuição de pressões e seu aumento para a condição de descarga em silos verticais com descarga excêntrica.

MARTINS (2012), em sua dissertação de mestrado "Estudo teórico e experimental de esforços devidos a cabos de termometria fixados em estruturas de coberturas de silos cilíndricos para armazenamento de grãos”, fez uma análise teórica e experimental da avaliação de esforços de cabos de termometria fixados em estruturas de cobertura de silos cilíndricos verticais.

Dentro desse contexto este trabalho tem como objetivo dar continuidade aos estudos que estão sendo realizados na área de estruturas de armazenamento na USP, realizando o estudo do fluxo de produtos armazenados e das pressões, propondo um software para determinação das pressões baseado nas recomendações normativas do BS EN 1991-4:2006.

\subsection{Objetivos}

\subsubsection{Geral}

Desenvolver um software para cálculo do fluxo e das pressões de produtos armazenados em silos metálicos cilíndricos, e apresentar exemplos de aplicação.

\subsubsection{Específicos}

- Revisar a bibliografia existente sobre teorias de pressões em silos.

- Apresentar os documentos normativos existentes de silos e fazer contribuições para a futura normatização de projetos de silos no Brasil. 
- Analisar os resultados obtidos do software proposto nos exemplos de aplicação, considerando variações no tipo de fundo e em possíveis excentricidades de descarregamento.

\subsection{Justificativa}

As falhas e colapsos em estruturas de armazenamento são decorrentes da variabilidade das propriedades físicas dos produtos e na estimativa incorreta das pressões. O desenvolvimento do software permitirá que os engenheiros na área tenham uma ferramenta de determinação das pressões em toda a altura, gerando projetos de estruturas de armazenamento com critérios seguros.

Foi implementado no software a norma europeia Eurocode BS EN 1991-4 por incorporar estudos de pressões excêntricas, que são apontados como as principais causas de problemas estruturais. O descarregamento excêntrico gera pressões assimétricas que geralmente levam a perda de estabilidade por compressão axial. 


\section{TEORIAS CLÁSSICAS DE PRESSÕES}

Com o objetivo de compreender o comportamento das pressões em silos, neste capítulo estão apresentadas as principais teorias existentes.

\subsection{Teoria de Janssen (1895)}

O engenheiro alemão H. A. Janssen fez os primeiros relatos sobre o comportamento peculiar de produtos em silos em um artigo publicado em 1895, que descreve o modelo mais utilizado, atualmente, no cálculo de pressões no corpo dos silos. Além de inúmeras publicações mostradas na Figura 6, o modelo de cálculo é utilizado nas normas estrangeiras atuais. Após ter feito ensaios em um silo-modelo quadrado, de madeira, com fundo plano, deduziu analiticamente as expressões para cálculo de pressões mostradas nessa seção.

Figura 6-Citações do artigo de Janssen (1895) desde 1978.

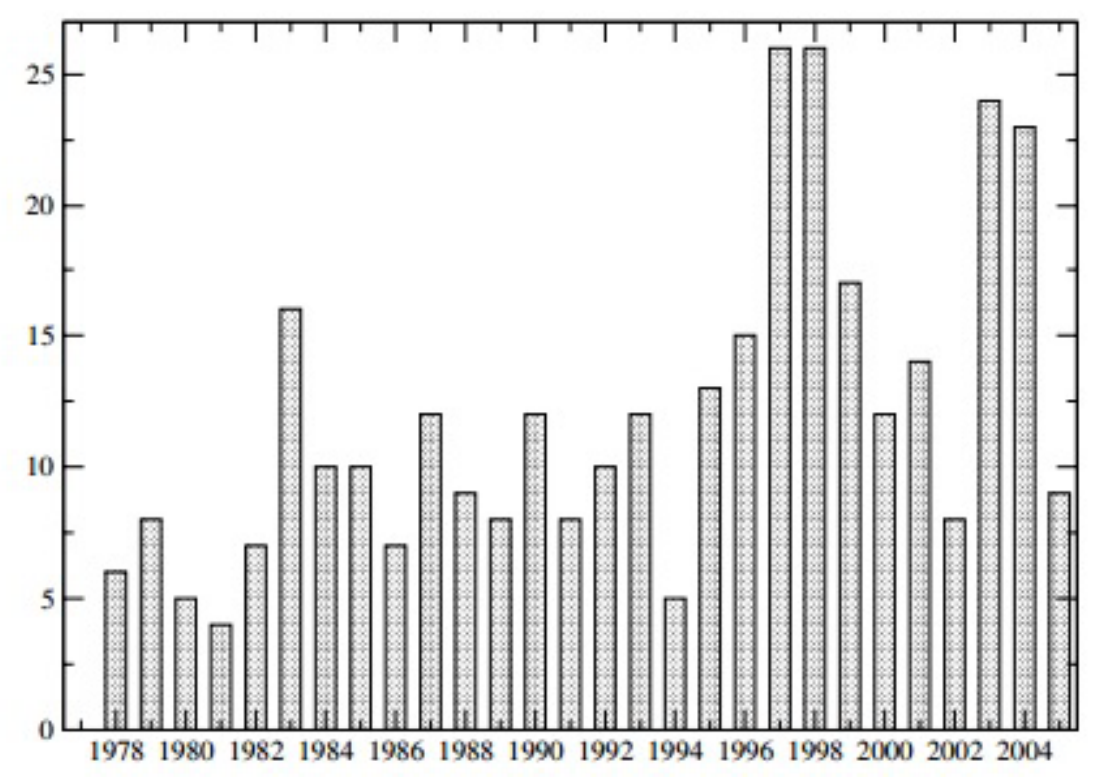

Fonte: MATTHIAS SPERL(2005).

Essa teoria foi desenvolvida através do equilíbrio estático de uma camada elementar de um produto com peso específico $\gamma$ a uma profundidade $\mathrm{z}$ a partir da superfície equivalente, mostrado na Figura 7. As simplificações utilizadas por Janssen foram: 
- Pressão vertical é constante no plano horizontal.

- Relação entre as pressões horizontais e verticais, conhecido como parâmetro K, é constante.

- Ângulo de atrito entre produto armazenado e parede vertical constante.

- Paredes verticais do corpo do silo totalmente rígidas.

- Peso específico do produto armazenado uniforme.

Figura 7 - Forças na camada elementar de altura dz adotada por Janssen(1895).

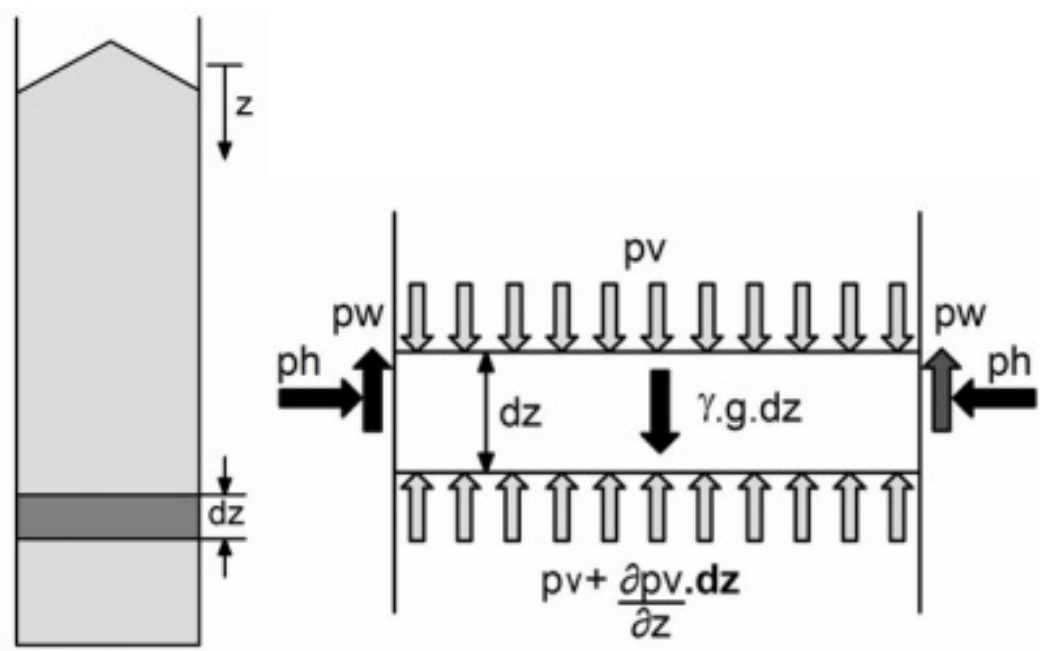

Fonte: MADRONA (2008)

Pelo equilíbrio estático atuantes na camada elementar, tem-se:

$$
P_{h f} \cdot \mu_{w} \cdot d_{z} \cdot U+\left(P_{v f}+p d_{v f}-P_{v f}\right) \cdot A-\gamma \cdot A \cdot d_{z}=0
$$

Considerando $K \cdot d p_{v p}=d p_{h f}$ e aplicando a condição de contorno $p_{v f}(0)=0$, tem-se a Equação de Janssen para o cálculo de pressão horizontal após o carregamento do silo:

$$
p_{h f}(z)=\frac{\gamma}{\mu_{w}} \cdot \frac{A}{U}\left(1-e^{-z \cdot K \cdot \mu_{w} \cdot \frac{U}{A}}\right)
$$

Utilizando o parâmetro $\mathrm{K}$, já mencionado anteriormente, temos para cálculo da pressão vertical a seguir: 


$$
\begin{gathered}
p_{v f}(z)=\frac{\gamma}{K \cdot \mu_{w}} \cdot \frac{A}{U}\left(1-e^{-z \cdot K \cdot \mu_{w} \cdot \frac{U}{A}}\right) \\
P_{w f}(z)=\mu_{w} \cdot p_{h f}(z)
\end{gathered}
$$

E pela relação, a pressão de atrito é:

$$
p_{w f}(z)=\gamma \cdot \frac{A}{U}\left(1-e^{-z \cdot K \cdot \mu_{w} \cdot \frac{U}{A}}\right)
$$

A pressão de atrito $\left(p_{w f}\right)$ causa esforço de compressão na parede ao longo da altura, Madrona (2008) explica que o atrito exercido pelo produto armazenado nas paredes faz com que as pressões horizontais não aumentem linearmente com a altura como as pressões hidrostáticas, mas sim um crescimento que tende a um valor máximo exponencial.

Rotter (2010) afirma que o modelo de Janssen é uma boa aproximação para o cálculo de pressões de carregamento, mas ressalva que ainda não é capaz de representar, por exemplo, modelo com excentricidades de carregamento.

\subsection{Teoria de Jenike et al. (1973)}

Na fase de descarregamento ocorrem efeitos de sobrepressão em silos, Jenike et al. (1973) estudou este fenômeno e propôs um modelo revolucionário baseado na teoria do balanço de energia.

Este modelo explica que há diferenças de pressões nas fases de carregamento ou estático, transição e descarregamento ou dinâmico. Durante o carregamento, ocorre compressão do produto verticalmente sem deformação horizontal, desenvolvendo um campo ativo de tensões com a maior tensão principal atuando na direção vertical, aproximando-se da horizontal próximo das paredes. Na transição, ocorre a mudança de campos de tensões no instante da abertura do orifício de saída, do estado ativo para o passivo de tensões com a direção da maior 
pressão vertical em forma de arcos na tremonha. No descarregamento, estabelece-se um estado passivo de tensões com direção da tensão principal tendendo a alinhar-se com a direção horizontal.

Para as pressões estáticas no corpo do silo, ensaios de Jenike et al. (1973) confirmaram boa aproximação com os resultados propostos pela teoria de Janssen (1895), utilizando o valor de $\mathrm{K}=0$,4, fornecendo uma boa relação com sua teoria de balanço de energia.

Jenike et al. definiram os dois principais tipos de fluxo: funil e massa, e propõe o modelo de cálculo de pressões dinâmicas para cada um deles. Para silos com fluxo de massa, as pressões máximas são calculadas pela segunda lei da termodinâmica, que declara que o funcional de energia interna no silo tende a ser minimizado, ou seja:

$$
\delta \pi(U)=0
$$

Pode ser encontrada detalhadamente em Jenike et al (1973) a derivação dessa teoria, partindo da energia de deformação. Neste trabalho será somente apresentada, de modo direto, a formulação proposta para o cálculo da pressão horizontal dinâmica $\left(p_{h e}\right)$ e para força de atrito $\left(p_{w e}\right)$ para silos cilíndricos com fluxo de massa.

Para pressão horizontal nos silos com fluxo de massa, tem-se:

$$
p_{h e}(z)=\left(\frac{\gamma \cdot R}{\mu_{e f f}}\right) \cdot\left(1-(\partial-\omega) \cdot \frac{\mu_{e f f}}{M^{m_{c}}}\right)
$$

Onde M e N são constantes, dadas por:

$$
\begin{gathered}
M=\sqrt{2 \cdot(1-v)} \\
N=\frac{2 \cdot v}{\mu_{e f f} \cdot M^{2 \cdot\left(1-m_{c}\right)}}
\end{gathered}
$$


$v$ é igual a 0,3 para fluxo assimétrico;

$v$ é igual a 0,2 para fluxo plano;

$m_{c}$ é igual a 0 para fluxo assimétrico;

$m_{c}$ é igual a 1 para fluxo plano.

$$
\begin{gathered}
\partial=\frac{-\left(K \cdot M^{m_{c}}-1\right) \cdot\left(S_{o}-N\right) \cdot e^{-j}+M^{m_{c}} \cdot\left(\mu_{e f f}{ }^{-1}-K \cdot N\right)}{\left(K_{h} \cdot M^{m_{c}}+1\right) \cdot e^{j}-\left(K_{h} \cdot M^{m_{c}}-1\right) \cdot e^{-j}} \\
\omega=S_{0}-N-\partial \\
j=\frac{\mu_{e f f}}{M^{m_{c}} \cdot R} \cdot(H-z) \\
S_{0}=\frac{1}{\mu_{e f f} \cdot K} \cdot\left(1-e^{-\frac{\mu_{e f f} \cdot K \cdot z}{R}}\right)
\end{gathered}
$$

O fluxo funil ocorre em casos onde o produto armazenado faz papel de tremonha, formando um cone nas paredes cilíndricas do silo. Na região onde o canal de fluxo intercepta a parede define-se a altura da transição efetiva, que é onde ocorre o maior pico de pressão horizontal, calculada pela expressão a seguir.

$$
p_{h e}(z)=\left(\frac{\gamma \cdot R}{\mu_{w}}\right) \cdot\left(1-e^{-\frac{\mu_{w} \cdot K \cdot z}{R}}\right)
$$

A força de atrito pode ser calculada da mesma maneira para ambos os tipos de fluxos, pelas expressões seguintes:

$$
P_{w e}(z)=\frac{\gamma \cdot D^{2}}{4} \cdot\left(\frac{z}{D}-\frac{A e^{x}+B e^{-x}+N}{4}\right)
$$

Onde:

$$
M=\sqrt{2 \cdot(1-v)}
$$




$$
\begin{gathered}
N=\frac{2 \cdot v}{\mu_{w} \cdot M^{2 \cdot\left(1-m_{c}\right)}} \\
K_{h}=K_{0}=K=\frac{v}{1-v} \\
x=\frac{\mu_{w} \cdot z}{M^{m_{c}} \cdot R} \\
A=\frac{-\left(K_{h} \cdot M^{m_{c}}-1\right) \cdot(-N) \cdot e^{-x}+M^{m_{c}} \cdot\left(\mu^{-1}-K_{h} \cdot N\right)}{\left(K_{h} \cdot M^{m_{c}}+1\right) \cdot e^{-x}-\left(K_{h} \cdot M^{\left.m_{c}-1\right) \cdot e^{-x}}\right.} \\
B=-A-N
\end{gathered}
$$

\subsection{Teoria de Rotter (1986)}

As pressões excêntricas são as mais críticas para silos de paredes finas, devido à dificuldade de caracterizar a distribuição de pressões provocado pelo fluxo de escoamento excêntrico do produto e em compreender as pressões assimétricas associadas a parede do silo (SADOWSKI \& ROTTER (2010)).

O método de cálculo para silos com descarregamento excêntrico, foi desenvolvido por Rotter (1986), e é utilizado pelo atual BS EN 1991-4 para silos de classe 3. Esta teoria propõe uma distribuição para as pressões resultantes a partir de um canal de fluxo circular de lados paralelos formado contra a parede, mostrado na Figura 8.

Figura 8-- Seção transversal com pressões excêntricas horizontais.

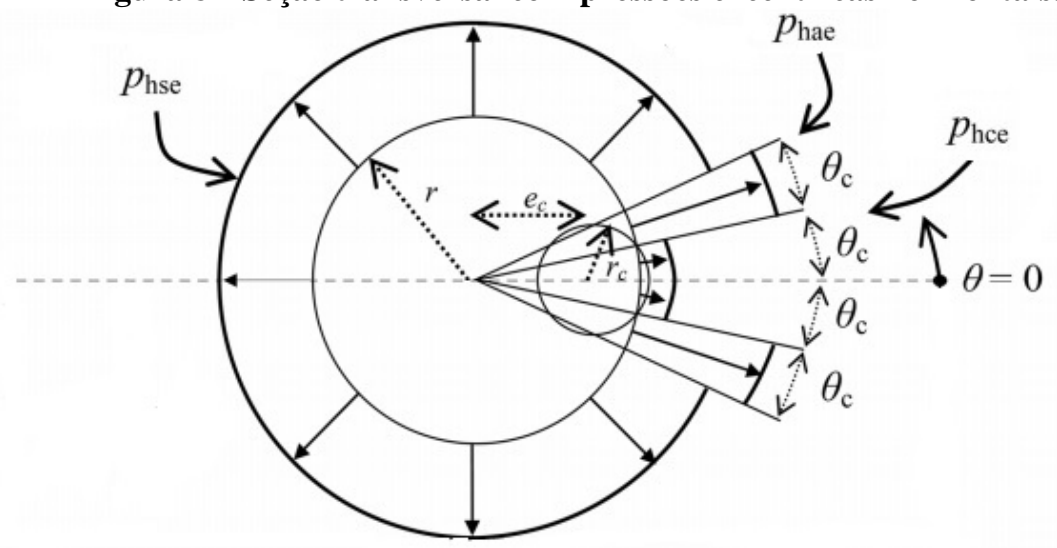

Fonte: Adaptado de SADOWSKI \& ROTTER (2010) 
O produto exerce pressões de Janssen fora do canal, pressões elevadas nas bordas e diminuição das pressões no interior do canal de fluxo, simplificando assim o que tem sido observado nos ensaios realizados.

O ângulo $\theta_{c}$ é formado pela reta que passa pelo centro do silo e centro do canal de fluxo e pela reta que cruza a intersecção do fluxo com a parede do silo, calculada pela equação abaixo.

$$
\cos \theta_{c}=\frac{r^{2}+e_{c}^{2}-r_{c}^{2}}{2 r e_{c}}
$$

São definidas a área transversal do canal do fluxo $\left(A_{c}\right)$ e a área do produto estático $\left(A_{s}\right)$, utilizadas no cálculo das pressões excêntricas como:

$$
\begin{gathered}
A_{c}=(\pi-\delta) r_{c}^{2}+\theta_{c} \cdot r^{2}-r r_{c} \operatorname{sen}\left(\delta-\theta_{c}\right) \\
A_{s}=\pi r^{2} \operatorname{sen} \theta_{c}
\end{gathered}
$$

O ângulo $\delta$ é determinado pela equação a seguir:

$$
\delta=\frac{r}{r_{c}} \operatorname{sen} \theta_{c}
$$

A pressão horizontal estática ( $\left.p_{\text {hse }}\right)$, a qualquer profundidade no exterior do canal de fluxo é tomada com igual a pressão de Janssen:

$$
p_{h s e}=\gamma K z_{o}\left(1-e^{-z / z_{o}}\right) \text {, onde } z_{o}=\frac{A}{K U \mu}
$$

A pressão horizontal no interior do canal de fluxo é dada por:

$$
\begin{gathered}
p_{h c e}=\gamma K z_{o c}\left(1-e^{-z / z_{o c}}\right) \text {, onde } z_{o c}=\frac{1}{K}\left(\frac{A_{c}}{U_{w c} \mu+U_{s c} \tan \emptyset_{i}}\right) \\
U_{w c}=2 \theta_{c} r
\end{gathered}
$$




$$
\mathrm{U}_{\mathrm{sc}}=2 \mathrm{r}_{\mathrm{c}}(\pi-\delta)
$$

As pressões nas bordas são dadas em função das pressões horizontais no interior e no exterior do canal de fluxo:

$$
p_{\text {hae }}=2 p_{\text {hse }}-p_{\text {hce }}
$$

As pressões de atrito $p_{w s e}, p_{w c e}$ e $p_{w a e}$, são definidas como as mesmas para pressões horizontais ponderadas pelo coeficiente de atrito da parede $\left(\mu_{w}\right)$.

Madrona (2008) explica que a principal diferença entre a teoria de Rotter (1986) e outros métodos de cálculo, é que, apesar das suas limitações, ela satisfaz as equações de equilíbrio estáticas em qualquer seção transversal do silo. As limitações, ou hipóteses de validade, estão citadas a seguir:

- Fluxo paralelo à parede vertical do silo;

- Parâmetro K constante;

- Pressão de atrito na parede é mobilizada integralmente pelo coeficiente de atrito da parede $\left(\mu_{w}\right)$.

- Coeficiente de atrito entre o produto estático e o produto em escoamento $\left(\mu_{s c}\right)$ igual à tangente do ângulo de atrito interno.

As definições completas podem ser encontradas no BS EN 1991-4 e as derivações em Rotter (1986). As magnitudes das pressões do canal do fluxo dependem diretamente do tamanho do canal, seu raio e excentricidade do centro do canal de fluxo $\left(e_{c}\right)$, calculada por:

$$
e_{c}=r \cos \delta-r_{c} \cos \theta_{c}
$$




\subsection{Teoria de Walker (1966)}

As pressões em tremonhas foram estudadas por Walker (1966) através do equilíbrio de forças verticais em uma fatia elementar do produto submetido a uma tensão inicial na parte superior (Figura 9).

Figura 9- Equilíbrio de forças que agem em uma camada infinitesimal da tremonha.

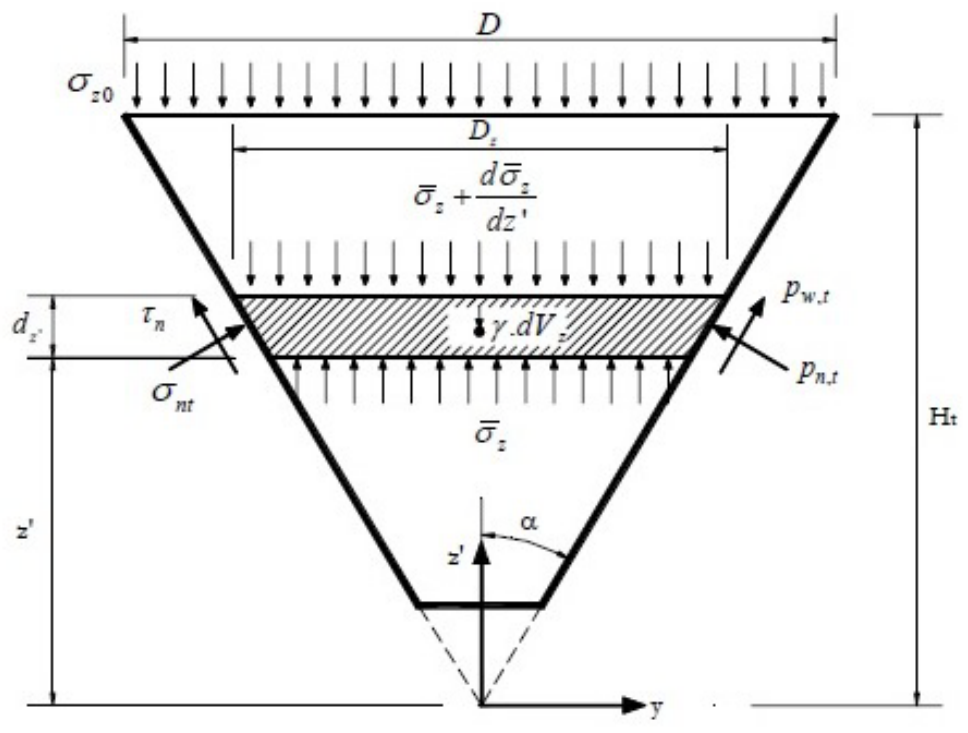

Fonte: CHEUNG (2007)

Considerando que a pressão vertical seja uniformemente distribuída na camada infinitesimal da tremonha, a equação para cálculo das pressões verticais no descarregamento é dada por:

$$
p_{v}=\left(\frac{\gamma h_{h}}{n-1}\right)\left\{\left(\frac{x}{h_{h}}\right)-\left(\frac{x}{h_{h}}\right)^{n}\right\}+p_{v f t}\left(\frac{x}{h_{h}}\right)^{n}
$$

Onde:

$$
n=S\left(F \mu_{\text {heff }} \cot \beta+F-1\right)
$$

Considera-se valores de $\mathrm{S}=1$ para tremonhas em cunha e $\mathrm{S}=2$ para tremonhas cônicas ou piramidais. O parâmetro F representa a razão entre a pressão normal na parede da tremonha e a tensão vertical principal. O valor da pressão vertical na transição $\left(p_{v f t}\right)$ deve ser anteriormente determinado para ser utilizado na expressão W. 
As pressões estáticas são obtidas pelas expressões:

$$
\begin{gathered}
p_{n f}=\frac{\tan \beta}{\tan \beta+\mu_{\text {heff }}} p_{v} \\
p_{t f}=\mu_{\text {heff }} p_{n f}
\end{gathered}
$$

As pressões dinâmicas são obtidas pelas expressões:

$$
p_{n e}=\frac{1+\operatorname{sen} \emptyset_{e} \cos (2 \varepsilon)}{1-\operatorname{sen} \emptyset_{e} \cos (2(\beta+\varepsilon))} p_{v}
$$

Sendo:

$$
\varepsilon=\frac{1}{2}\left(\emptyset_{w}+\operatorname{sen}^{-1}\left(\frac{\operatorname{sen} \emptyset_{w}}{\operatorname{sen} \emptyset_{e}}\right)\right)
$$

2.5. Teorias de pressões implementadas

CHEUNG (2007) afirma que a teoria de Janssen (1985) é adequada para a determinação das pressões estáticas e de descarregamento, desde que sejam incorporados os coeficientes de sobrepressões.

O software Eurosilo proposto neste trabalho utiliza a teoria de Janssen (1895) no cálculo das pressões de carregamento no corpo de silos esbeltos e a teoria de Walker (1966) no cálculo de pressões na tremonha por seguir as recomendações do documento normativo BS EN 19914:2006. 


\section{NORMAS ESTRANGEIRAS E RECOMENDAÇÕES DO EUROCODE}

\subsection{Documentos normativos em projetos de silos}

Há cerca de 50 anos, começaram as tentativas de normatização no cálculo de pressões em silos. O primeiro documento normativo publicado em 1964, foi desenvolvido pelos alemães na norma DIN 1055-Part 6 “Design loads for buildings: Loads in silo bins” depois dos ensaios realizados por PIEPER \& WENZEL (1964). No entanto, este documento foi substituído pelo DIN EN 1991-4:2006, que é a tradução alemã do BS EN 1991-4:2006.

A versão atual da norma americana ACI 313-97, "Standard Practice for Design and Construction of Concrete Silos and Stacking Tubes for Storing Granular Materials” foi proposta em 1997. Diferente do BS EN 1991-4:2006, que tem aplicabilidade ampla, este documento é focado exclusivamente em métodos para cálculo de pressões sobre paredes verticais em silos de concreto.

O documento normativo ANSI/ASAE EP433 DEC1988 (R2011) "Loads Exerted by FreeFlowing Grain on Bins”, publicado na versão mais atual em fevereiro de 2011, tem aplicação limitada a silos de carregamento e descarregamento concêntrico e para produtos de fluxo livre.

A norma internacional ISO 11697 (1995) não inclui o cálculo de pressões em silos cuja excentricidade de descarregamento excede $25 \%$ do diâmetro do silo, não considerando portanto um estudo de pressões assimétricas.

Segundo PALMA (2005) as normas DIN e EUROCODE apresentam pressões no corpo do silo coincidentes e também são as que fornecem maiores valores em relação as outras normas. Isto ocorre por adotarem além da formulação de Janssen (1985), pressões adicionais na fase de carregamento. 
Apesar da norma DIN 1055-6 ser muito parecido com o BS EN 1991-4:2006, não propõe um procedimento simplificado no cálculo das pressões assimétricas, por este motivo neste trabalho optou-se pelo Eurocode.

No próximo item estão detalhadas as recomendações do BS EN 1991-4:2006. As recomendações específicas de outros documentos não foram detalhadas por não fazer parte do escopo deste trabalho.

\subsection{Eurocode}

Escrita pelo Comitê Europeu de Normalização (CEN) em Outubro de 2005, este é o código de projeto de silos mais moderno e completo em uso hoje. É comumente chamado de Eurocode e a designação formal para a versão em inglês é a norma britânica, publicado em Maio de 2006, BS EN 1991-4:2006 - "Eurocode 1: Actions on structures. Part 4:Silos and tanks”.

Esse documento é a norma estrangeira de referência mais completa atualmente para determinação das pressões exercidas pelo produto armazenado em silos. Entretanto, possuem algumas limitações geométricas, descritas a seguir:

- As formas da seção transversal são limitadas àquelas apresentadas na Figura 10, embora pequenas variações sejam aceitas desde que se garanta que não acarretarão mudanças significativas nas pressões.

- As seguintes limitações nas dimensões no corpo do silo:

$\frac{\mathrm{h}_{\mathrm{b}}}{\mathrm{d}_{\mathrm{c}}}<10$

$\mathrm{h}_{\mathrm{b}}<100 m$

$\mathrm{d}_{\mathrm{c}}<60 \mathrm{~m}$

- O diâmetro máximo permitido do produto armazenado não deve ser maior que $0,03 \mathrm{~d}_{\mathrm{c}}$.

- A transição está contida em um único plano horizontal. 


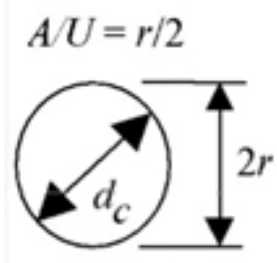

Figura 10- Formas de seção transversal.
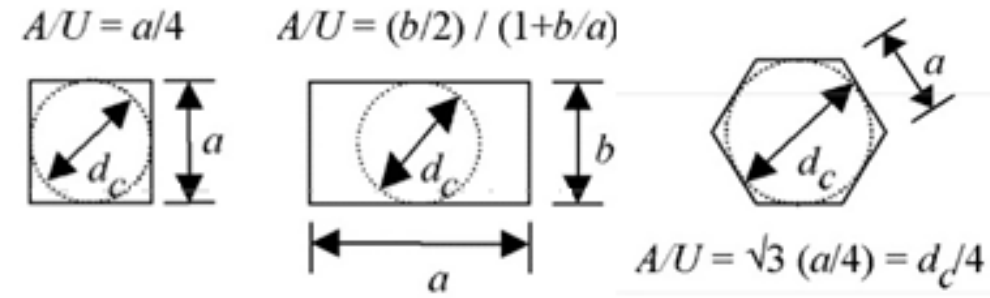

Fonte BS EN 1991-4:2006.

\subsubsection{Classificações dos silos}

Os silos são divididos nesse documento normativo em três classes de acordo com a complexidade das estruturas, mostrado no Quadro 2.

Quadro 2- Descrição das classes.

\begin{tabular}{|c|c|}
\hline Classes & Descrição \\
\hline 3 & $\begin{array}{l}\text { Silos com capacidade acima de } 10000 \text { toneladas. } \\
\text { Silos com capacidade acima de } 1000 \text { toneladas, que possuem: } \\
\text { a. } \quad \text { Excentricidade de descarregamento com } \mathrm{e}_{\mathrm{c}} / \mathrm{d}_{\mathrm{c}}>0,25 \text {. } \\
\text { b. } \quad \text { Silos baixos com excentricidade de carregamento maior que } \mathrm{e}_{\mathrm{t}} / \mathrm{d}_{\mathrm{c}}>0,25 \text {. }\end{array}$ \\
\hline 2 & Nenhuma das outras classes. \\
\hline $\mathbf{1}$ & acidade abaixo de 100 toneladas. \\
\hline
\end{tabular}

Fonte: BS EN 1991-4:2006.

Essa classificação tem por finalidade reduzir o risco de falha para diferentes estruturas. Silos de classe 1 possuem simplificações nas análises estruturais por serem menores e isso não prejudica sua segurança, ao contrário das estruturas classe 3 que requerem um método de cálculo mais rigoroso

O BS EN 1991-4:2006 propõe um método de cálculo de pressões específico de acordo com as excentricidades do silo. A distribuição de pressões nas paredes verticais do silo, para ambas as situações de carregamento e descarregamento, podem ser simétrica e global no caso de pequenas excentricidades, ou assimétrica e local, no caso de grandes excentricidades (e $\geq 0,25$ $\left.d_{c}\right)$. 
3.2.2. Propriedades dos produtos armazenados

Quanto a caracterização dos produtos armazenados, o documento normativo BS EN 19914:2006 recomenda que, sempre que possível, sejam feitos ensaios, apesar de propor valores médios para as propriedades físicas dos produtos, mostrados na Tabela 2.

Tabela 2 - Valores médios de propriedades dos produtos.

\begin{tabular}{|c|c|c|c|c|c|c|c|c|}
\hline \multirow{2}{*}{$\begin{array}{c}\text { Produtos } \\
\text { armazenados }\end{array}$} & \multicolumn{2}{|c|}{ Peso específico } & \multirow{2}{*}{$\begin{array}{c}\text { Ângulo de } \\
\text { repouso }\end{array}$} & \multicolumn{2}{|c|}{$\begin{array}{c}\text { Ângulo de atrito } \\
\text { interno }\end{array}$} & \multicolumn{2}{|c|}{$\begin{array}{c}\text { Relação pressões } \\
\text { laterais }\end{array}$} & \multirow{2}{*}{$\mathrm{C}_{\mathrm{op}}$} \\
\hline & $\begin{array}{c}\gamma_{l} \\
\left(\mathrm{kN} / \mathrm{m}^{3}\right)\end{array}$ & $\begin{array}{c}\gamma_{u} \\
\left(\mathrm{kN} / \mathrm{m}^{3}\right)\end{array}$ & & $\begin{array}{l}\emptyset_{\mathrm{im}} \\
\left(^{\circ}\right)\end{array}$ & $\mathrm{a} \varnothing$ & $\mathrm{K}_{\mathrm{m}}$ & ак & \\
\hline Açúcar & 8,0 & 9,5 & 38 & 32 & 1,19 & 0,50 & 1,20 & 0,4 \\
\hline Agregado & 17,0 & 18,0 & 36 & 31 & 1,16 & 0,52 & 1,15 & 0,4 \\
\hline Alumina & 10,0 & 12,0 & 36 & 30 & 1,22 & 0,54 & 1,20 & 0,5 \\
\hline Areia & 14,0 & 16,0 & 39 & 36 & 1,09 & 0,45 & 1,11 & 0,4 \\
\hline Batata & 6,0 & 8,0 & 34 & 30 & 1,12 & 0,54 & 1,11 & 0,5 \\
\hline Beterraba & 6,5 & 7,0 & 36 & 31 & 1,16 & 0,52 & 1,15 & 0,5 \\
\hline Cal hidratado & 6,0 & 8,0 & 34 & 27 & 1,26 & 0,58 & 1,20 & 0,6 \\
\hline Calcário em pó & 11,0 & 13,0 & 36 & 30 & 1,22 & 0,54 & 1,20 & 0,5 \\
\hline Carvão & 7,0 & 10,0 & 36 & 31 & 1,16 & 0,52 & 1,15 & 0,6 \\
\hline Carvão betuminoso & 6,5 & 8,0 & 36 & 31 & 1,16 & 0,52 & 1,15 & 0,6 \\
\hline Carvão em pó & 6,0 & 8,0 & 34 & 27 & 1,26 & 0,58 & 1,20 & 0,5 \\
\hline Cevada & 7,0 & 8,0 & 31 & 28 & 1,14 & 0,59 & 1,11 & 0,5 \\
\hline Cimento & 13,0 & 16,0 & 36 & 30 & 1,22 & 0,54 & 1,20 & 0,5 \\
\hline Cinzas & 8,0 & 15,0 & 41 & 35 & 1,16 & 0,46 & 1,20 & 0,5 \\
\hline Clínquer & 15,0 & 18,0 & 47 & 40 & 1,20 & 0,38 & 1,31 & 0,7 \\
\hline Escória de clínquer & 10,5 & 12,0 & 39 & 36 & 1,09 & 0,45 & 1,11 & 0,6 \\
\hline Farinha & 6,5 & 7,0 & 45 & 42 & 1,06 & 0,36 & 1,11 & 0,6 \\
\hline Fosfato & 16,0 & 22,0 & 34 & 29 & 1,18 & 0,56 & 1,15 & 0,5 \\
\hline Milho & 7,0 & 8,0 & 35 & 31 & 1,14 & 0,53 & 1,14 & 0,9 \\
\hline Minério de ferro & 19,0 & 22,0 & 36 & 31 & 1,16 & 0,52 & 1,15 & 0,5 \\
\hline Mix ração animal & 5,0 & 6,0 & 39 & 36 & 1,08 & 0,45 & 1,10 & 1,0 \\
\hline Pellets ração animal & 6,5 & 8,0 & 37 & 35 & 1,06 & 0,47 & 1,07 & 0,7 \\
\hline Soja & 7,0 & 8,0 & 29 & 25 & 1,16 & 0,63 & 1,11 & 0,5 \\
\hline Trigo & 7,5 & 9,0 & 34 & 30 & 1,12 & 0,54 & 1,11 & 0,5 \\
\hline
\end{tabular}


A característica da superfície de escoamento influencia na magnitude das pressões, o BS EN 1991-4:2006 define quatro tipos de parede de acordo com a sua rugosidade: polido (D1), liso (D2), rugoso (D3) e corrugado (D4). Este último possui um método de cálculo específico para chapas corrugadas senoidais e trapezoidais, utilizado nos exemplos de aplicação neste trabalho, que dependem dos valores de ângulo de atrito interno $\left(\Phi_{i}\right)$, coeficiente de atrito da parede lisa $\left(\mu_{\boldsymbol{w}}\right)$ e um fator $\left(\boldsymbol{a}_{w}\right)$. Os demais possuem valores médios mostrados na Tabela 3.

Tabela 3- Valores de coeficiente de atrito da parede.

\begin{tabular}{|c|c|c|c|c|}
\hline \multirow{3}{*}{ Produtos armazenados } & \multicolumn{4}{|c|}{ Coeficiente de atrito da parede } \\
\hline & \multicolumn{4}{|c|}{$\mu=\tan \emptyset_{w}$} \\
\hline & Parede Polida & Parede Lisa & Parede Rugosa & $\mathbf{a}_{\mu}$ \\
\hline Açúcar & 0,46 & 0,51 & 0,56 & 1,07 \\
\hline Agregado & 0,39 & 0,49 & 0,59 & 1,12 \\
\hline Alumina & 0,41 & 0,46 & 0,51 & 1,07 \\
\hline Areia & 0,38 & 0,48 & 0,57 & 1,16 \\
\hline Batata & 0,33 & 0,38 & 0,48 & 1,16 \\
\hline Beterraba & 0,35 & 0,44 & 0,54 & 1,12 \\
\hline Cal hidratado & 0,36 & 0,41 & 0,51 & 1,07 \\
\hline Calcário em pó & 0,41 & 0,51 & 0,56 & 1,07 \\
\hline Carvão & 0,44 & 0,49 & 0,59 & 1,12 \\
\hline Carvão betuminoso & 0,49 & 0,54 & 0,59 & 1,12 \\
\hline Carvão em pó & 0,41 & 0,51 & 0,56 & 1,07 \\
\hline Cevada & 0,24 & 0,33 & 0,48 & 1,16 \\
\hline Cimento & 0,41 & 0,46 & 0,51 & 1,07 \\
\hline Cinzas & 0,51 & 0,62 & 0,72 & 1,07 \\
\hline Clínquer & 0,46 & 0,56 & 0,62 & 1,07 \\
\hline Escória de clínquer & 0,48 & 0,57 & 0,67 & 1,16 \\
\hline Farinha & 0,24 & 0,33 & 0,48 & 1,16 \\
\hline Fosfato & 0,39 & 0,49 & 0,54 & 1,12 \\
\hline Milho & 0,22 & 0,36 & 0,53 & 1,24 \\
\hline Minério de ferro & 0,49 & 0,54 & 0,59 & 1,12 \\
\hline Mix ração animal & 0,22 & 0,30 & 0,43 & 1,28 \\
\hline Pellets ração animal & 0,23 & 0,28 & 0,37 & 1,20 \\
\hline Soja & 0,24 & 0,38 & 0,48 & 1,16 \\
\hline Trigo & 0,24 & 0,38 & 0,57 & 1,16 \\
\hline
\end{tabular}

Fonte: BS EN 1991-4:2006. 
No projeto de silos de classe 1 , são utilizados diretamente os valores médios das propriedades do produto e do coeficiente de atrito da parede. Para classes 2 ou 3, são determinados dois limites, inferior e superior, para cada propriedade do produto armazenado e do coeficiente de atrito da parede, para dessa forma obter as combinações mais desfavoráveis para cada caso durante a vida útil do silo. Basta multiplicar ou dividir os valores médios pelo fator de conversão (a), como é mostrado abaixo na Tabela 4:

Tabela 4-Valores inferior e superior das propriedades físicas.

\begin{tabular}{|c|c|c|}
\hline Propriedade & Inferior & Superior \\
\hline $\mathrm{K}$ & $\mathrm{K}=K_{m} / a_{K}$ & $\mathrm{~K}=a_{K}{ }^{*} K_{m}$ \\
\hline$\varnothing$ & $\varnothing=\emptyset_{i m} / a_{\emptyset}$ & $\varnothing=a_{\varnothing}{ }^{*} \emptyset_{i m}$ \\
\hline$\mu$ & $\mu=\mu_{\boldsymbol{m}} / a_{\mu}$ & $\mu=a_{\mu}{ }^{*} \mu_{\boldsymbol{m}}$ \\
\hline
\end{tabular}

Fonte: A autora.

\subsubsection{Pressões de carregamento}

\section{- Silos esbeltos}

As pressões de carregamento, também chamadas de estáticas possuem distribuições simétricas aplicadas em todos os pontos da parede vertical do silo em contato com o produto armazenado e simetria axial, embora os valores aumentem de acordo com a profundidade (z). Compreendem a pressão horizontal $\left(p_{h f}\right)$, pressão de atrito na parede $\left(p_{w f}\right)$ e pressão vertical $\left(p_{v f}\right)$, mostradas na Figura 11. São calculadas usando a formulação de Janssen (1895), mostrada pelas expressões a seguir:

$$
\begin{gathered}
p_{h f}(z)=p_{h o} Y_{J}(z) \\
\mathrm{p}_{\mathrm{wf}}(\mathrm{z})=\mu \mathrm{p}_{\mathrm{ho}} \mathrm{Y}_{\mathrm{J}}(\mathrm{z}) \\
p_{v f}(z)=\frac{p_{h o}}{K} Y_{J}(z)
\end{gathered}
$$


Onde:

$$
p_{h o}=\gamma \frac{1}{\mu} \frac{A}{U}
$$

$$
z_{o}=\frac{1}{K \mu} \frac{A}{U}
$$

$$
Y_{J}(z)=1-e^{-z / z_{o}}
$$

Figura 11-Pressões estáticas.

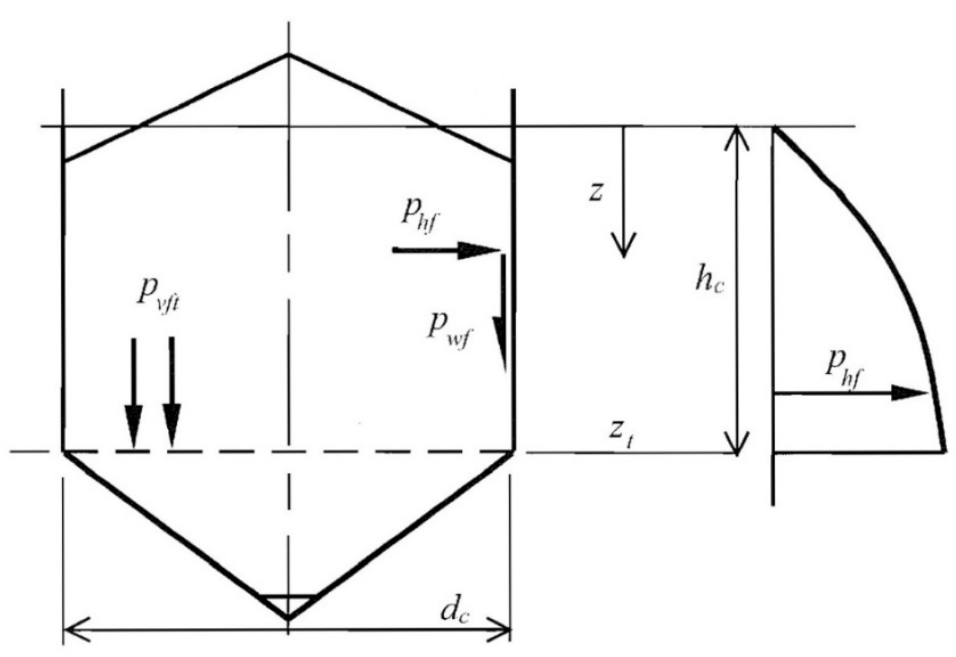

Fonte: Adaptado do BS EN 1991-4:2006.

A origem da coordenada vertical z é no centroide do talude formado pelo produto armazenado, chamada de altura de referência.

- Silo medianamente esbelto ou baixo

Diferem da distribuição de pressões em silos esbeltos por serem nulas na altura $\mathrm{z}=h_{o}$ e não em $\mathrm{z}=0$, ou seja no ponto de contato entre a parede e o grão, mostrado na Figura 12. São determinados valores para pressão horizontal $\left(p_{h f}\right)$, pressão de atrito na parede $\left(p_{w f}\right)$ e pressão vertical $\left(p_{v f}\right)$, conforme expressões: 


$$
\begin{gathered}
p_{h f}(z)=p_{h o} Y_{R}(z) \\
p_{w f}(z)=\mu p_{h o} Y_{R}(z) \\
p_{v f}(z)=\gamma z_{V}(z)
\end{gathered}
$$

Onde:

$$
\begin{gathered}
p_{h o}=\gamma K z_{o} \\
z_{o}=\frac{1}{K \mu} \frac{A}{U} \\
Y_{R}(z)=\left(1-\left\{\left(\frac{z-h_{o}}{z_{o}-h_{o}}\right)+1\right\}^{n}\right. \\
n=-\left(1+\tan \emptyset_{r}\right)+\left(1-h_{o} / z_{o}\right) \\
z_{V}=h_{o}-\frac{1}{(n+1)}\left(z_{o}-h_{o}-\frac{\left(z+z_{o}-2 h_{o}\right)^{n+1}}{\left(z_{o}-h_{o}\right)^{n}}\right)
\end{gathered}
$$

Figura 12- Diferença entre pressões em silos esbetos e medianamente esbelto/baixo.

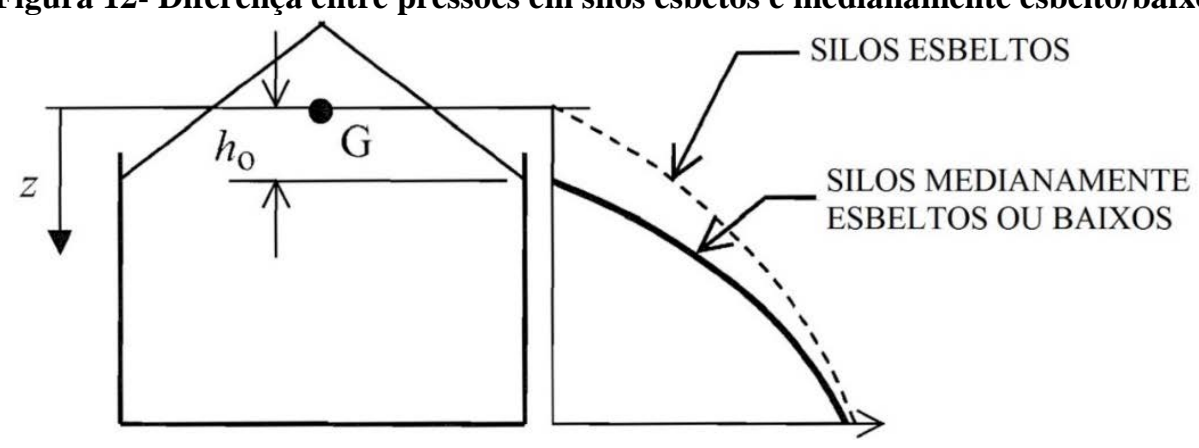

Fonte: Adaptado do BS EN 1991-4:2006.

3.2.4. Sobrecarga nas pressões de carregamento

- Silos esbeltos 
A sobrecarga $\left(p_{p f}\right)$ é uma distribuição assimétrica local usada para representar assimetrias acidentais durante o processo de carregamento, mostrada na Figura 13. Compreende apenas pressões horizontais e o BS EN 1991-4:2006 recomenda a área de aplicação em uma faixa de parede (s) localizada a uma profundidade definida $\left(z_{p}\right)$. Para silos com paredes finas $\left(\frac{d_{c}}{t}>\right.$ 200), a altura $z_{p}$ é o menor valor entre $z_{o}$ e $h_{c} / 2$.

Figura 13 - Sobrecarga nas pressões de carregamento.
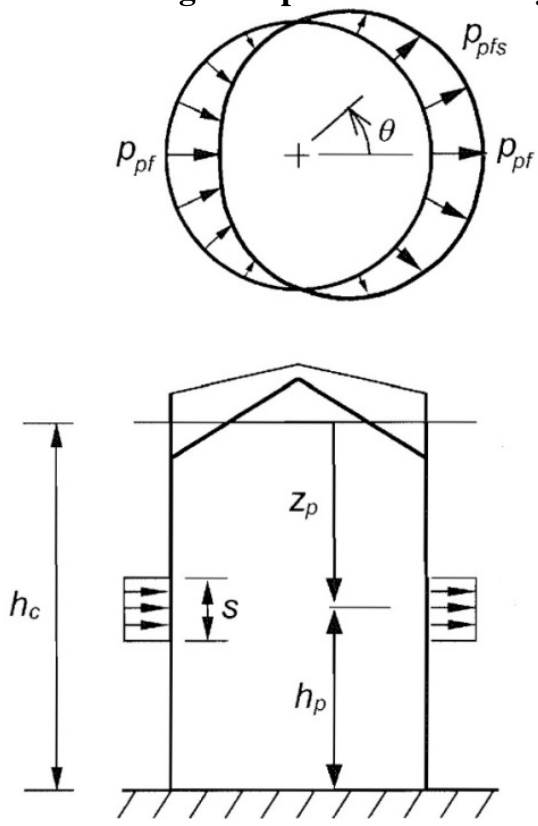

Fonte: Adaptado do BS EN 1991-4:2006.

Para silos classe 1 a sobrecarga é ignorada. Nos demais casos é calculada pelas expressões abaixo, considerando a máxima excentricidade de carregamento $\left(e_{f}\right)$ e o fator de sobrecarga de cada produto armazenado $\left(C_{o p}\right)$.

$$
\begin{gathered}
p_{p f}=C_{p f} P_{h f} \\
C_{p f}=0,21 C_{o p}\left[1+2 E^{2}\right]\left(1-e^{\left\{-1,5\left[\left(\frac{h c}{d c}\right)-1\right]\right\}}\right) \\
E=2 e_{f} / d_{c} \\
s=0,2 d_{c}
\end{gathered}
$$


As pressões $\left(P_{p f s}\right)$ usadas implicitamente para silos com paredes finas tem valores com sinais opostos e diminui até a metade da seção com a expressão $P_{p f s}=P_{p f} \cdot \cos \theta$. Os valores de pressão são constantes, para uma única linha meridional da faixa, mas há uma variação contínua com a coordenada circunferencial $(\theta)$, os máximos ocorrem em $\theta=0$ e $\theta=180$, contudo com sinais inversos.

Finalmente, basta somar os dois componentes de pressões, mostrada na Figura 14, para fazer o estudo completo das pressões na fase de carregamento pelo BS EN 1991-4:2006.

Figura 14-Componentes de pressões sobrecarga de carregamento.

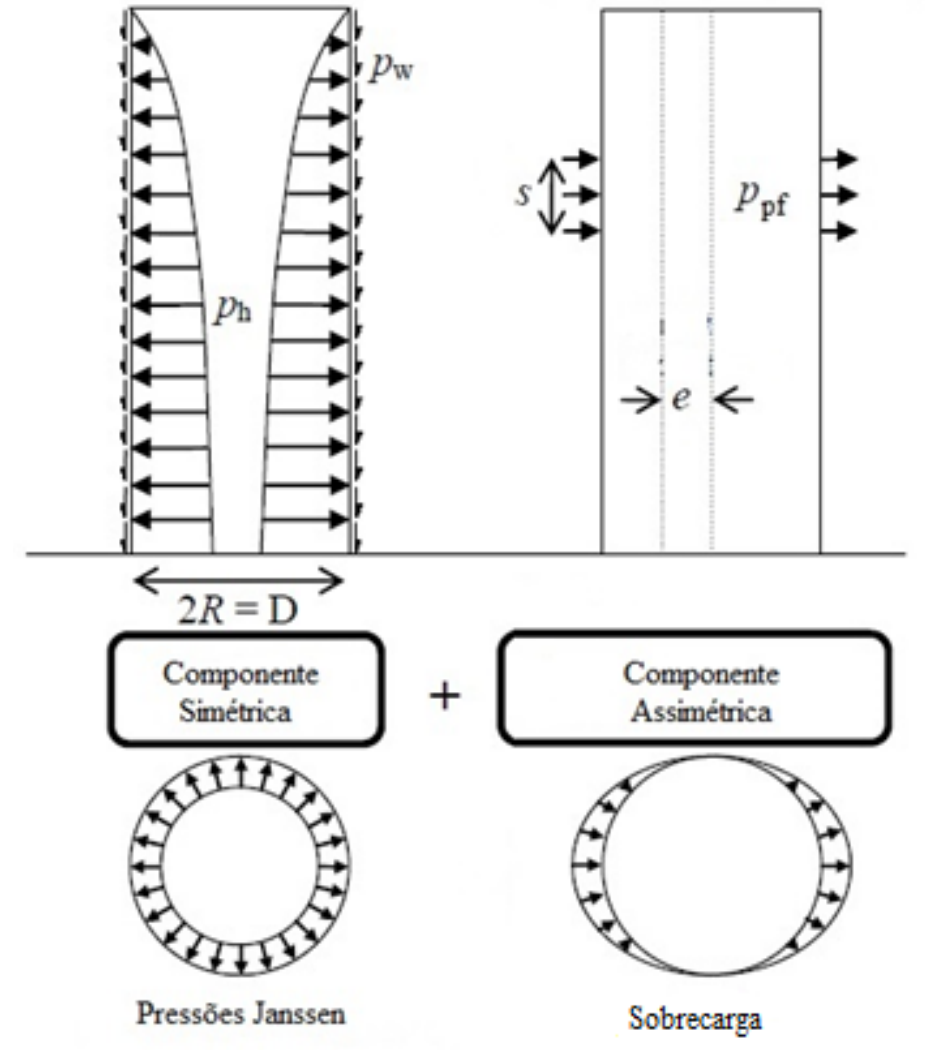

Fonte: SADOWSKI \& ROTTER (2010).

Portanto, a distribuição de pressões simétricas e assimétricas atuantes no perímetro da seção transversal do silo, resulta conforme mostrado na Figura 15. 
Figura 15-Distribuição de pressões simétricas e assimétricas.

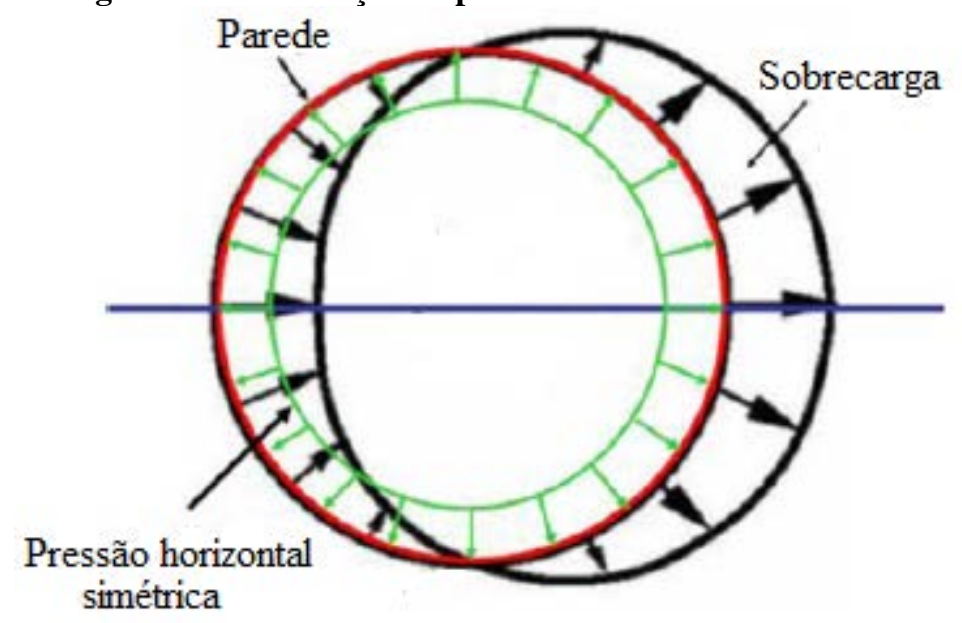

Fonte: Adaptado de GALLEGO et al. (2011).

- Silo medianamente esbelto ou baixo

A sobrecarga é considerada agindo em qualquer profundidade do silo e deve ser aplicada apenas na pressão normal. Para silos baixos, em todas as classes de risco, e silos de esbeltez intermediária classe 1 , a sobrecarga é desconsiderada $\left(C_{p f}=0\right)$.

Para silos de esbeltez intermediária, classes 2 e 3 , a sobrecarga de carregamento $\left(P_{p f}\right)$ deve ser calculada conforme silos esbeltos para representar assimetrias acidentais de carregamento e pequenas excentricidades de carregamento.

\subsubsection{Pressões de descarregamento}

- Silos esbeltos

As pressões na fase de descarregamento, também conhecido como dinâmicas, chamadas de pressão horizontal $\left(p_{h e}\right)$ e pressão de atrito na parede $\left(p_{w e}\right)$ são calculas a partir dos valores 
obtidos no cálculo das pressões na fase de carregamento ponderadas pelos fatores de descarregamento. O primeiro fator é constante para todos os produtos armazenados $C_{o}=$ 1,15. Os demais fatores $C_{h}$ e $C_{w}$ variam de acordo com as classes e estão mostradas na Tabela 5 .

Tabela 5 - Valores para fatores de descarregamento em silos esbeltos.

\begin{tabular}{|c|c|}
\hline Classe 1 & Classes 2 e 3 \\
\hline$C_{h}=1,15+1,5\left(1+0,4 e / d_{c}\right) C_{o p}$ & $C_{h}=1,15$ \\
\hline$C_{w}=1,4\left(1+0,4 e / d_{c}\right)$ & $\mathrm{C}_{\mathrm{w}}=1,10$ \\
\hline
\end{tabular}

Fonte: A autora.

$$
\begin{gathered}
P_{h e}=C_{h} p_{h f} \\
P_{w e}=C_{w} p_{w f}
\end{gathered}
$$

\section{- Silo medianamente esbelto ou baixo}

Para silos baixos, a pressão simétrica de descarregamento deve ser tomada como idêntica à pressão de carregamento. Para silos de esbeltez intermediária, as pressões simétricas de descarregamento horizontal $\left(p_{h e}\right)$ e de atrito $\left(p_{w e}\right)$ são determinadas pelas mesmas expressões utilizadas para silos esbeltos. Porém os fatores de descarregamento $C_{h}$ e $C_{w}$ não são iguais e variam de acordo com a Tabela 6. O fator de ajuste de esbeltez é calc $C_{s}=h_{c} / d_{c}-1,0$. Os silos que são descarregados pelo topo, ou seja, sem fluxo do produto armazenado, deve-se considerar $C_{h}=C_{w}=1,0$. O fator de ajuste de esbeltez é calculado pela expressão que segue.

Tabela 6 - Valores para fatores de descarregamento em silos medianamente esbeltos.

\begin{tabular}{|c|c|}
\hline Classe $\mathbf{1}$ & Classes 2 e 3 \\
\hline $\mathbf{C}_{\mathbf{h}}=\mathbf{1}, \mathbf{0}+\left\{\mathbf{0}, \mathbf{1 5}+\mathbf{1}, \mathbf{5}\left(\mathbf{1}+\mathbf{0}, \mathbf{4 e} / \mathbf{d}_{\mathbf{c}}\right) \mathbf{C}_{\mathbf{o p}}\right\} \boldsymbol{C}_{\boldsymbol{s}}$ & $\mathrm{C}_{\mathrm{h}}=1,0+0,15 C_{s}$ \\
\hline $\mathbf{C}_{\mathrm{w}}=\mathbf{1}, \mathbf{0}+\mathbf{0}, \mathbf{4}\left(\mathbf{1}+\mathbf{0}, \mathbf{4 e} / \mathbf{d}_{\mathbf{c}}\right) \boldsymbol{C}_{\boldsymbol{s}}$ & $\mathrm{C}_{\mathrm{w}}=1,0+0,10 C_{s}$ \\
\hline
\end{tabular}

Fonte: A autora. 


$$
C_{s}=h_{c} / d_{c}-1,0
$$

\subsubsection{Sobrecarga nas pressões de descarregamento}

- Silos esbeltos

A sobrecarga $\left(p_{p e}\right)$ nas pressões de descarregamento é usada para representar assimetrias acidentais durante o processo de descarregamento. Silos classe 1 devem ignorar estas pressões adicionais, para as demais classes as pressões adicionais devem ser calculadas conforme equação a seguir:

$$
p_{p e}=C_{p e} p_{h e}
$$

O valor da constante $C_{p e}$ varia de acordo com a razão entre a altura do silo $\left(h_{c}\right)$ e seu diâmetro $\left(d_{c}\right)$, mostrados na Tabela 7. Adota-se para valor da excentricidade (e) o maior valor entre as excentricidades de carregamento e descarregamento.

\begin{tabular}{|c|c|}
\hline$h_{c} / d_{c}>1,2$ & $h_{c} / d_{c} \leq 1,2$ \\
\hline$C_{p e}=0,42 C_{o p}\left[1+2 E^{2}\right]\left(1-e^{\left\{-1,5\left[\left(\frac{h}{d c}\right)-1\right]\right\}}\right)$ & $\begin{array}{c}\text { Maior valor entre: } \\
\mathrm{C}_{\mathrm{pe}}=0,272 \mathrm{C}_{\mathrm{op}}\left\{\left(\mathrm{h}_{\mathrm{c}} / \mathrm{d}_{\mathrm{c}}\right)-1+\mathrm{E}\right\} \\
\mathrm{C}_{\mathrm{pe}}=0\end{array}$ \\
\hline
\end{tabular}

Tabela 7- Valores para fator de sobrepressão no descarregamento.

Fonte: A autora.

$$
E=2 e / d_{c}
$$

Caso existam grandes excentricidades em silos circulares, ou seja, que excedem o valor limite (e $>0,25 d_{c}$ ), é proposto um caso específico em adição as pressões descritas a seguir. 
Assim como a sobrepressão, no caso de carregamento, compreende apenas pressões horizontais e sua área de aplicação é recomendada a uma faixa de parede (s) localizada a uma profundidade definida $\left(z_{p}\right)$, mostrada na Figura 16, para silos com paredes finas (metálicas $\frac{d_{c}}{t}>200$ ) como o o menor valore entre $z_{o}$ e $h_{c} / 2$.

As pressões $\left(P_{\text {pes }}\right)$ também utilizadas implicitamente para silos com paredes finas tem valores com sinais opostos e diminui até a metade da seção com a expressão $P_{p e s}=P_{p e} \cdot \cos \theta$. Os valores de pressão são constantes, para uma única linha meridional da faixa, mas há uma variação contínua com a coordenada circunferencial $(\theta)$, os máximos ocorrem em $\theta=0^{\circ} \mathrm{e}$ $\theta=180^{\circ}$, contudo com sinais inversos (Figura 16).

Figura 16- Sobrecarga nas pressões de descarregamento.
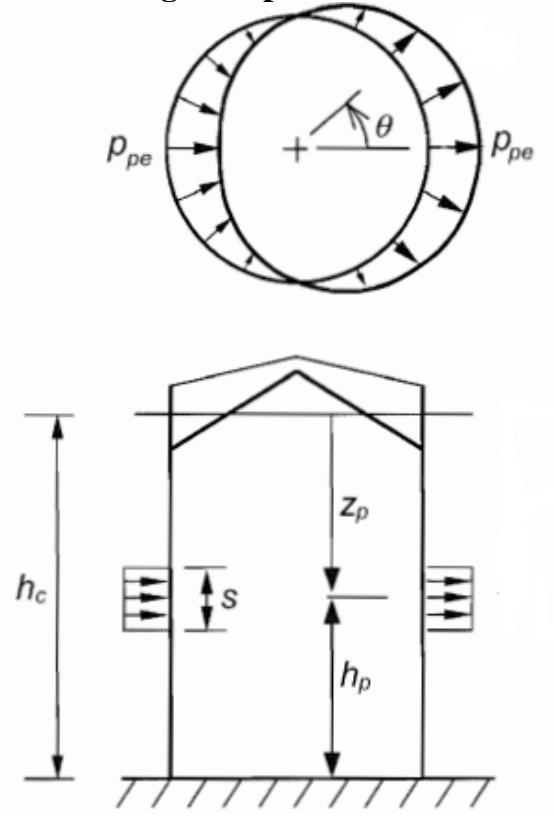

Fonte: Adaptado do BS EN 1991-4:2006.

- Silo medianamente esbelto ou baixo

A forma, localização e magnitude das sobrepressões de descarregamento são calculadas pelas mesmas expressões utilizadas em silos esbeltos para silos com excentricidade de descarregamento que não excede o valor crítico. 
Vale ressaltar que para silos baixos, com excentricidade de descarregamento menor que $0,1 d_{c}$ ou classe 1e silos de esbeltez intermediária classe 1 , a sobrecarga de descarregamento pode ser desconsiderada $\left(C_{p e}=0\right)$.

\subsubsection{Pressões de descarregamento para silos circulares com grande excentricidade}

Para silos circulares que excedem o valor crítico de excentricidade de descarregamento $\left(e_{o}>\right.$ $0,25 d_{c}$ ), existe um procedimento específico para determinação das pressões excêntricas, ilustrado na Figura 17, durante descarregamento excêntrico em fluxo de funil para as classes 2 e 3. A excentricidade do canal do fluxo $\left(e_{c}\right)$ é determinado pelas equações seguintes.

$$
\begin{gathered}
e_{c}=r\{\eta(1-G)+(1-\eta) \sqrt{1-G}\} \\
G=r_{c} / r \\
\eta=\mu_{l} / \tan \phi_{i u}
\end{gathered}
$$

Figura 17-Distribuição de pressões com descarregamento excêntrico.

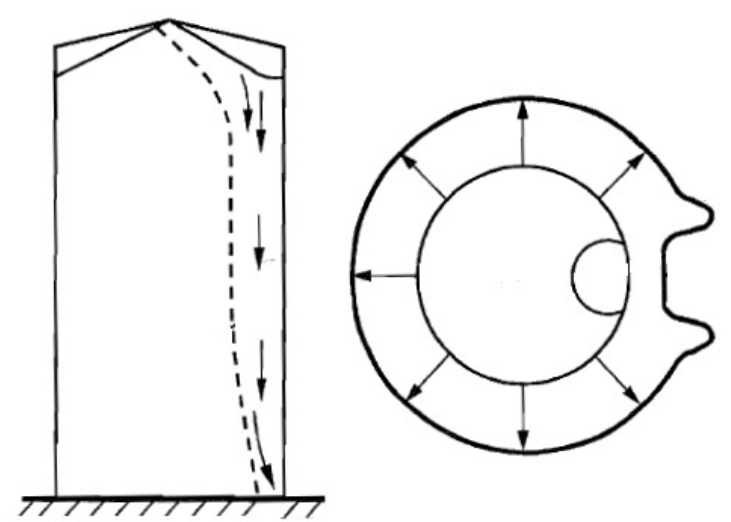

Fonte: Adaptado do BS EN 1991-4:2006.

Um estudo sobre a geometria do canal de escoamento deve ser feito para posteriormente calcular pressões, e nem sempre essa geometria é bem definida e localizada (Figura 18). 
Figura 18-Geometria do canal de escoamento.

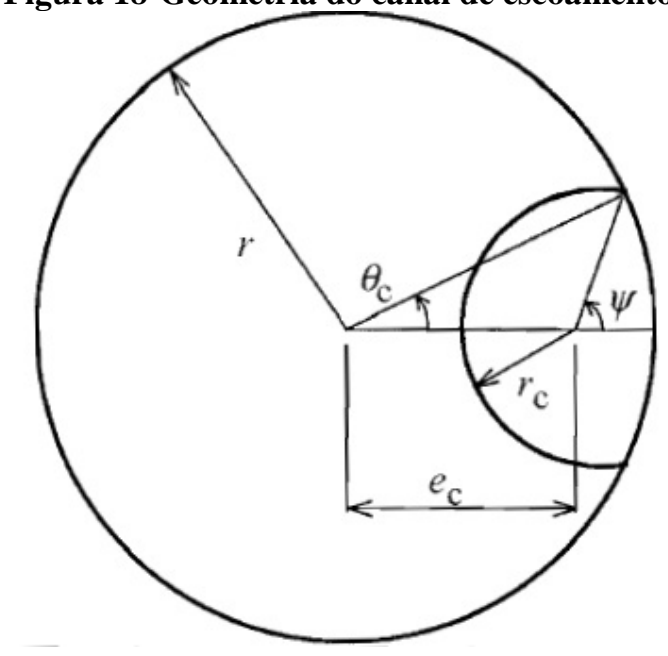

Fonte: BS EN 1991-4:2006.

Para silo classe 2, deve-se apenas adotar o valor de $35^{\circ}$ para a coordenada $(\theta)$, enquanto que para classe 3 deve-se calcular a coordenada $\theta_{c}$ e três valores de raios de canal de escoamento $\left(r_{c}\right)$ para permitir variações. Recomenda-se valores para $k_{1}$, $k_{2}$ e $k_{3}$ sendo 0,25 ; 0,40 e 0,60 respectivamente.

$$
\begin{gathered}
r_{c}=k_{1} r \\
r_{c}=k_{2} r \\
r_{c}=k_{3} r \\
\cos \theta_{c}=\frac{r^{2}+e_{c}{ }^{2}-r_{c}{ }^{2}}{2 r e_{c}}
\end{gathered}
$$

O comprimento do arco de contato entre o canal de escoamento e a parede, e o comprimento do arco de contato entre o canal de escoamento e o produto armazenado, são determinados por:

$$
\begin{gathered}
U_{w c}=2 \theta_{c} r \\
U_{s c}=2 r_{c}(\pi-\psi)
\end{gathered}
$$


Onde:

$$
\operatorname{sen} \psi=\frac{r}{r_{c}} \operatorname{sen} \theta_{c}
$$

A área da seção transversal do canal de escoamento é determinada por:

$$
A_{c}=(\pi-\psi) r_{c}^{2}+\theta_{c} r^{2}-r r_{c} \operatorname{sen}\left(\psi+\theta_{c}\right)
$$

São calculadas na profundidade local (z) as pressões na parede vertical em contato com o produto armazenado $\left(p_{\text {hse }}\right.$ e $\left.p_{\text {hae }}\right)$, pressões de atrito na parede $\left(p_{w s e}\right.$ e $\left.p_{\text {wae }}\right)$ e a pressão horizontal na parede vertical na zona de fluxo $\left(p_{\text {hce }}\right)$, mostradas na Figura 19, pelas expressões na Tabela 8.

Figura 19- Pressões excêntricas.

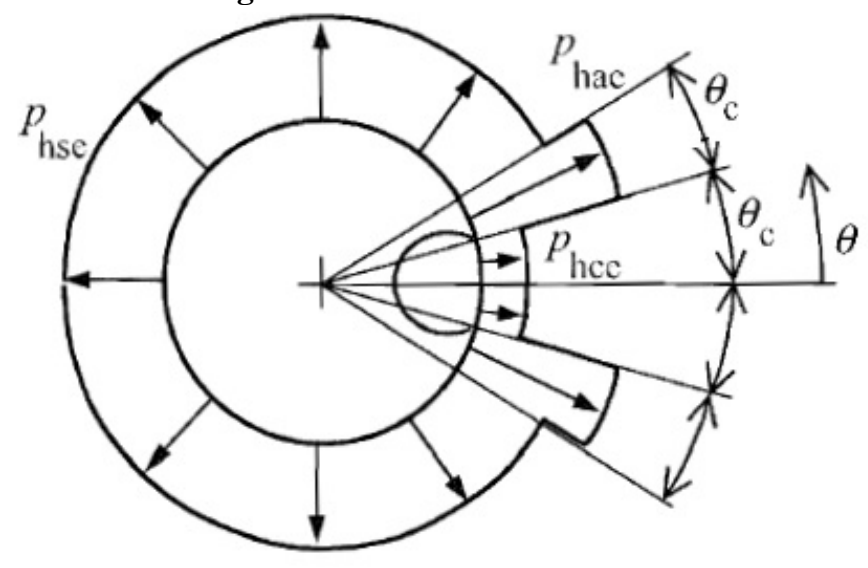

Fonte: BS EN 1991-4:2006.

Tabela 8-Expressões para cálculo de pressões excêntricas.

\begin{tabular}{|c|c|}
\hline \multicolumn{2}{|c|}{ Cálculo de pressões excêntricas } \\
\hline Classe 2 & Classe 3 \\
\hline $\mathrm{p}_{\mathrm{hce}}=0$ & $p_{\text {hce }}=p_{\text {hco }}\left(1-e^{-z / z_{o c}}\right)$ \\
\hline $\mathrm{p}_{\mathrm{hse}}=\mathrm{p}_{\mathrm{hf}}$ & $p_{\text {hse }}=p_{h f}$ \\
\hline $\mathrm{p}_{\mathrm{hae}}=2 \mathrm{p}_{\mathrm{hf}}$ & $p_{\text {hae }}=2 p_{h f}-p_{\text {hce }}$ \\
\hline $\mathrm{p}_{\mathrm{wse}}=\mathrm{p}_{\mathrm{wf}}$ & $p_{\text {wse }}=p_{w f}$ \\
\hline $\mathrm{p}_{\mathrm{wae}}=2 \mathrm{p}_{\mathrm{wf}}$ & $p_{\text {wae }}=\mu p_{\text {hae }}$ \\
\hline
\end{tabular}

Fonte: A autora.

$$
p_{\text {hco }}=\gamma K z_{o c}
$$




$$
z_{o c}=\frac{1}{k}\left(\frac{A_{c}}{U_{w c} \mu+U_{s c} \tan \phi_{i}}\right)
$$

\subsubsection{Pressões no fundo do silo}

O documento normativo específico BS EN 1991-4:2006 sugere a determinação gráfica do tipo de fluxo, mostrada nas Figuras 20 e 21, que depende do ângulo da tremonha ( $\beta$ ) e o coeficiente de atrito com a parede $\left(\mu_{\mathbf{w}}\right)$.

Figura 20 - Determinação do tipo de fluxo em tremonhas em forma de cunha

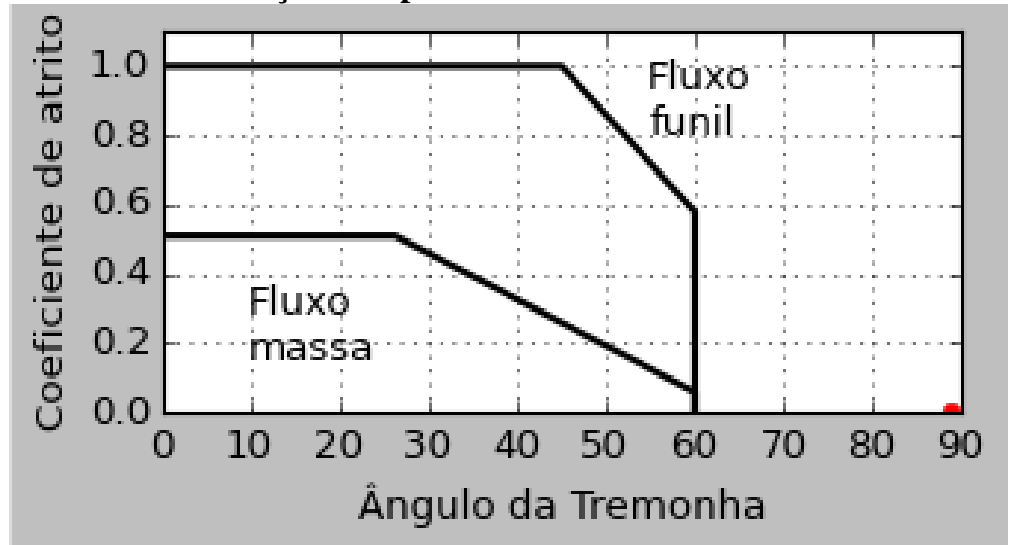

Fonte: Adaptado do BS EN 1991-4:2006.

Figura 21 - Determinação do tipo de fluxo em tremonhas cônicas e piramidais quadrada.

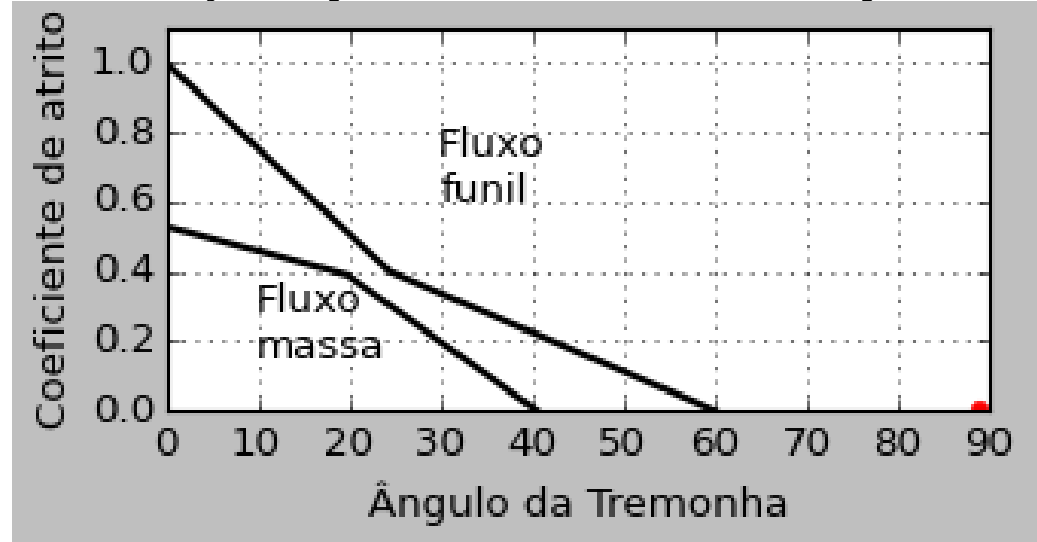

Fonte: Adaptado do BS EN 1991-4:2006. 
As pressões que atuam no fundo do silo foram programadas para os seguintes tipos:

o Fundo plano: fundo do silo com paredes inclinadas inferior a $5^{\circ} \mathrm{com}$ a horizontal.

o Tremonha íngreme: satisfaz o critério $\tan \beta<\frac{1-K_{l}}{2 \mu_{h l}}$.

o Tremonha rasa: não é classificada em nenhum dos dois casos.

A pressão vertical média na transição entre a parede vertical e a tremonha ou fundo plano é determinada pelo valor da pressão vertical ponderada pelo valor do coeficiente $C_{b}$. Os valores de $C_{b}$ variam de acordo com as classes de risco distintas, mostrados na Tabela 9:

$$
p_{v f t}=C_{b} P_{v f}
$$

Tabela 9-Valores do coeficiente $\mathbf{C}_{\mathbf{b}}$.

\begin{tabular}{|c|c|}
\hline Classe 1 & Classe $2 \boldsymbol{e} \mathbf{3}$ \\
\hline$C_{b}=1,6$ & $C_{b}=1,2$ \\
\hline
\end{tabular}

Fonte: A autora.

- Fundo plano

A pressão vertical no fundo plano para silos esbeltos é adotada como uniforme $\left(p_{v}=p_{v f t}\right)$, e durante descarregamento é tomada como idêntica à pressão vertical no fim do carregamento.

Em um silo baixo ou de esbeltez intermediária, a pressão vertical $\left(p_{v s q}\right)$ é determinada por:

$$
p_{v s q}=p_{v b}+\Delta p_{s q}\left(\frac{2,0-h_{c} / d_{c}}{2,0-h_{t p} / d_{c}}\right)
$$

Onde:

$$
\Delta p_{s q}=p_{v t p}-p_{v h o}
$$




$$
p_{v t p}=\gamma h_{t p}
$$

$\mathrm{O}$ valor de $p_{v b}$ é a componente uniforme da pressão vertical, obtida com $\mathrm{z}=h_{c}$, adotando valores característicos para as propriedades dos produtos armazenados mais desfavoráveis. O valor de $p_{v h o}$ é a pressão vertical de Janssen na base da parte superior da pilha obtida pela expressão (y) com z $=h_{0}$.

\section{- Tremonhas íngremes e rasas}

Para ambos carregamento e descarregamento, nas tremonhas íngremes o coeficiente de atrito efetivo da parede da tremonha $\left(\mu_{h e f f}\right)$ foi tomado como o valor característico inferior $\left(\mu_{h l}\right)$. Nas tremonhas rasas, pode ser calculado conforme Tabela 10.

Tabela 10-Valor do coeficiente de atrito efetivo na tremonha.

\begin{tabular}{|c|c|c|}
\hline & Tremonha íngreme & Tremonha rasa \\
\hline Coeficiente de atrito efetivo & $\mu_{\text {heff }}=\mu_{h l}$ & $\mu_{\text {heff }}=\frac{\left(1-K_{l}\right)}{2 \tan \beta}$ \\
\hline
\end{tabular}

Fonte: A autora.

Em ambas as fases de carregamento e descarregamento, a pressão vertical média $\left(p_{v}\right)$ do produto armazenado a qualquer nível em uma tremonha acima do vértice é determinado pelas expressões a seguir:

$$
\begin{gathered}
p_{v}=\left(\frac{\gamma_{u} \cdot h_{h}}{n-1}\right)\left\{\left(\frac{x}{h_{h}}\right)-\left(\frac{x}{h_{h}}\right)^{n}\right\}+p_{v f t}\left(\frac{x}{h_{h}}\right)^{n} \\
n=S 0,8 \mu_{\text {heff }} \cot \beta
\end{gathered}
$$

O valor do coeficiente de forma da tremonha (S) é determinado de acordo com a geometria da tremonha, para tremonha cônica e piramidal quadrada $S=2$, tremonha em forma de cunha $S=$ 1 e plataforma retangular $S=(1+b / a)$. Na fase de carregamento o parâmetro $F$ para tremonhas íngremes e rasas deve ser dado por $F_{f}$ : 


$$
F=F_{f}=1-\frac{0,2}{\left(1+\frac{\tan \beta}{\mu_{\text {heff }}}\right)}
$$

A pressão normal $\left(\mathrm{p}_{\mathrm{nf}}\right)$ e tração por atrito $\left(\mathrm{p}_{\mathrm{tf}}\right)$ na fase de carregamento no fundo do silo estão mostradas na Figura 22, e equacionadas a seguir:

$$
\begin{gathered}
p_{n f}=F_{f} p_{v} \\
p_{t f}=\mu_{h e f f} F_{f} p_{v}
\end{gathered}
$$

Figura 22- Pressões na tremonha no carregamento do silo.

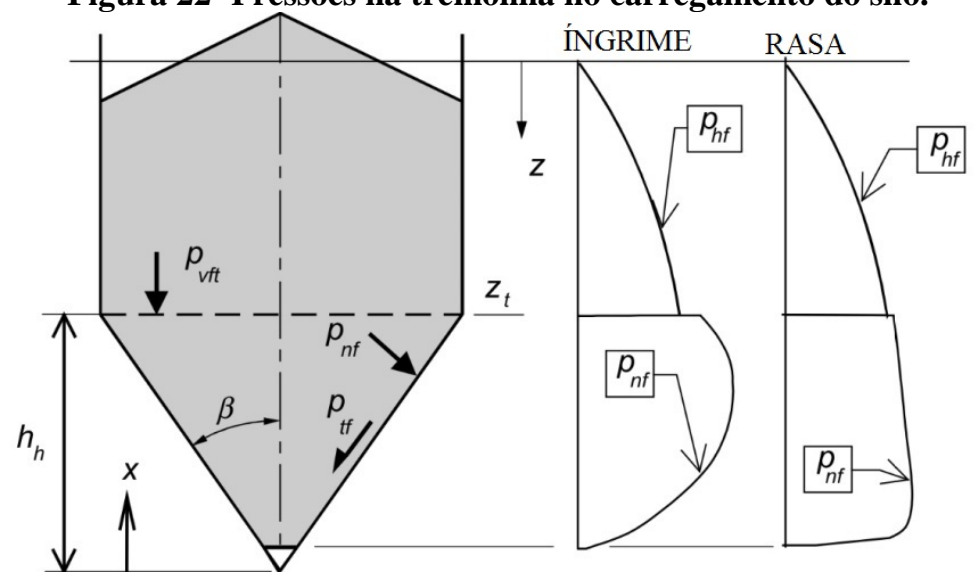

Fonte Adaptado BS EN 1991-4:2006.

Em tremonhas rasas sob descarregamento, a pressão normal $\left(p_{n e}\right)$ e tração de atrito $\left(p_{t e}\right)$ deve ser tomada como idêntica aos valores de carregamento. Em tremonhas íngremes sob descarregamento, a pressão vertical média do produto armazenado em qualquer nível pode ser usada pela mesma expressão de carregamento, porém o parâmetro $\mathrm{F}$ deve ser dado por $F_{e}$ que é baseado na teoria de Walker.

$$
F=F_{e}=\frac{1+\operatorname{sen} \phi_{i} \cos \varepsilon}{1-\operatorname{sen} \phi_{i} \cos (2 \beta+\varepsilon)}
$$

Onde:

$$
\phi_{w h}=\tan ^{-1} \mu_{h e f f}
$$




$$
\varepsilon=\phi_{w h}+\operatorname{sen}^{-1}\left(\frac{\operatorname{sen} \phi_{w h}}{\operatorname{sen} \phi_{i}}\right)
$$

A pressão normal $\left(p_{n e}\right)$ e tração por atrito $\left(p_{\text {te }}\right)$ na fase de descarregamento no fundo do silo estão mostradas na Figura 23, e equacionadas a seguir.

$$
\begin{gathered}
p_{n f}=F_{f} p_{v} \\
p_{n f}=\mu_{h e f f} F_{f} p_{v}
\end{gathered}
$$

Figura 23- Pressões na tremonha no descarregamento do silo.
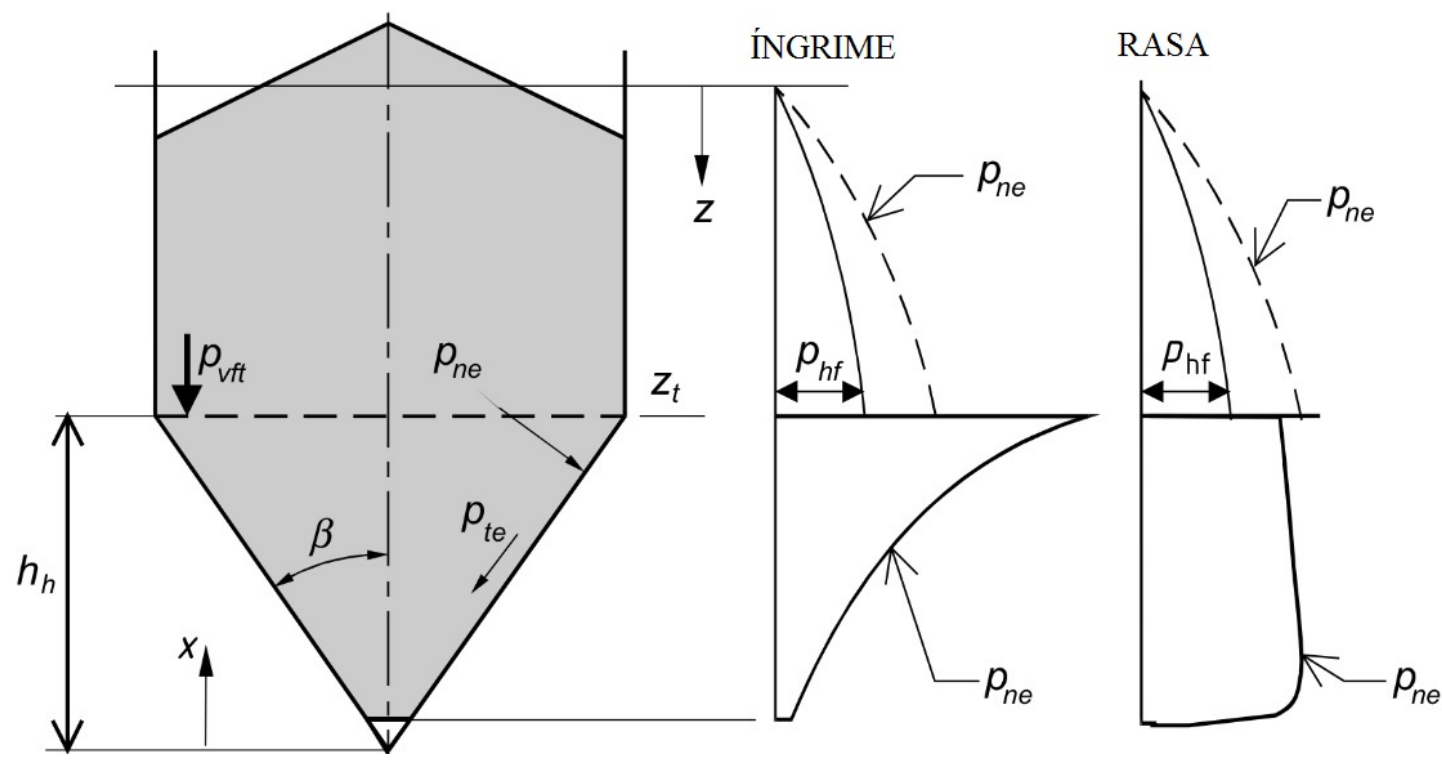

Fonte: Adaptado BS EN 1991-4:2006.

Nas Figuras 22 e 23, observa-se que o maior pico de pressões ocorrerá no nível da transição efetiva e sua magnitude dependerá da localização da transição efetiva no cilindro e ocorre quando a pressão vertical do cilindro é máxima para o campo de pressões de Janssen. Esse pico deve ser obtido para vários valores de z com o objetivo de determinar a envoltória dos picos de pressão. 


\section{SOFTWARES PARA CÁLCULO EM SILOS}

Neste capítulo serão mostrados alguns softwares desenvolvidos anteriormente para cálculo de pressões em silos e o programa desenvolvido neste trabalho detalhadamente, denominado Eurosilo.

\subsection{Softwares desenvolvidos}

O primeiro software para cálculo de silos foi proposto por Benink (1989), na Holanda, no qual foram feitas análises críticas sobre as teorias e formulações, comparando com resultados experimentais. Neste trabalho foi desenvolvido um programa em MS-DOS, capaz de determinar o tipo de fluxo com base no comportamento do produto durante o escoamento, a abertura crítica da tremonha e as pressões nas paredes tanto na fase de carregamento, quanto na fase de descarregamento, com base nas teorias de Walker (1966), Walters (1873), Jenike (1964), Janssen (1895) e nas normas ACI, BMHB e DIN, vigentes na época.

Outros programas computacionais foram desenvolvidos no Brasil para análise e dimensionamento de silos. Alves (2001) desenvolveu um programa em linguagem FORTRAN, denominado PROGSILO, que calcula ações que atuam sobre estruturas de silos unicelulares em concreto armado de forma cilíndrica e também calculam as armaduras necessárias para absorver as tensões e solicitações geradas por tais ações.

Palma (2005) desenvolveu um programa denominado “Pressões Silos Esbeltos 1.0”, que foi desenvolvido pelas orientações da norma internacional ISO 11697 (1995), cuja tela principal está apesentada na Figura 24. O programa calcula as pressões devidas ao produto armazenado em silos verticais esbeltos com fundo plano e cônico. A saída de dados é realizada por meio da apresentação dos resultados (pressões) na forma de tabela e na forma gráfica. 
Figura 24- Interface programa "Pressões Silos Esbeltos 1.0”.

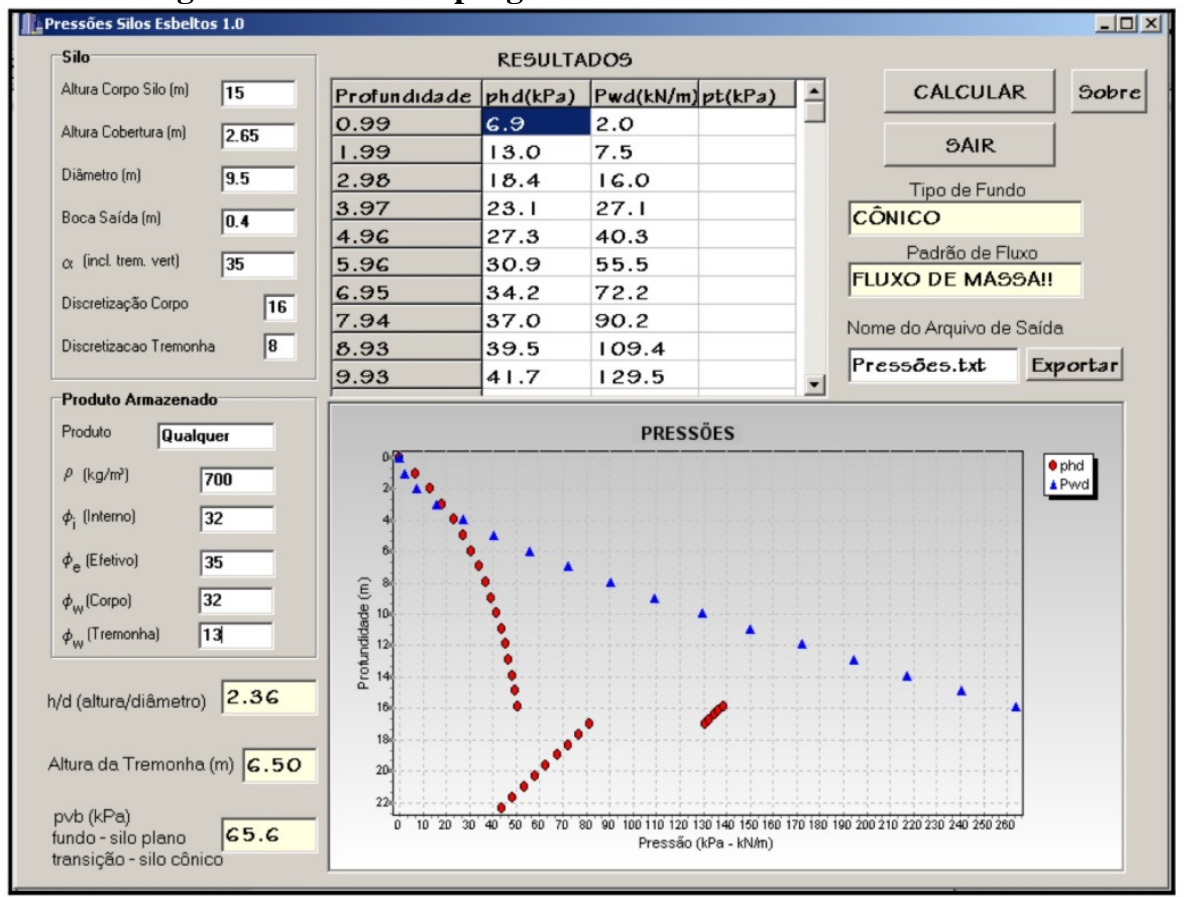

Fonte: Palma (2005)

Cheung (2007) desenvolveu um programa mais refinado, baseado em computação bioinspirada e em confiabilidade. Denominado P-Silos, o programa é capaz de realizar os seguintes procedimentos:

- determinar as propriedades físicas dos produtos armazenados;

- calcular as pressões no corpo e nas paredes do silo;

- calibrar os modelos de pressões de Janssen e de Jenike com os Algoritimos Genéticos;

- calcular as vazões do silo;

- calcular a função radial por meio do método de Runge-Kutta de $4^{\mathrm{a}}$ ordem;

- calcular a confiabilidade de silos metálicos de chapa ondulada e fundo plano por meio de simulação de Monte Carlo;

- estimar os parâmetros das distribuições de probabilidades a partir dos dados experimentais das propriedades físicas aplicando os testes de Kolmogorov-Smirnov e de Anderson-Darling.

O programa P-Silos foi implementado em $\mathrm{C}++$, na plataforma Borland $\mathrm{C}++$ Builder5, a mesma utilizada por Palma (2005). Para o cálculo da pressão de carregamento foi utilizado o modelo de Janssen (1895), por apresentar simplicidade e consistência, sendo o mesmo adotado neste trabalho. Já para o cálculo das pressões de descarregamento, 
Cheung (2007) utilizou o modelo de Jenike et at. (1973) e os coeficientes de sobrepressão, constatando, posteriormente, que os valores obtidos de sobrepressões dinâmicas com este modelo apresentam-se um pouco elevados quando comparados com os valores obtidos em ensaios em silos reais.

Para a tremonha, foi utilizado o modelo genérico baseado na taxa de compactação constante da tremonha $(\mathrm{C})$ e na relação entre a tensão na parede e a tensão média vertical na tremonha $\left(K_{t}\right)$. Nas Figuras 25, 26 e 27 são apresentadas as interfaces gráficas do programa P-Silos.

Figura 25- Tela principal do progrma P-Silos.

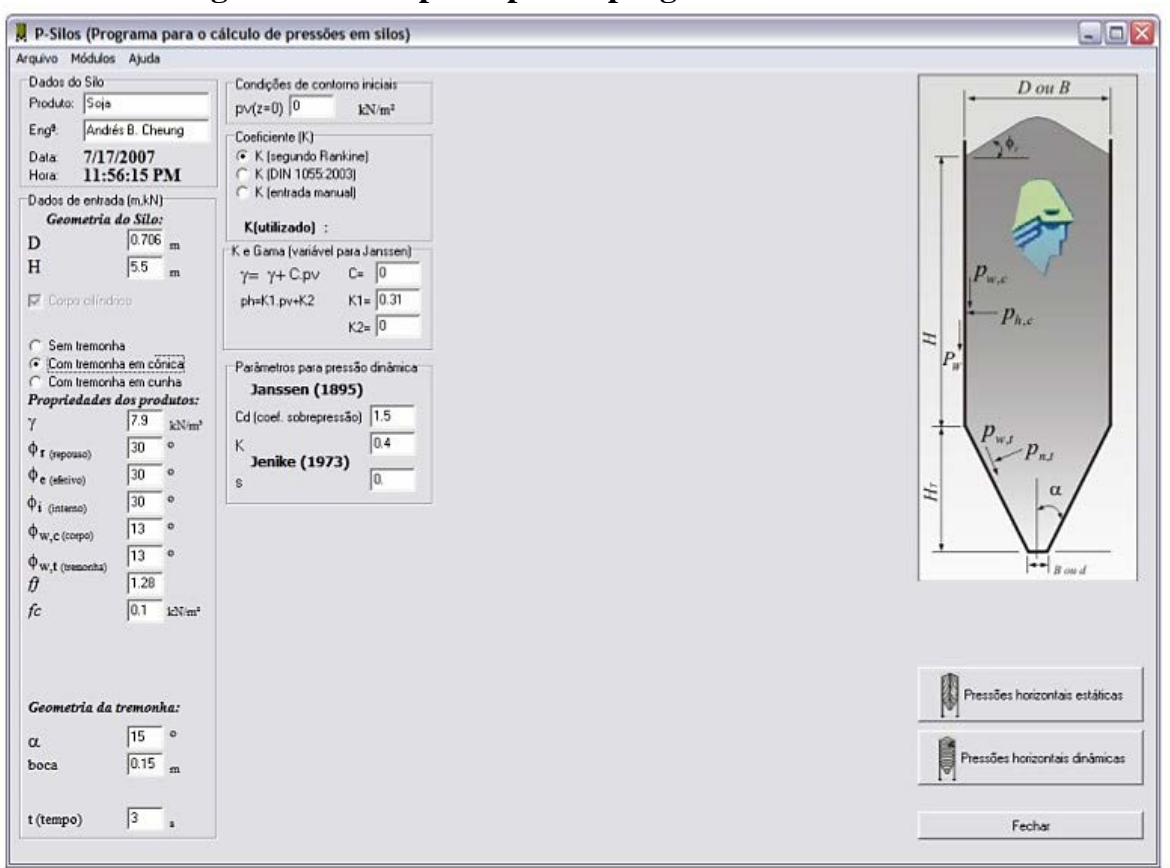

Fonte: CHEUNG (2007). 
Figura 26- Pressões de carregamento calculadas.

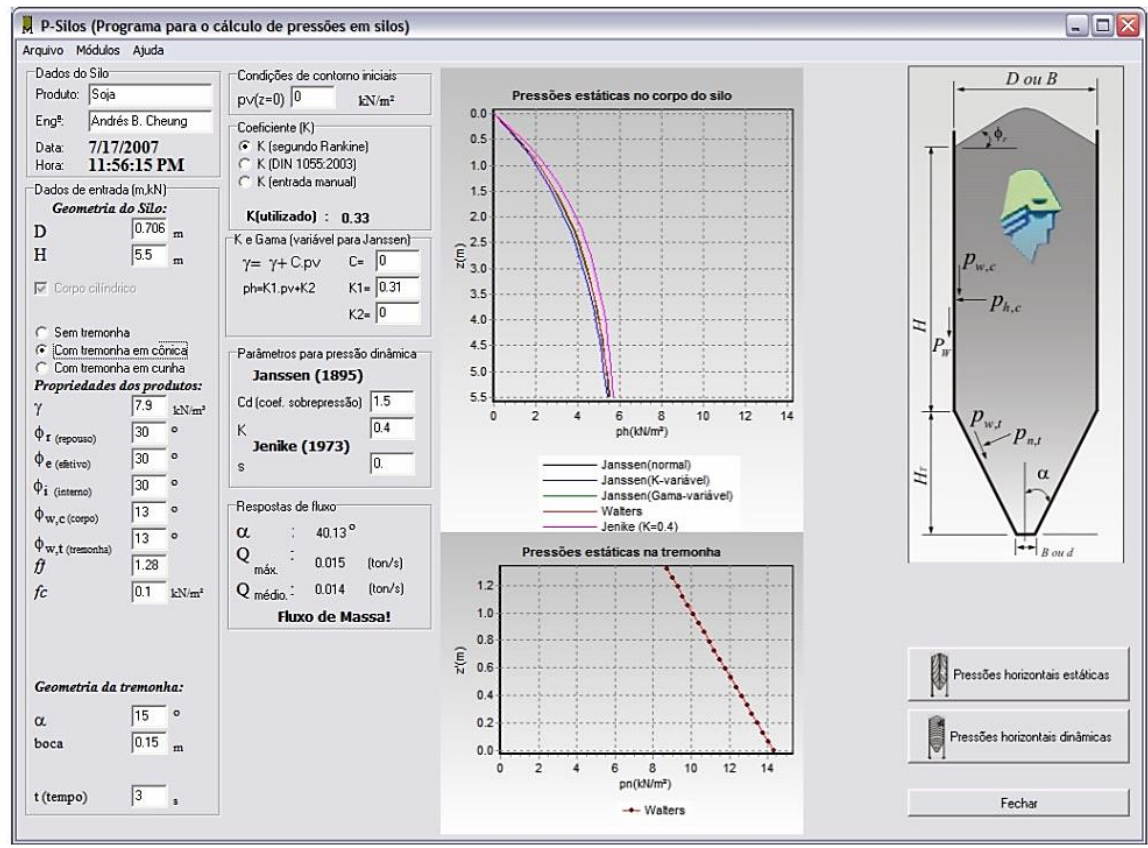

Fonte: CHEUNG (2007).

Figura 27- Pressões de descarregamento calculadas e visualização dos módulos disponíveis.

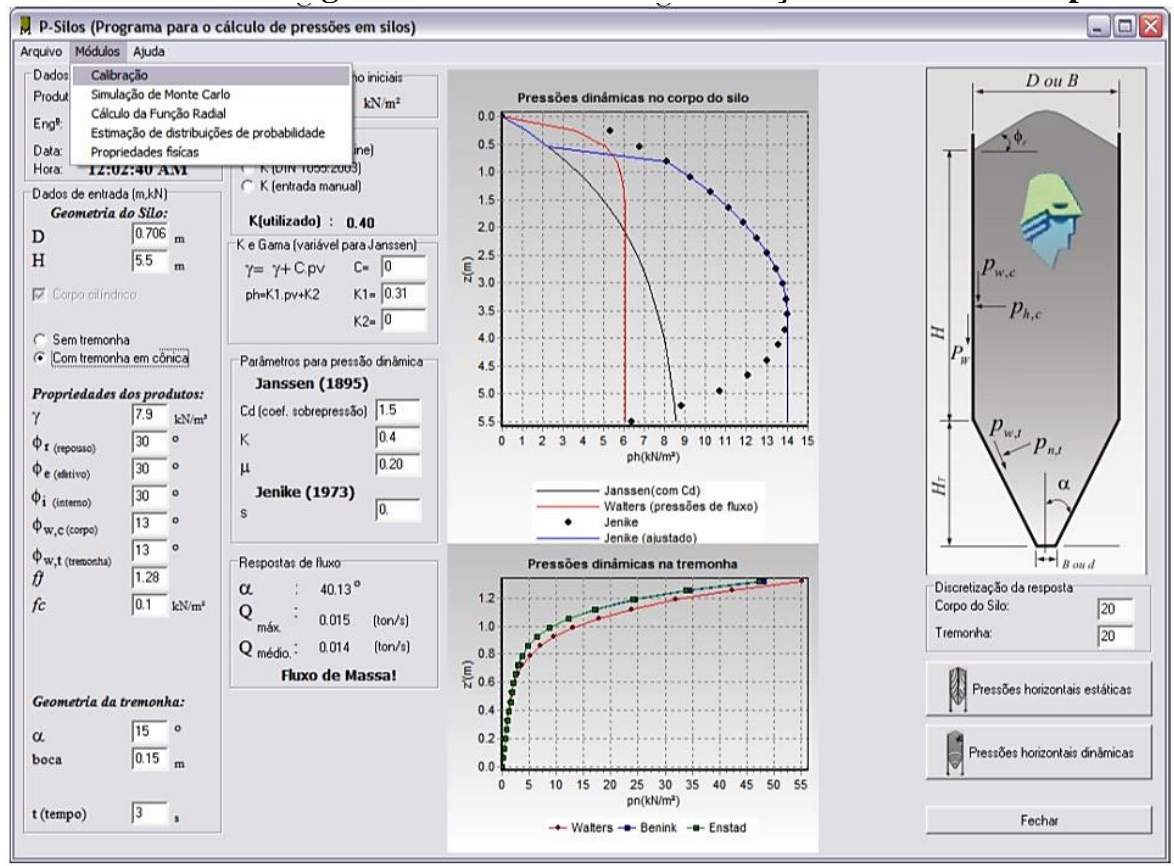

Fonte: CHEUNG (2007).

O módulo do programa P-Silos que calcula as propriedades do produto armazenado, através dos resultados obtidos pelo aparelho de cisalhamento direto, esta mostrado nas Figuras 28 e 29. 
Figura 28-Tela do módulo do P-Silos para determinação das propriedades dos produtos.

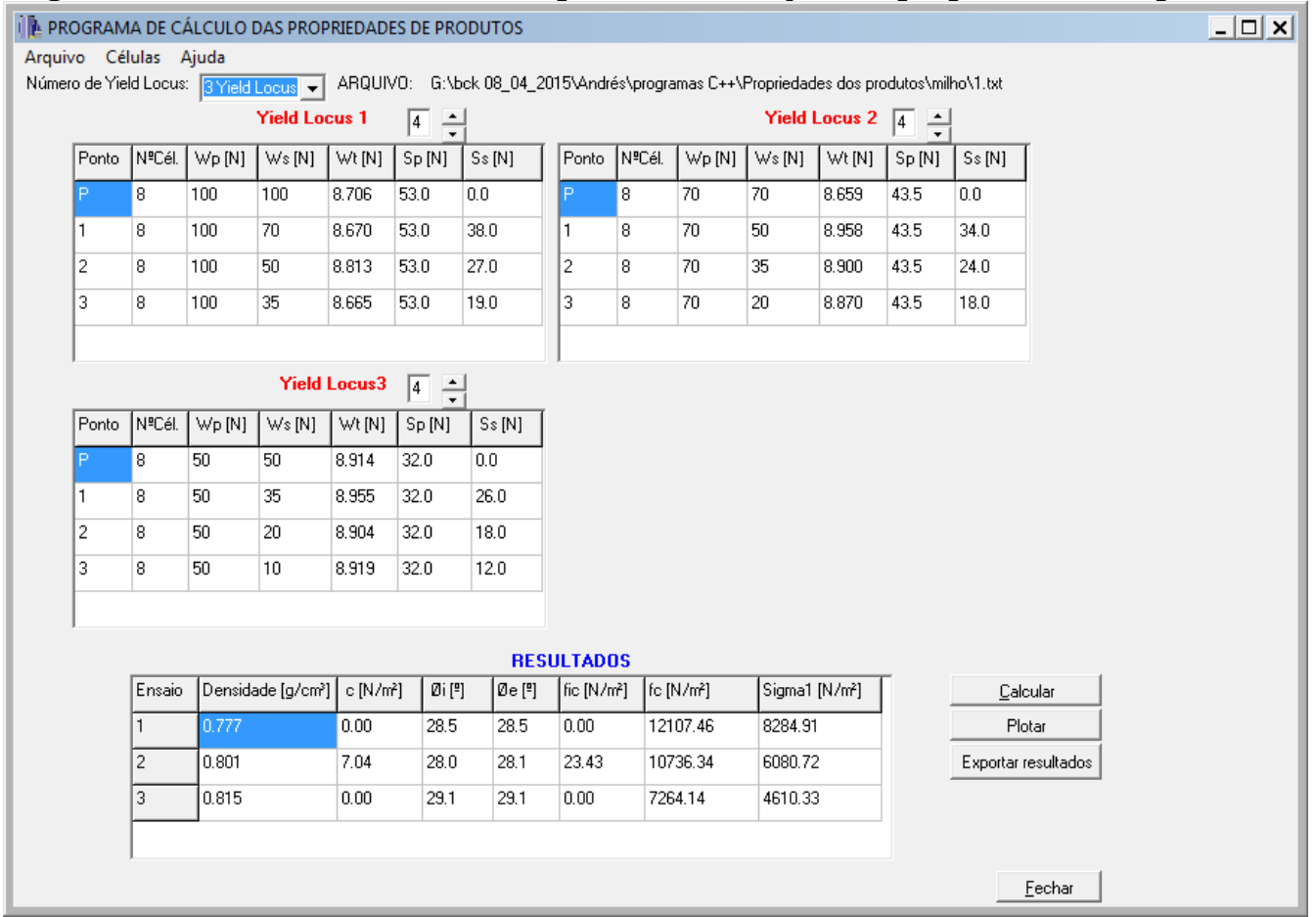

Fonte: CHEUNG (2007).

Figura 29-Tela do módulo do P-Silos para traçado do Yield Locus.

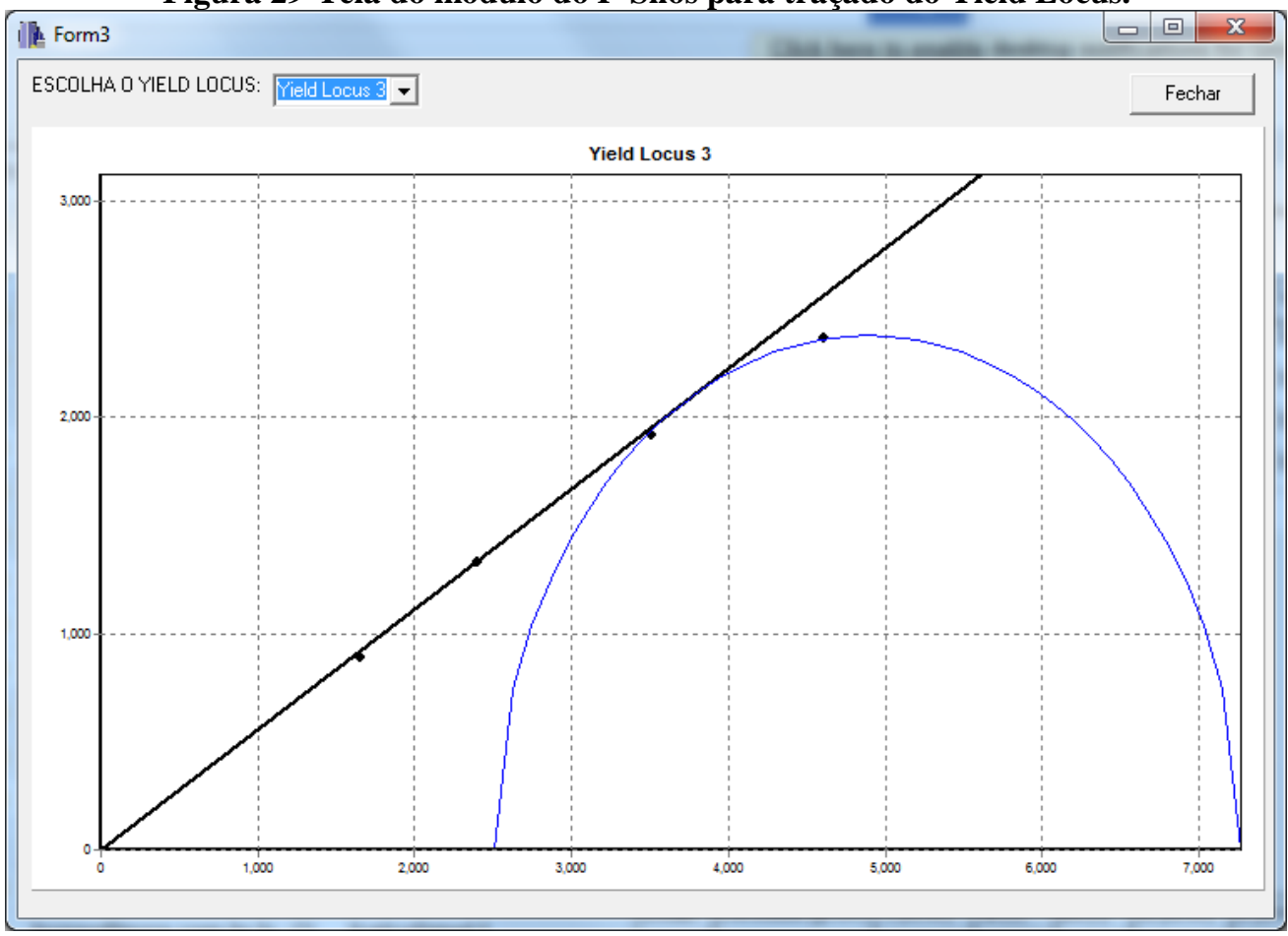

Fonte: CHEUNG (2007). 


\subsection{O software Eurosilo}

O programa desenvolvido neste trabalho, denominado Eurosilo, propõe em silos cilíndricos metálicos: determinação do tipo de fluxo, cálculo das pressões de carregamento, descarregamento, sobrecarga e excêntricas no corpo do silo, das pressões de carregamento e descarregamento atuantes no fundo do silo.

O software foi programado em linguagem Python, por ser uma linguagem de programação de alto nível, orientada a objetos e compatível com sistemas operacionais usuais: Windows, Linux e Mac. Uma de suas principais características é exigir poucas linhas de código se comparado ao mesmo programa em outras linguagens de programação e de fácil aprendizado. Foi utilizada uma biblioteca de desenvolvimento de interfaces gráficas de usuários baseado no Qt, denominada PySide.

A estrutura do programa baseia-se em uma única tela de entrada de dados e saída de resultados, mostrado na Figura 30. Além do traçado dos gráficos em função da altura do silo e da tremonha, os resultados também são fornecidos em arquivo extensão “.txt”.

Figura 30- Tela incial Eurosilo.

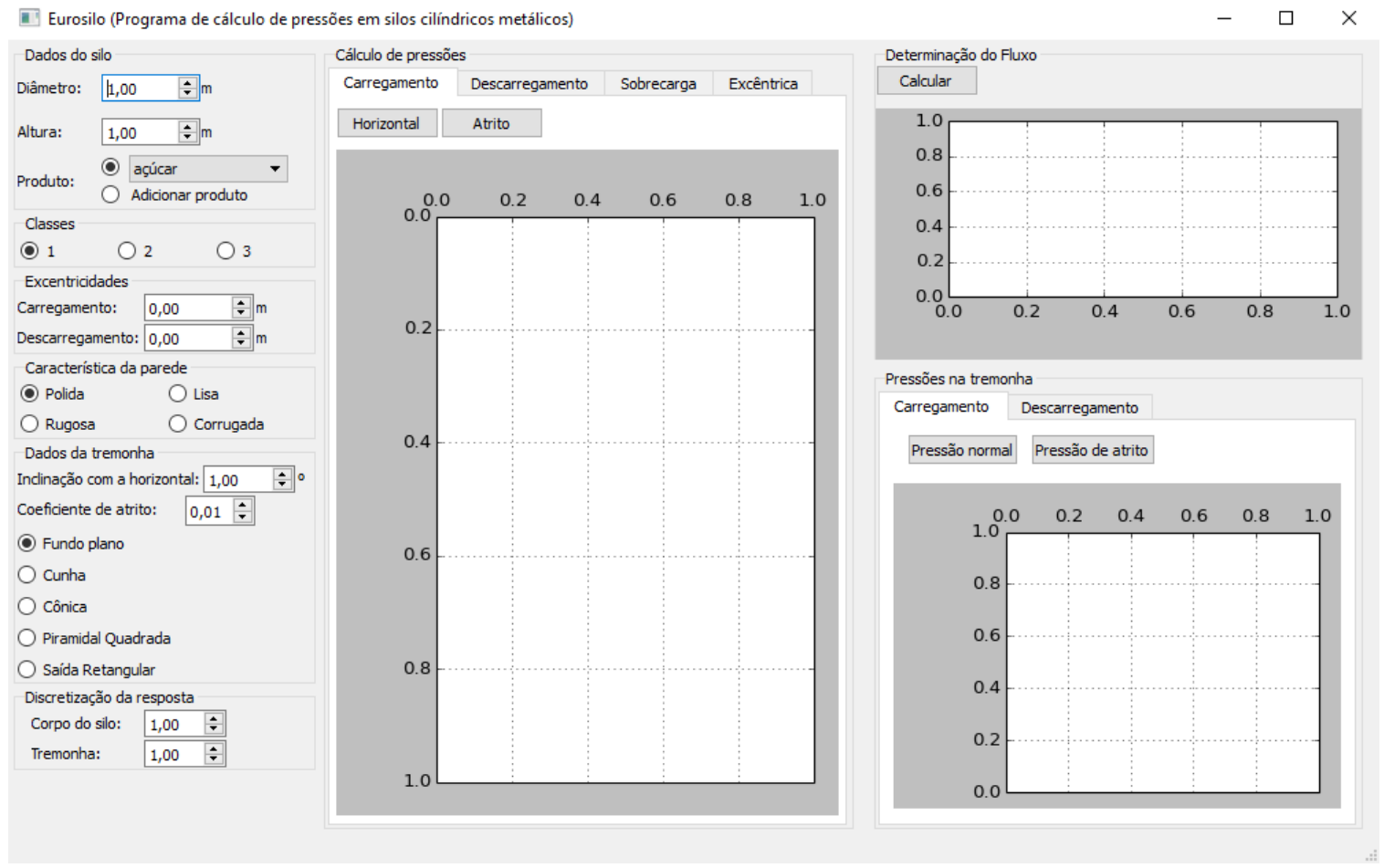

Fonte: A autora. 
A seguir são mostradas as principais telas do programa que calculam as pressões de sobrecarga e excêntricas (Figuras 31 e 32). Observa-se também que o gráfico do cálculo de fluxo, varia de acordo com os dados da tremonha.

Figura 31-Tela do Eurosilo para cálculo da sobrecarga.

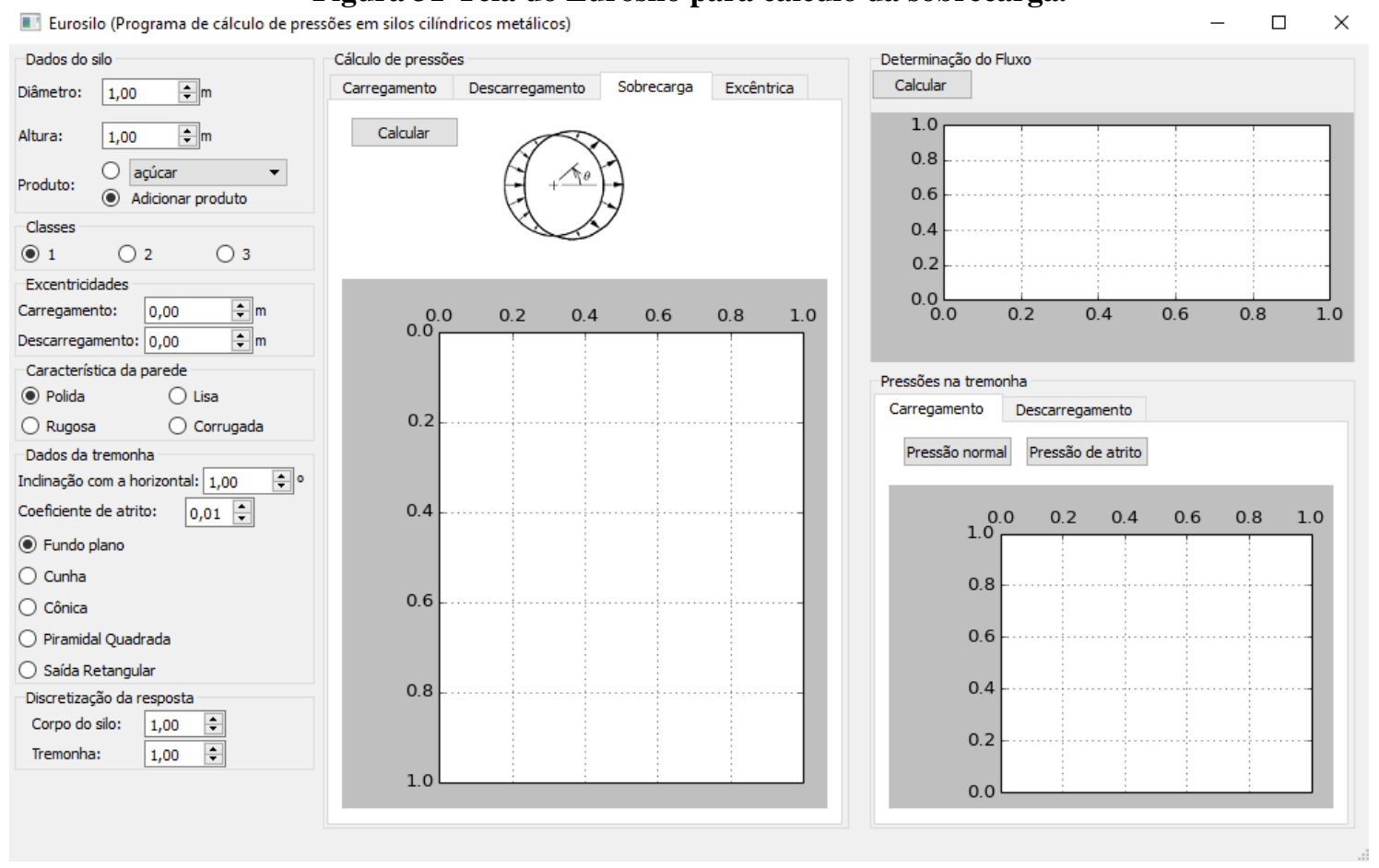

.Fonte: A autora.

Figura 32-Tela do Eurosilo para cálculo das pressões excêntricas.

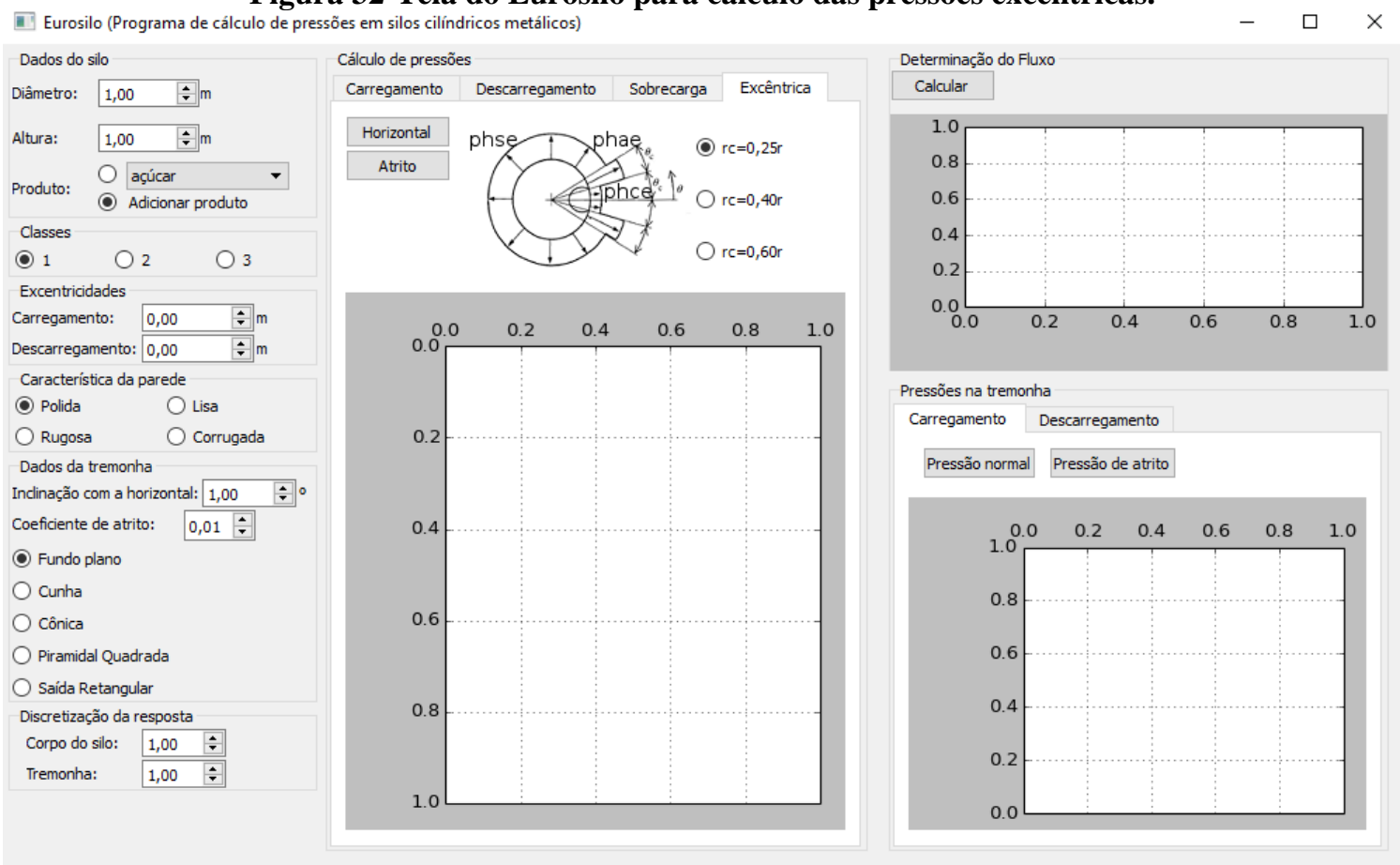

Fonte: A autora. 
O fluxo e as pressões são calculados no Eurosilo seguindo as recomendações do documento normativo BS EN 1991-4, descritas no capítulo anterior.

Foram implementados todos os produtos caracterizados pelo BS EN 1991-4, e também dada a opção do usuário entrar com as propriedades de qualquer produto na tela adicional mostrada na Figura 33.

Figura 33-Tela auxiliar do programa Eurosilo para adicionar produto.

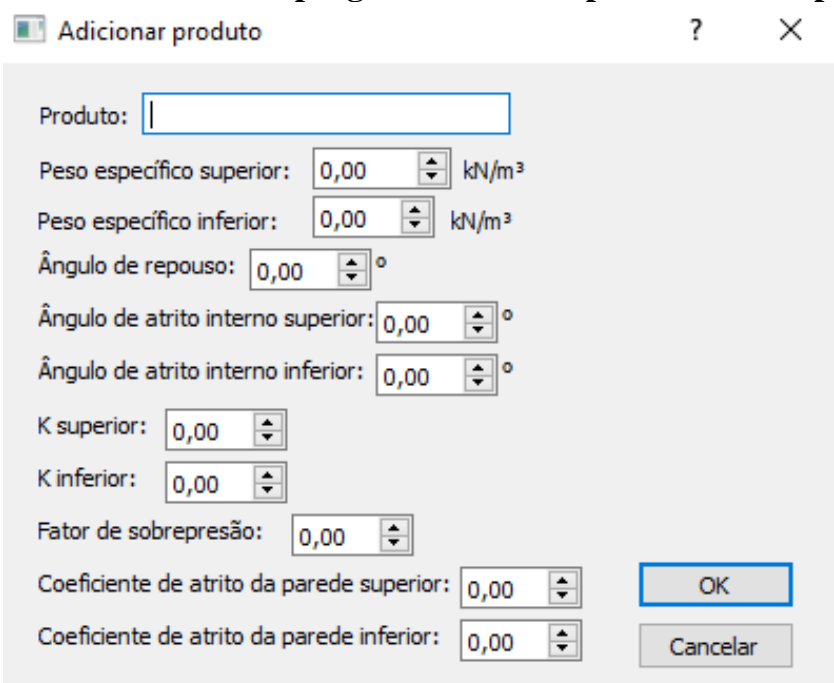

Fonte: A autora.

Para consideração da característica da parede corrugada, uma tela auxiliar se abre para que mais informações sejam inseridas no programa, mostrada na Figura 34. O mesmo acontece para tremonhas com saída retangular, exibida na Figura 35.

Figura 34-Tela auxiliar do Eurosilo para entrada de dados de paredes corrugadas.

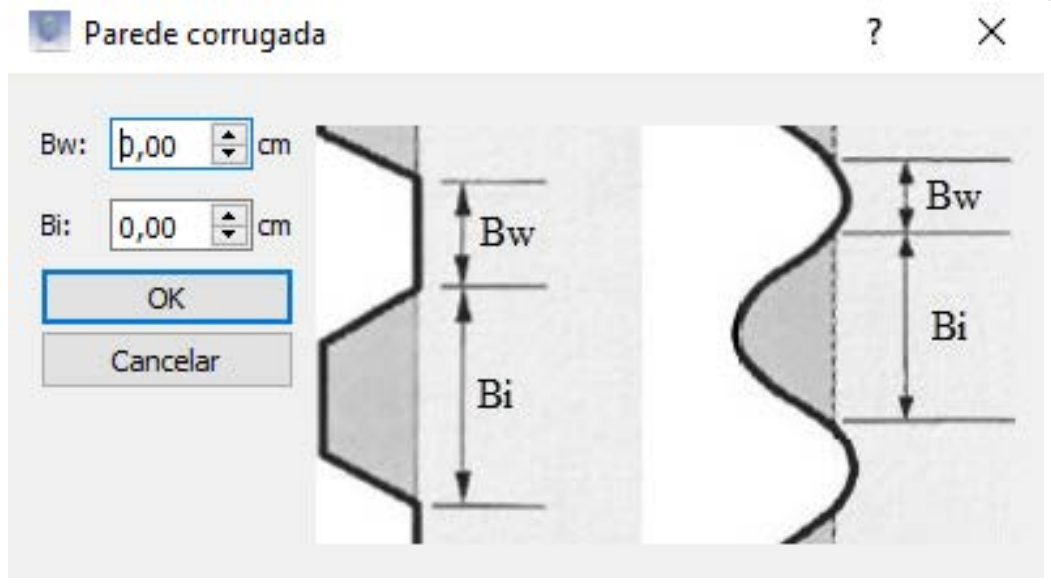

Fonte: A autora. 
Figura 35-Tela auxiliar do Eurosilo entrada de dados de saída retangular.

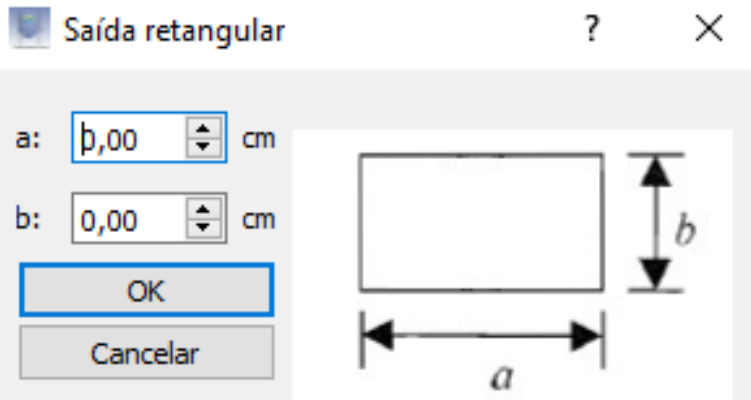

Fonte: A autora. 


\section{EXEMPLOS DE APLICAÇÃO}

Neste capitulo foram propostos modelos estruturais de silos metálicos cilíndricos de chapa ondulada enrijecidos comumente utilizados em fazendas e cooperativas. Foram realizadas as seguintes análises:

SILO 1. Fundo plano e descarregamento concêntrico.

SILO 2. Fundo inclinado e descarregamento concêntrico.

SILO 3. Fundo plano e descarregamento excêntrico.

SILO 4. Fundo inclinado e descarregamento excêntrico.

A determinação das propriedades físicas dos produtos armazenados é o primeiro passo para o projeto estrutural e de fluxo dos silos e deve ser conduzida nas condições mais severas daquelas esperadas que ocorram em um silo. Em todos os exemplos, o produto armazenado é grão de soja. As propriedades físicas utilizadas para este produto, tabelado pelo BS EN 19914, estão apresentadas na Tabela 11:

Tabela 11 - Propriedades físicas do grão de soja.

\begin{tabular}{|c|c|c|c|c|c|c|c|}
\hline \multicolumn{2}{|c|}{ Peso específico $(\gamma)$} & \multirow{2}{*}{$\begin{array}{c}\text { Ângulo de } \\
\text { repouso } \\
\left(\emptyset_{r}\right)\end{array}$} & \multicolumn{2}{|c|}{ Ângulo de atrito interno $\left(\emptyset_{i}\right)$} & \multicolumn{2}{|c|}{$\mathbf{K}$} & \multirow{2}{*}{$C_{o p}$} \\
\hline Inferior & Superior & & Médio & Fator & Médio & Fator & \\
\hline $7,0 \mathrm{kN} / \mathrm{m}^{3}$ & $8,0 \mathrm{kN} / \mathrm{m}^{3}$ & $29^{\circ}$ & 25 & 1,16 & 0,63 & 1,11 & 0,5 \\
\hline
\end{tabular}

Fonte: BS EN 1991-4:2006

\subsection{Silos 1 e 2}

Os silos estudados nestes exemplos possuem 11 metros de diâmetro e altura de 15,20m, com capacidade aproximada de $1140 \mathrm{~m}^{3}$, o que corresponde a \pm 912 toneladas de grãos de soja. 
A parede do silo foi adotada com chapas galvanizadas corrugadas (ondulada de 4") com um enrijecimento interno por meio de montantes conformados a frio de geometria definida na Figura 36.

Figura 36- Geometria da onde de 4".

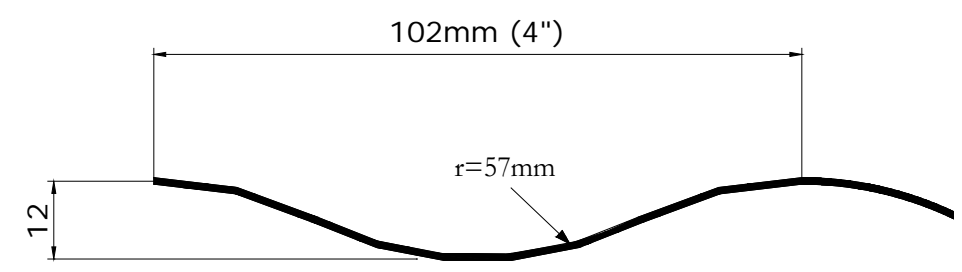

Fonte: A autora.

O silo 1 possui fundo plano e o silo 2 possui tremonha cônica com inclinação de 45 graus, mostrados nas Figuras 37 e 38. Em ambos os casos, o descarregamento é concêntrico.

Figura 37 -Exemplo de aplicação Silo 1.

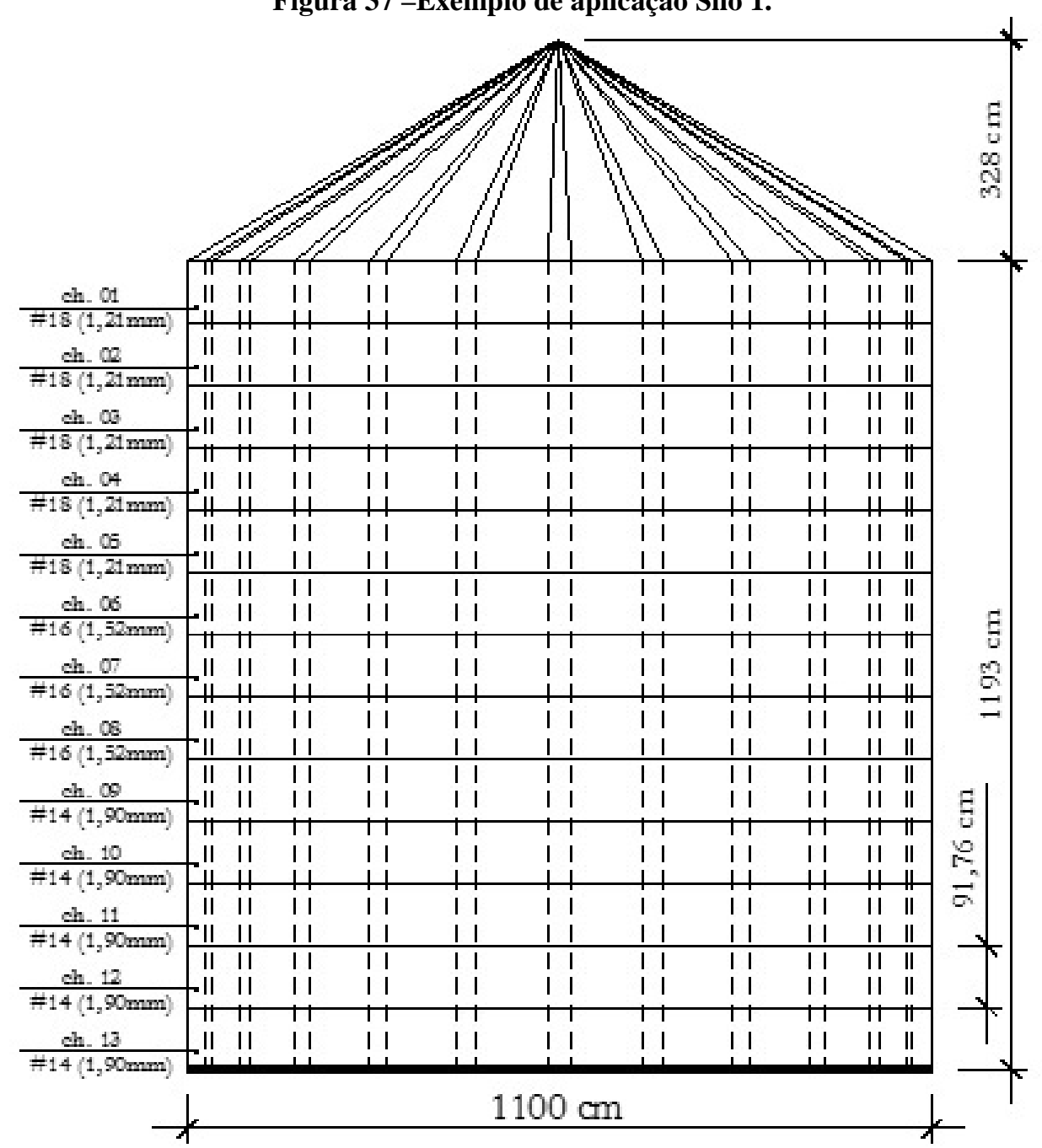

Fonte: a autora. 
Figura 38 Exemplo de aplicação Silo 2-

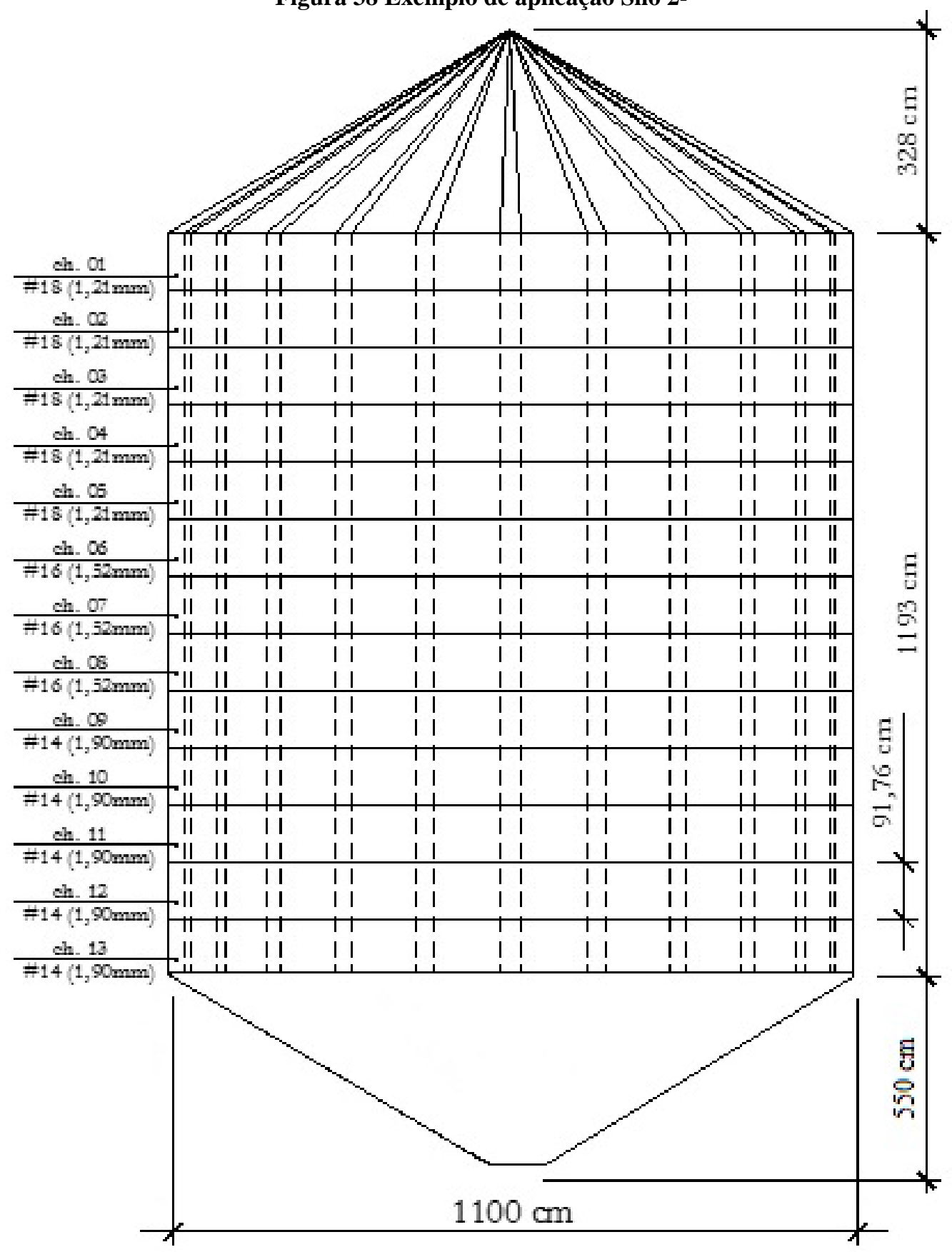

Fonte: A autora.

\subsection{Silos 3 e 4}

Neste exemplo foram utilizadas as mesmas dimensões geométricas dos silos 1 e 2 no exemplo de aplicação anterior e mesmo produto armazenado. A diferença é que, nos silos 3 e 4, o 
descarregamento foi excêntrico, com boca de saída com excentricidade de descarregamento de 5,00 metros, mostrados na Figura 39.

Figura 39- Excentricidades dos exemplos de aplicação Silos 3 e 4.

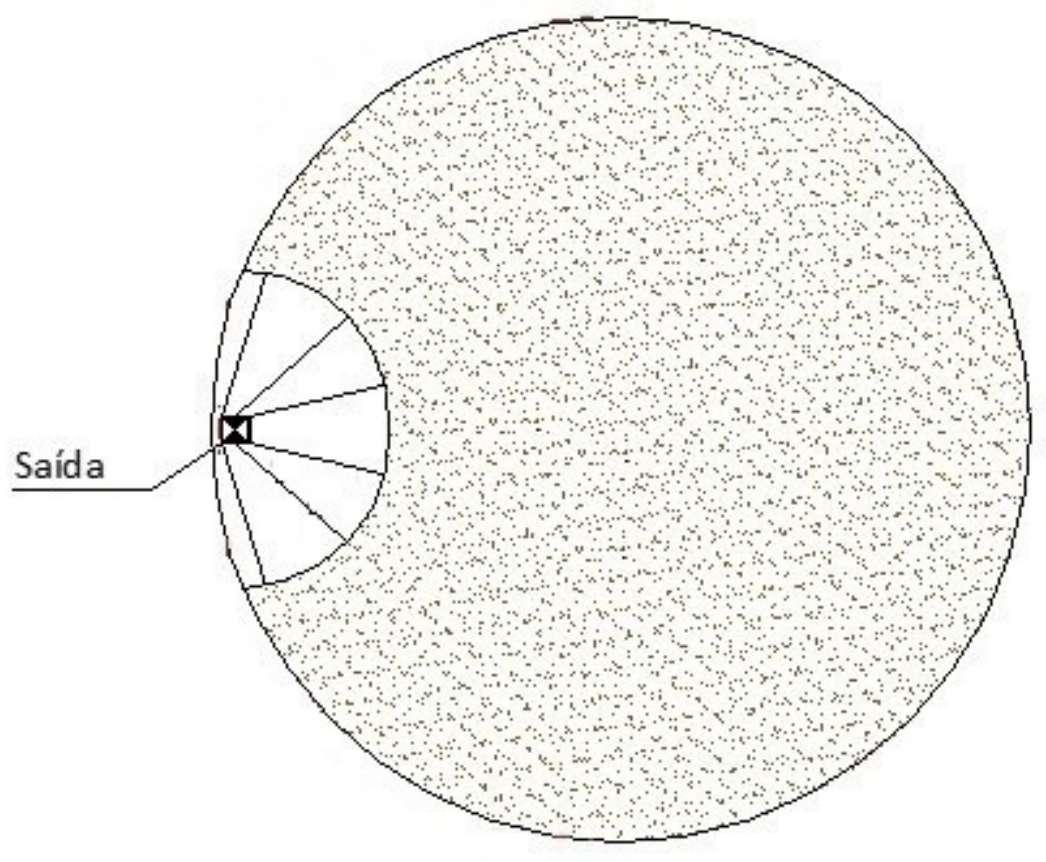

Fonte: A autora

Essa geometria favoreceu a formação do canal de fluxo excêntrico e não assimétrico, podendo avaliar qual a importância de considerar as excentricidades em projetos de silos. 


\section{RESULTADOS}

\subsection{Determinação do índice de esbeltez}

Para a classificação do silo pelo BS EN 1991-4 é necessário determinar o valor do índice de esbeltez pela razão entre a altura total e o diâmetro. A altura total foi considerada como sendo a soma da altura da parede e a altura $h_{o}$, mostrado na Figura 40.

Figura 40 - Alturas para o cálculo do índice de esbeltez.

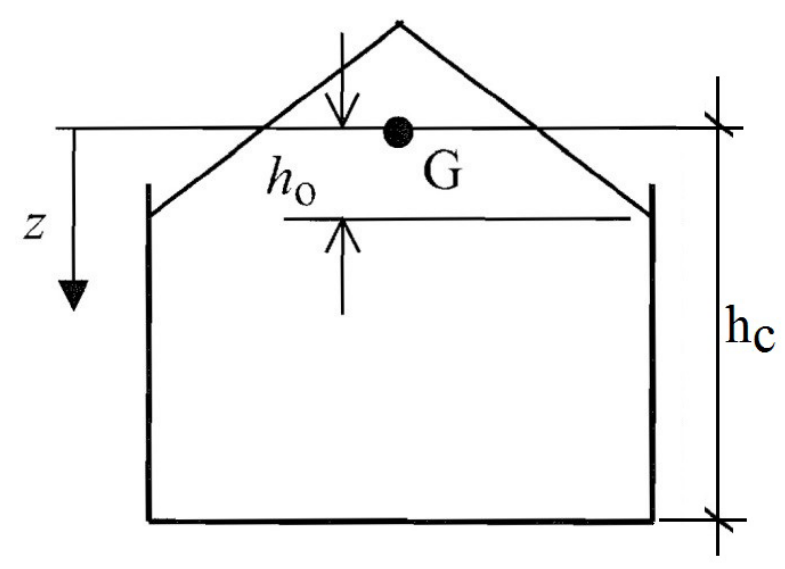

Fonte: A autora

Para este silo circular, o valor da altura $h_{o}$ foi calculada pela expressão:

$$
h_{o}=\frac{r}{3} \tan \emptyset_{r}
$$

Portanto, o índice de esbeltez é 1,18 e trata-se de um silo medianamente esbelto.

$$
\frac{h_{c}}{d_{c}}=\frac{11,93+1,01}{11,00}=1,18
$$




\subsection{Determinação do tipo de fluxo}

Para o fundo plano, não é necessário fazer a determinação do tipo de fluxo pois sempre apresentam fluxo funil. Os valores utilizados na determinação do tipo de fluxo na tremonha cônica, foram 0,20 para o coeficiente de atrito da parede da tremonha $\left(\mu_{w}\right)$, e inclinação de 45 graus. Na Figura 41, está o resultado pelo software Eurosilo. O ponto vermelho destacado mostra que o fluxo é funil.

Figura 41- Determinação de fluxo pelo Eurosilo

Determinação do Fluxo

\section{Calcular}

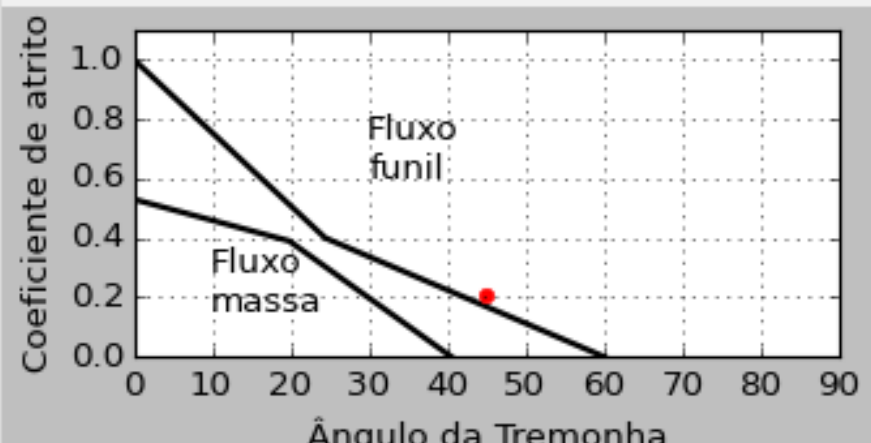

Ângulo da Tremonha

Fonte: A autora.

\subsection{Cálculo do coeficiente de atrito para parede corrugada}

Para paredes do tipo ondulada (d4), o cálculo do coeficiente de atrito da parede específico foi determinado por:

$$
\mu_{e f f}=\left(1-a_{w}\right) \tan \left(\varnothing_{i}\right)+a_{w} \mu_{w}
$$

O valor do coeficiente de atrito da parede $\left(\mu_{\mathrm{w}}\right)$ refere-se ao da superfície de parede lisa (D1) e o fator $a_{w}$ calculado conforme dimensões do perfil da chapa de aço, mostrados na Figura 42. 


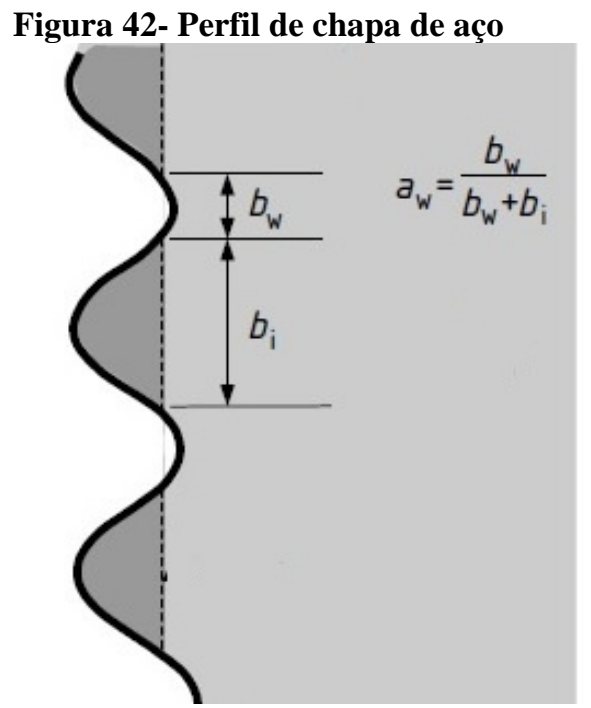

Fonte: BS EN 1991-4:2006

Os valores de $b_{w}$ e $b_{i}$ representam os comprimentos relativos dentro de uma onda completa da parede, neste caso foram utilizados os valores de $20 \%$ e $80 \%$ da altura total da onda recomendados pelo PrEN 1991-4:2002 mostrados na Figura 43. Os valores utilizados no cálculo do coeficiente de atrito estão mostrados na Tabela 12.

Figura 43 - Tela adicional para incluir valores dos comprimentos relativos da chapa corrugada.

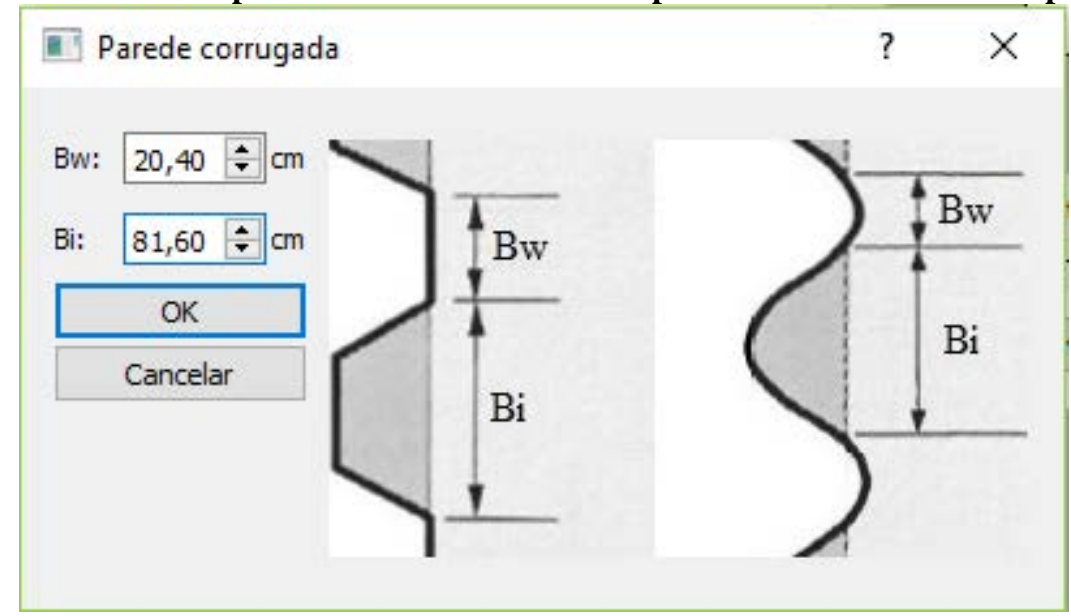

Tabela 12-Valores utilizados no cálculo do coeficiente de atrito efetivo.

\begin{tabular}{|c|c|}
\hline $\boldsymbol{b}_{\boldsymbol{w}}$ & $20,40 \mathrm{~mm}$ \\
\hline $\mathbf{b}_{\mathbf{i}}$ & $81,60 \mathrm{~mm}$ \\
\hline $\mathbf{a}_{\mathbf{w}}$ & 0,20 \\
\hline $\boldsymbol{\mu}_{\boldsymbol{w}}$ & 0,24 \\
\hline $\boldsymbol{\mu}_{\boldsymbol{e f f}}$ & 0,49 \\
\hline
\end{tabular}

Fonte: A autora 
6.4. Estudo das pressões nos silos 1 e 2

Nas duas análises, as pressões nas paredes do corpo do silo nas fases de carregamento e descarregamento são as mesmas. Os resultados obtidos pelo software Eurosilo estão mostrados a seguir.

- Pressões no corpo dos silos na fase de carregamento:

Os valores obtidos no arquivo de texto estão mostrados na Tabela 13. Pode-se perceber que a pressão é zero na altura $h_{o}=1,02$, conforme era esperado por se tratar de silo medianamente esbelto. Na Figura 44, está o resultado mostrado pelo programa graficamente.

Tabela 13-Valores das pressões de carregamento

\begin{tabular}{|c|c|c|}
\hline$Z_{(\boldsymbol{m})}$ & $\mathbf{p}_{\mathbf{h f}}\left[\mathbf{k N} / \mathbf{m}^{2}\right]$ & $\mathbf{p}_{\mathbf{w f}}\left[\mathbf{k N} / \mathbf{m}^{\mathbf{2}}\right]$ \\
\hline $\mathbf{0 , 0 0}$ & - & - \\
\hline $\mathbf{1 , 0 0}$ & - & - \\
\hline $\mathbf{2 , 0 0}$ & 6,23 & 3,55 \\
\hline $\mathbf{3 , 0 0}$ & 11,36 & 6,47 \\
\hline $\mathbf{4 , 0 0}$ & 15,58 & 8,88 \\
\hline $\mathbf{5 , 0 0}$ & 19,1 & 10,89 \\
\hline $\mathbf{6 , 0 0}$ & 22,07 & 12,58 \\
\hline $\mathbf{7 , 0 0}$ & 24,62 & 14,03 \\
\hline $\mathbf{8 , 0 0}$ & 26,81 & 15,29 \\
\hline $\mathbf{9 , 0 0}$ & 28,72 & 16,38 \\
\hline $\mathbf{1 0 , 0 0}$ & 30,4 & 17,33 \\
\hline $\mathbf{1 1 , 0 0}$ & 31,88 & 18,17 \\
\hline $\mathbf{1 2 , 0 0}$ & 33,19 & 18,92 \\
\hline
\end{tabular}

Fonte: A autora. 
Figura 44 - Pressões de carregamento nos silos 1 e 2.

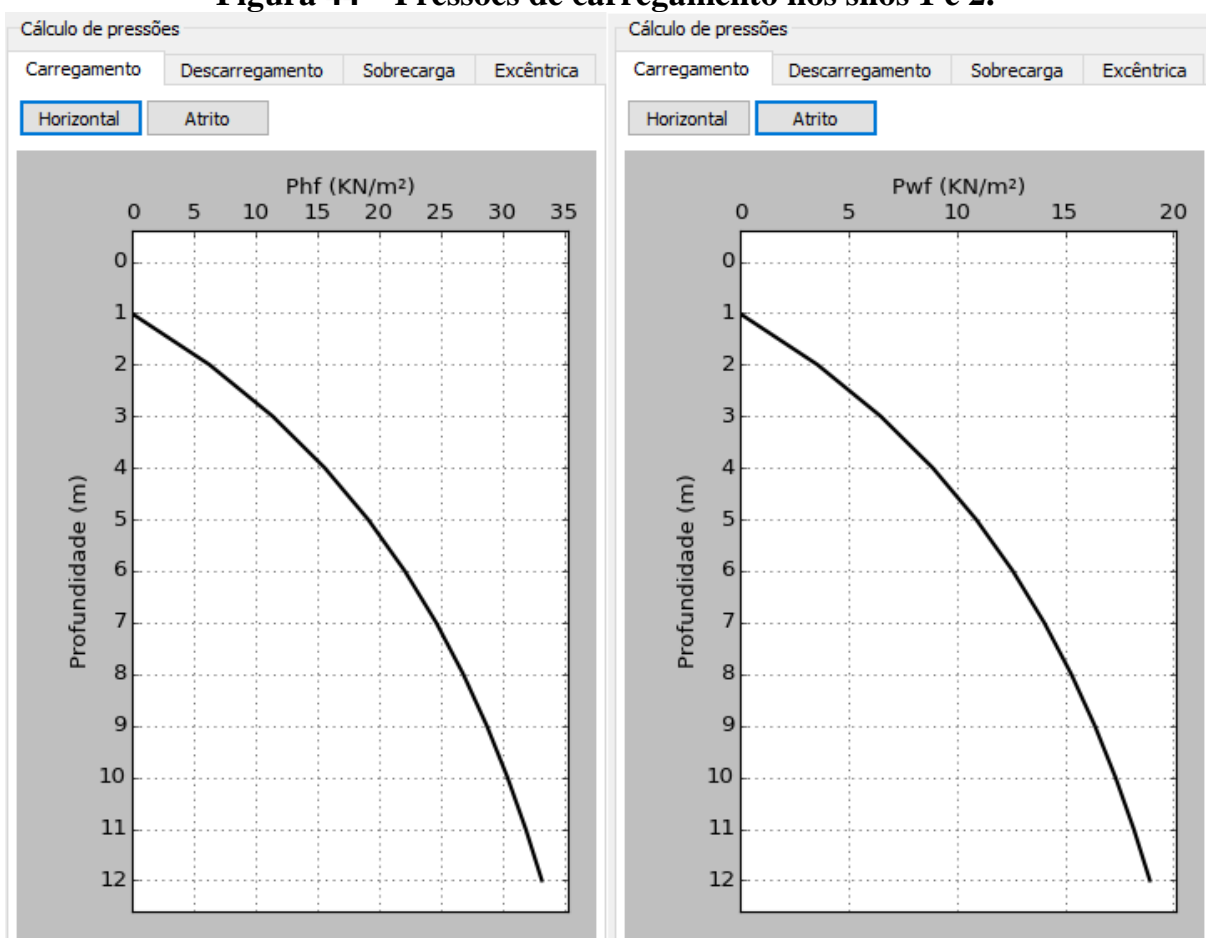

Fonte: A autora.

- Pressões no corpo do silo na fase de descarregamento:

Os resultados das pressões de descarregamento, estão na Tabela 14 e na Figura 45 a seguir:

Tabela 14- Valores das pressões de descarregamento

\begin{tabular}{|c|c|c|}
\hline $\mathbf{Z}$ (m) & phe $_{\left.\mathbf{k} \mathbf{N} / \mathbf{m}^{\mathbf{2}}\right]}$ & $\mathbf{p}_{\text {we }}\left[\mathbf{k N} / \mathbf{m}^{\mathbf{2}}\right]$ \\
\hline $\mathbf{0 , 0 0}$ & - & - \\
\hline $\mathbf{1 , 0 0}$ & - & - \\
\hline $\mathbf{2 , 0 0}$ & 6,39 & 3,61 \\
\hline $\mathbf{3 , 0 0}$ & 11,66 & 6,59 \\
\hline $\mathbf{4 , 0 0}$ & 15,99 & 9,04 \\
\hline $\mathbf{5 , 0 0}$ & 19,60 & 11,08 \\
\hline $\mathbf{6 , 0 0}$ & 22,66 & 12,81 \\
\hline $\mathbf{7 , 0 0}$ & 25,27 & 14,28 \\
\hline $\mathbf{8 , 0 0}$ & 27,53 & 15,56 \\
\hline $\mathbf{9 , 0 0}$ & 29,49 & 16,66 \\
\hline $\mathbf{1 0 , 0 0}$ & 31,21 & 17,64 \\
\hline $\mathbf{1 1 , 0 0}$ & 32,72 & 18,49 \\
\hline $\mathbf{1 2 , 0 0}$ & 34,07 & 19,26 \\
\hline
\end{tabular}

Fonte: A autora. 
Figura 45- Pressões de descarregamento nos silos 1 e 2.

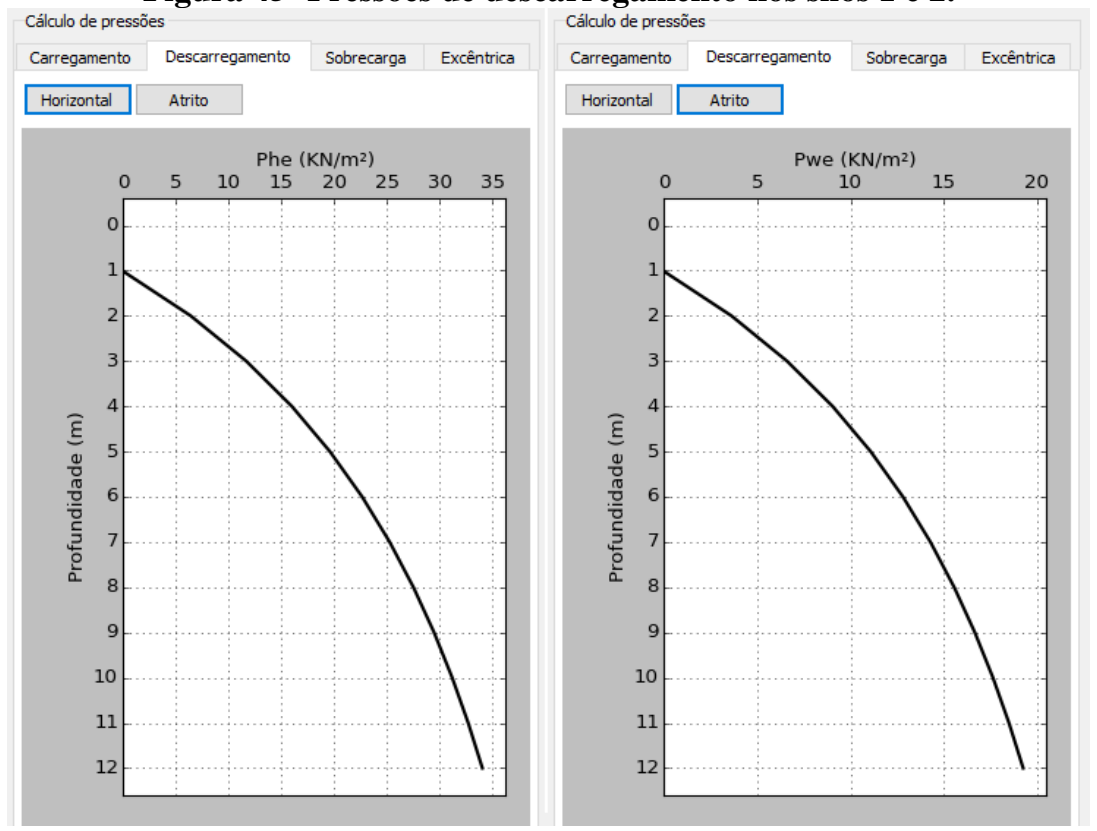

Fonte: A autora.

Os resultados não demonstraram variação significativa neste caso para pressões horizontais e de atrito, pois os coeficientes utilizados na ponderação das pressões foram aproximadamente: $\mathrm{C}_{\mathrm{s}},=0,18, \mathrm{C}_{\mathrm{h}}=1,03$ e $\mathrm{C}_{\mathrm{w}}=1,02$.

- Sobrecarga de carregamento e descarregamento:

A sobrecarga varia além da profundidade (z) do silo, mostrado na Tabela 15, com a coordenada circunferencial $(\theta)$. Percebe-se que os máximos sempre ocorrem para $\theta=0^{\circ} \mathrm{e}$ $\theta=180^{\circ}$, enquanto que é nula em $\theta=90^{\circ}$ e $\theta=270^{\circ}$.

Tabela 15- Valores positivos das sobrecargas variando com a profundidade.

\begin{tabular}{|c|c|c|}
\hline $\mathbf{Z}_{\mathbf{~} \mathbf{m})}$ & $\mathbf{p p f}_{\mathbf{p f}}\left[\mathbf{k N} / \mathbf{m}^{\mathbf{2}}\right]$ & $\mathbf{p p e}_{\mathbf{p}}\left[\mathbf{k N} / \mathbf{m}^{2}\right]$ \\
\hline $\mathbf{0 , 0 0}$ & - & - \\
\hline $\mathbf{1 , 0 0}$ & - & - \\
\hline $\mathbf{2 , 0 0}$ & 0,15 & 0,15 \\
\hline $\mathbf{3 , 0 0}$ & 0,28 & 0,28 \\
\hline $\mathbf{4 , 0 0}$ & 0,38 & 0,38 \\
\hline $\mathbf{5 , 0 0}$ & 0,47 & 0,47 \\
\hline $\mathbf{6 , 0 0}$ & 0,54 & 0,55 \\
\hline $\mathbf{7 , 0 0}$ & 0,60 & 0,61 \\
\hline $\mathbf{8 , 0 0}$ & 0,66 & 0,66 \\
\hline
\end{tabular}




\begin{tabular}{|c|c|c|}
\hline $\mathbf{9 , 0 0}$ & 0,70 & 0,71 \\
\hline $\mathbf{1 0 , 0 0}$ & 0,74 & 0,75 \\
\hline $\mathbf{1 1 , 0 0}$ & 0,78 & 0,79 \\
\hline $\mathbf{1 2 , 0 0}$ & 0,81 & 0,82 \\
\hline \multicolumn{3}{|c|}{ Fonte: A autora. }
\end{tabular}

Para exemplificar a variação de valores de acordo $\operatorname{com} \theta$, alguns valores retirados do arquivo texto gerado pelo programa, para $z=2,00$ metros, estão mostrados na Tabela 16. Identifica-se também que os valores são os mesmos com sinais opostos para ângulos equivalentes do círculo trigonométrico.

Tabela 16- Valores de sobrecarga com variação circunferencial nos silos 1 e 2.

\begin{tabular}{|c|c|c|}
\hline $\mathbf{Z} \mathbf{( \mathbf { m } )}$ & $\boldsymbol{\theta} \mathbf{(}^{\circ} \mathbf{)}$ & $\mathbf{p}_{\mathbf{p f}}\left[\mathbf{k N} / \mathbf{m}^{2}\right]$ \\
\hline 2,00 & 0 & 0,15 \\
\hline 2,00 & 45 & 0,11 \\
\hline 2,00 & 90 & 0,00 \\
\hline 2,00 & 135 & $-0,11$ \\
\hline 2,00 & 180 & $-0,15$ \\
\hline \multicolumn{3}{|c|}{ Fonte: A autora. }
\end{tabular}

Na Figura 46, está representado graficamente as pressões.

Figura 46- Sobrecarga nos silos 1 e 2.

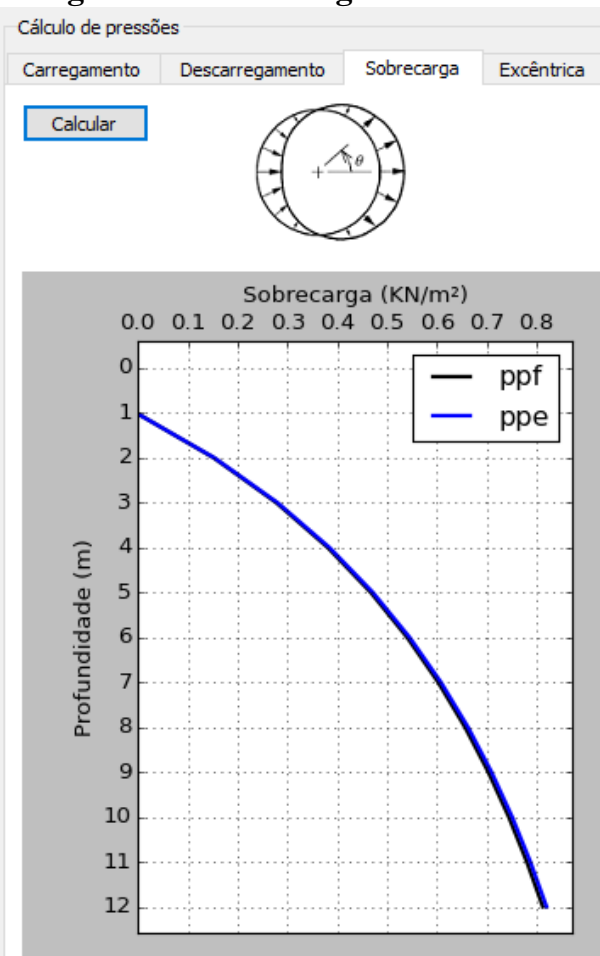

Fonte: A autora. 
- Pressões excêntricas:

Nesse caso o descarregamento é concêntrico, portanto as pressões excêntricas foram desconsideradas (Figura 47).

Figura 47-Pressões excêntricas nos Silos 1 e 2.

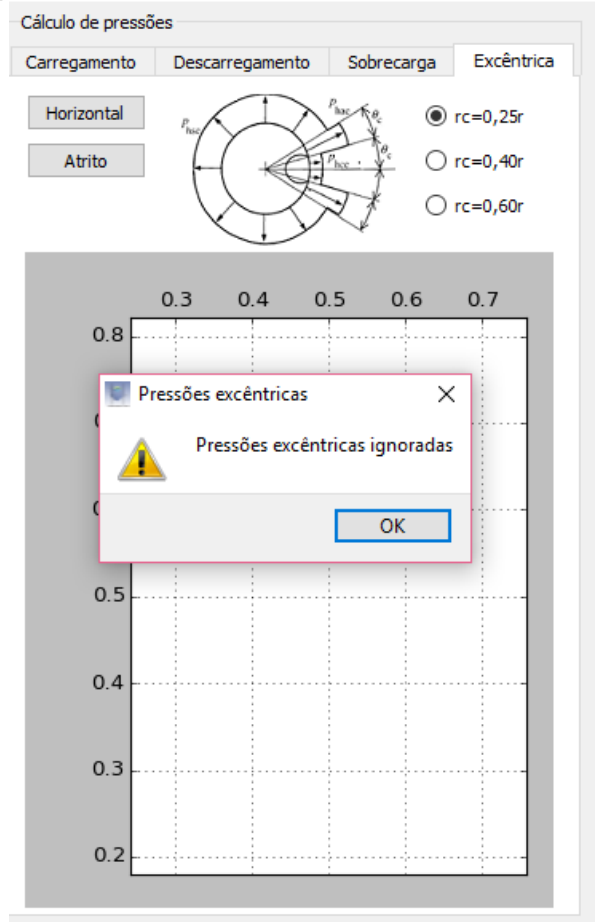

Fonte: A autora.

- Resultado das pressões no corpo do silo:

Fazendo aleatoriamente um estudo na seção transversal de altura $z=2,00$ metros, temos a seguinte pressão horizontal resultante mostrada na Tabela 17:

Tabela 17-Estudo das pressões na seção transversal de altura $\mathrm{z}=2,00$ metros.

\begin{tabular}{|c|c|c|c|}
\hline $\mathbf{Z}(\mathbf{m})$ & $\boldsymbol{\theta}\left(^{\circ}\right)$ & $\mathbf{p h f}_{\mathbf{h f}}\left[\mathbf{k N} / \mathbf{m}^{2}\right]$ & $\mathbf{p h e}_{\mathbf{h e}}\left[\mathbf{k N} / \mathbf{m}^{\mathbf{2}} \mathbf{]}\right.$ \\
\hline 2,00 & 0 & 6,38 & 6,54 \\
\hline 2,00 & 90 & 6,23 & 6,39 \\
\hline 2,00 & 180 & 6,08 & 6,24 \\
\hline
\end{tabular}

Fonte: A autora.

- Pressões no fundo do silo: 
No silo 1 com fundo plano, o gráfico não é traçado, pois se considera apenas a pressão vertical no fundo, e uma mensagem é dada pelo programa em uma tela auxiliar, mostrada na Figura 48.

Figura 48-Pressão vertical no fundo plano.

Fundo Plano

$\times$

O valor da pressão vertical no centro do fundo plano é $68.95 \mathrm{KN} / \mathrm{m}^{2}$

\section{OK}

Fonte: A autora.

No silo 2 com tremonha cônica de 45 graus, íngrime, as pressões estão mostradas nas Figuras 49 e 50, para os casos de carregamento e descarregamento.

Figura 49- Pressões de carregamento na tremonha íngreme silo 1 e 2.
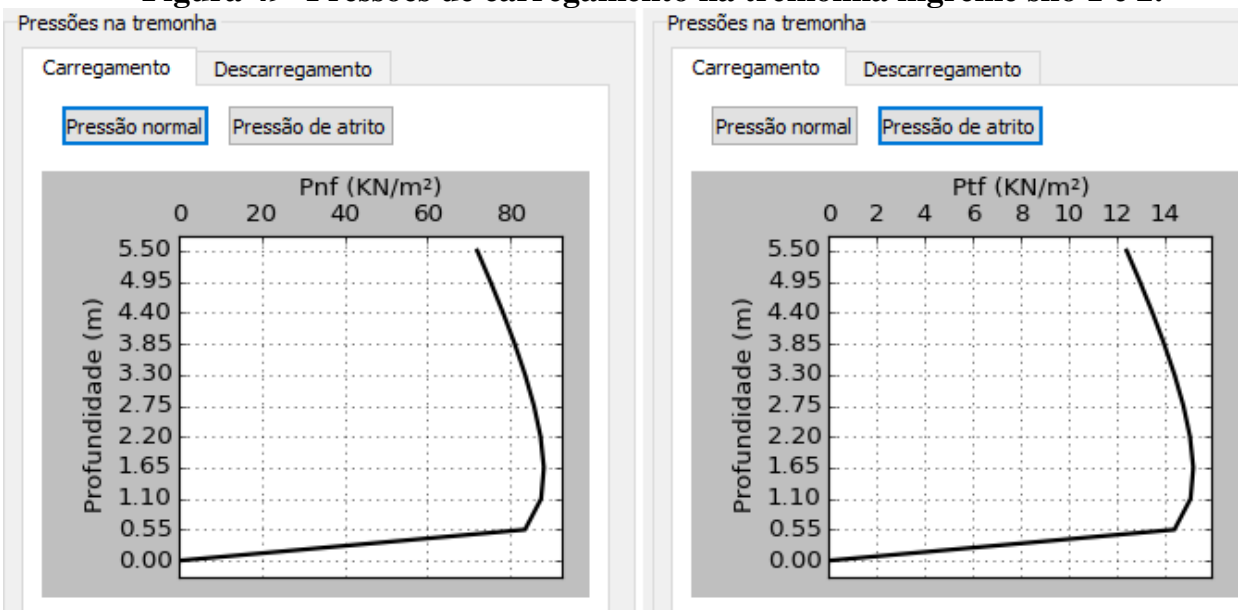

Fonte: A autora.

Figura 50- Pressões de descarregamento na tremonha íngreme silo 1 e 2.
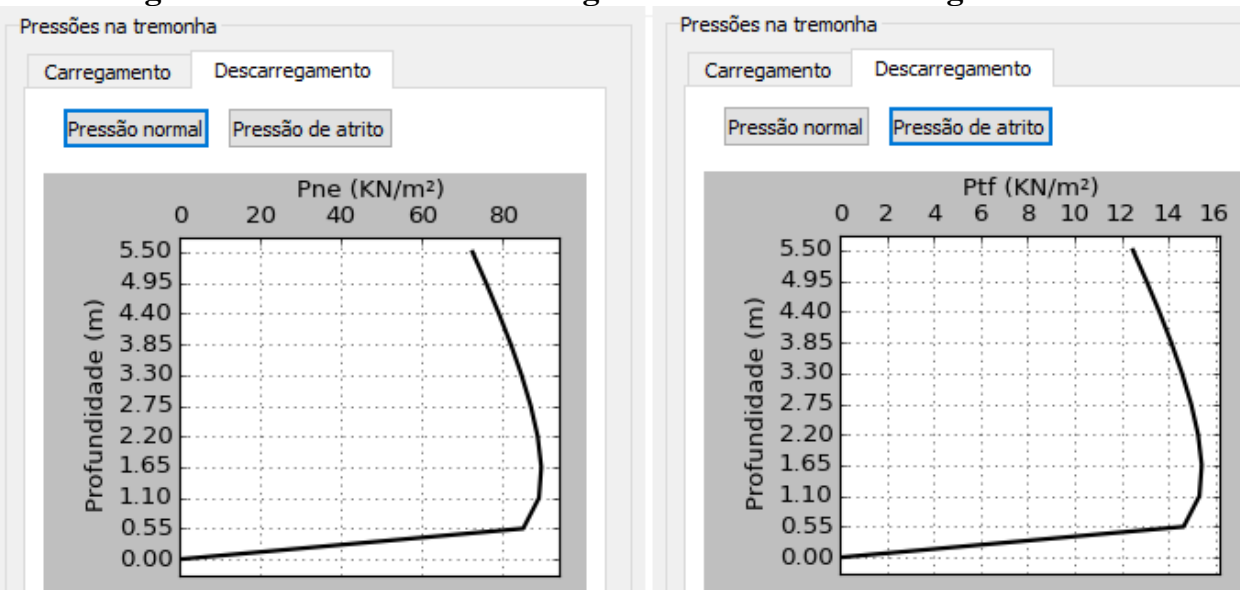

Fonte: A autora. 
6.5. Estudo das pressões nos silos 3 e 4

- Pressões no corpo do silo na fase de carregamento:

As mesmas encontradas no caso de silos 1 e 2 .

- Pressões no corpo do silo na fase de descarregamento:

As mesmas encontradas no caso de silos 1 e 2 .

- Sobrecarga de carregamento e descarregamento:

Como a excentricidade de descarregamento é 5 metros, a sobrecarga é maior do que no caso de silos com descarregamento concêntrico, mostradas na Tabela 18:

Tabela 18- Sobrecarga de carregamento e descarregamento nos Silos 3 e 4.

\begin{tabular}{|c|c|c|}
\hline $\mathbf{Z}_{(\mathbf{m})}$ & $\mathbf{p}_{\mathbf{p f}}\left[\mathbf{k N} / \mathbf{m}^{2}\right]$ & $\mathbf{p p e}_{\mathbf{p e}}\left[\mathbf{k N} / \mathbf{m}^{\mathbf{2}}\right]$ \\
\hline $\mathbf{0 , 0 0}$ & $-0,20$ & $-1,23$ \\
\hline $\mathbf{1 , 0 0}$ & 0,00 & $-0,02$ \\
\hline $\mathbf{2 , 0 0}$ & 0,15 & 0,94 \\
\hline $\mathbf{3 , 0 0}$ & 0,28 & 1,72 \\
\hline $\mathbf{4 , 0 0}$ & 0,38 & 2,36 \\
\hline $\mathbf{5 , 0 0}$ & 0,47 & 2,90 \\
\hline $\mathbf{6 , 0 0}$ & 0,54 & 3,35 \\
\hline $\mathbf{7 , 0 0}$ & 0,60 & 3,73 \\
\hline $\mathbf{8 , 0 0}$ & 0,66 & 4,07 \\
\hline $\mathbf{9 , 0 0}$ & 0,70 & 4,36 \\
\hline $\mathbf{1 0 , 0 0}$ & 0,74 & 4,61 \\
\hline $\mathbf{1 1 , 0 0}$ & 0,78 & 4,83 \\
\hline $\mathbf{1 2 , 0 0}$ & 0,81 & 5,03 \\
\hline
\end{tabular}

Fonte: A autora.

Graficamente, o resultado pelo Eurosilo está mostrado na Figura 51: 
Figura 51- Sobrecarga de carregamento e descarregamento nos Silos 3 e 4.

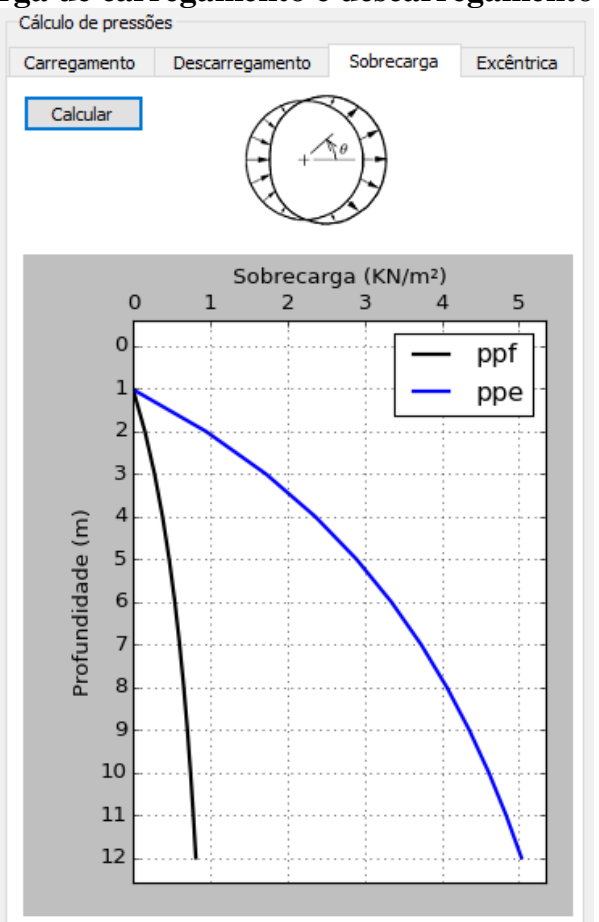

Fonte: A autora.

Semelhante ao exemplo anterior, para exemplificar a variação de valores de acordo $\operatorname{com} \theta$, alguns valores retirados do arquivo-texto gerado pelo programa, para $\mathrm{z}=2,00$ metros, estão mostrados na Tabela 19.

Tabela 19- Valores de sobrecarga com variação circunferencial nos silos 3 e 4.

\begin{tabular}{|c|c|c|c|}
\hline $\mathbf{Z}(\mathbf{m})$ & $\left.\boldsymbol{\theta} \mathbf{(}^{\circ}\right)$ & $\mathbf{p p f}_{\mathbf{p}}\left[\mathbf{k N} / \mathbf{m}^{\mathbf{2}}\right]$ & $\mathbf{p p e}_{\mathbf{p e}} \mathbf{k N} / \mathbf{m}^{\mathbf{2}} \mathbf{~}$ \\
\hline 2,00 & 0 & 0,15 & 0,94 \\
\hline 2,00 & 45 & 0,11 & 0,67 \\
\hline 2,00 & 90 & 0,00 & 0,00 \\
\hline 2,00 & 135 & $-0,11$ & $-0,67$ \\
\hline 2,00 & 180 & $-0,15$ & $-0,94$ \\
\hline
\end{tabular}

Fonte: A autora.

- Pressões excêntricas:

O Eurosilo faz o estudo das pressões excêntricas para os três tamanhos nos raios de excentricidade do canal de escoamento, mostrados nas Tabelas 20, 21 e 22 e Figuras 52 e 53 a seguir. 
Tabela 20-Pressões excêntricas para $\mathbf{r}_{\mathbf{c}}=0,25 \mathrm{r}$.

\begin{tabular}{|c|c|c|c|c|c|}
\hline \multicolumn{5}{|c|}{$\boldsymbol{r}_{\mathbf{c}}=\mathbf{0 , 2 5 r} \mathbf{e} \boldsymbol{\theta}_{\mathbf{c}}=\mathbf{7 , 3 9}$} \\
\hline $\mathbf{Z}$ (m) & $\boldsymbol{p}_{\text {hce }}\left[\mathbf{k N} / \mathbf{m}^{2}\right]$ & $\boldsymbol{p}_{\text {hse }}\left[\mathbf{k N} / \mathbf{m}^{2}\right]$ & $\boldsymbol{p}_{\text {hae }}\left[\mathbf{k N} / \mathbf{m}^{2}\right]$ & $\boldsymbol{p}_{\text {wse }}\left[\mathbf{k N} / \mathbf{m}^{2}\right]$ & $\boldsymbol{p}_{\text {wae }}\left[\mathbf{k N} / \mathbf{m}^{2}\right]$ \\
\hline $\mathbf{0 , 0 0}$ & 0,00 & 0,00 & 0,00 & 0,00 & 0,00 \\
\hline $\mathbf{1 , 0 0}$ & 4,75 & 5,36 & 5,96 & 3,05 & 3,40 \\
\hline $\mathbf{2 , 0 0}$ & 8,15 & 10,27 & 12,38 & 5,85 & 7,06 \\
\hline $\mathbf{3 , 0 0}$ & 10,58 & 14,76 & 18,95 & 8,42 & 10,80 \\
\hline $\mathbf{4 , 0 0}$ & 12,32 & 18,88 & 25,45 & 10,76 & 14,51 \\
\hline $\mathbf{5 , 0 0}$ & 13,56 & 22,66 & 31,76 & 12,92 & 18,11 \\
\hline $\mathbf{6 , 0 0}$ & 14,44 & 26,12 & 37,79 & 14,89 & 21,54 \\
\hline $\mathbf{7 , 0 0}$ & 15,08 & 29,29 & 43,50 & 16,70 & 24,80 \\
\hline $\mathbf{8 , 0 0}$ & 15,53 & 32,19 & 48,85 & 18,35 & 27,85 \\
\hline $\mathbf{9 , 0 0}$ & 15,86 & 34,85 & 53,85 & 19,87 & 30,70 \\
\hline $\mathbf{1 0 , 0 0}$ & 16,09 & 37,29 & 58,50 & 21,26 & 33,35 \\
\hline $\mathbf{1 1 , 0 0}$ & 16,26 & 39,53 & 62,80 & 22,53 & 35,80 \\
\hline $\mathbf{1 2 , 0 0}$ & 16,37 & 41,58 & 66,78 & 23,70 & 38,07 \\
\hline
\end{tabular}

Fonte: A autora.

Tabela 21- Pressões excêntricas para $\mathbf{r}_{\mathrm{c}}=\mathbf{0 , 4 0} \mathbf{r}$.

\begin{tabular}{|c|c|c|c|c|c|}
\hline \multicolumn{6}{|c|}{$\boldsymbol{r}_{\mathbf{c}}=\mathbf{0 , 4 0 r} \mathbf{e} \boldsymbol{\theta}_{\mathbf{c}}=\mathbf{1 2 , 6 7}$} \\
\hline $\mathbf{Z}_{\mathbf{~ ( m ) ~}}$ & $\boldsymbol{p}_{\text {hce }}\left[\mathbf{k N} / \mathbf{m}^{2}\right]$ & $\boldsymbol{p}_{\mathbf{h s e}}\left[\mathbf{k N} / \mathbf{m}^{2}\right]$ & $\boldsymbol{p}_{\text {hae }}\left[\mathbf{k N} / \mathbf{m}^{2}\right]$ & $\boldsymbol{p}_{\text {wse }}\left[\mathbf{k N} / \mathbf{m}^{2}\right]$ & $\boldsymbol{p}_{\text {wae }}\left[\mathbf{k N} / \mathbf{m}^{2}\right]$ \\
\hline $\mathbf{0 , 0 0}$ & 0,00 & 0,00 & 0,00 & 0,00 & 0,00 \\
\hline $\mathbf{1 , 0 0}$ & 5,05 & 5,36 & 5,67 & 3,05 & 3,23 \\
\hline $\mathbf{2 , 0 0}$ & 9,14 & 10,27 & 11,39 & 5,85 & 6,49 \\
\hline $\mathbf{3 , 0 0}$ & 12,46 & 14,76 & 17,07 & 8,42 & 9,73 \\
\hline $\mathbf{4 , 0 0}$ & 15,15 & 18,88 & 22,62 & 10,76 & 12,90 \\
\hline $\mathbf{5 , 0 0}$ & 17,33 & 22,66 & 27,99 & 12,92 & 15,96 \\
\hline $\mathbf{6 , 0 0}$ & 19,09 & 26,12 & 33,14 & 14,89 & 18,89 \\
\hline $\mathbf{7 , 0 0}$ & 20,53 & 29,29 & 38,05 & 16,70 & 21,69 \\
\hline $\mathbf{8 , 0 0}$ & 21,69 & 32,19 & 42,70 & 18,35 & 24,34 \\
\hline $\mathbf{9 , 0 0}$ & 22,63 & 34,85 & 47,08 & 19,87 & 26,84 \\
\hline $\mathbf{1 0 , 0 0}$ & 23,40 & 37,29 & 51,19 & 21,26 & 29,18 \\
\hline $\mathbf{1 1 , 0 0}$ & 24,02 & 39,53 & 55,04 & 22,53 & 31,38 \\
\hline $\mathbf{1 2 , 0 0}$ & 24,52 & 41,58 & 58,63 & 23,70 & 33,42 \\
\hline
\end{tabular}

Fonte: A autora.

Tabela 22- Pressões excêntricas para $r_{c}=0,60 \mathrm{r}$.

\begin{tabular}{|c|c|c|c|c|c|}
\hline \multicolumn{5}{|c|}{$\boldsymbol{r}_{\mathbf{c}}=\mathbf{0 , 6 0 r}$ e $\boldsymbol{\theta}_{\mathbf{c}}=\mathbf{2 1 , 4 1}$} \\
\hline $\mathbf{Z}_{\mathbf{~ ( m ) ~}}$ & $\boldsymbol{p}_{\text {hce }}\left[\mathbf{k N} / \mathbf{m}^{2}\right]$ & $\boldsymbol{p}_{\text {hse }}\left[\mathbf{k N} / \mathbf{m}^{2}\right]$ & $\boldsymbol{p}_{\text {hae }}\left[\mathbf{k N} / \mathbf{m}^{2}\right]$ & $\boldsymbol{p}_{\text {wse }}\left[\mathbf{k N} / \mathbf{m}^{2}\right]$ & $\boldsymbol{p}_{\text {wae }}\left[\mathbf{k N} / \mathbf{m}^{2}\right]$ \\
\hline $\mathbf{0 , 0 0}$ & 0,00 & 0,00 & 0,00 & 0,00 & 0,00 \\
\hline $\mathbf{1 , 0 0}$ & 5,22 & 5,36 & 5,49 & 3,05 & 3,13 \\
\hline $\mathbf{2 , 0 0}$ & 9,76 & 10,27 & 10,77 & 5,85 & 6,14 \\
\hline $\mathbf{3 , 0 0}$ & 13,71 & 14,76 & 15,82 & 8,42 & 9,02 \\
\hline $\mathbf{4 , 0 0}$ & 17,14 & 18,88 & 20,63 & 10,76 & 11,76 \\
\hline
\end{tabular}




\begin{tabular}{|c|c|c|c|c|c|}
\hline $\mathbf{5 , 0 0}$ & 20,12 & 22,66 & 25,20 & 12,92 & 14,36 \\
\hline $\mathbf{6 , 0 0}$ & 22,71 & 26,12 & 29,52 & 14,89 & 16,83 \\
\hline $\mathbf{7 , 0 0}$ & 24,97 & 29,29 & 33,61 & 16,70 & 19,16 \\
\hline $\mathbf{8 , 0 0}$ & 26,93 & 32,19 & 37,46 & 18,35 & 21,35 \\
\hline $\mathbf{9 , 0 0}$ & 28,64 & 34,85 & 41,07 & 19,87 & 23,42 \\
\hline $\mathbf{1 0 , 0 0}$ & 30,12 & 37,29 & 44,47 & 21,26 & 25,35 \\
\hline $\mathbf{1 1 , 0 0}$ & 31,41 & 39,53 & 47,65 & 22,53 & 27,16 \\
\hline $\mathbf{1 2 , 0 0}$ & 32,53 & 41,58 & 50,62 & 23,70 & 28,86 \\
\hline
\end{tabular}

Fonte: A autora.

Figura 52-Pressões excêntricas horizontais nos Silos 3 e 4.

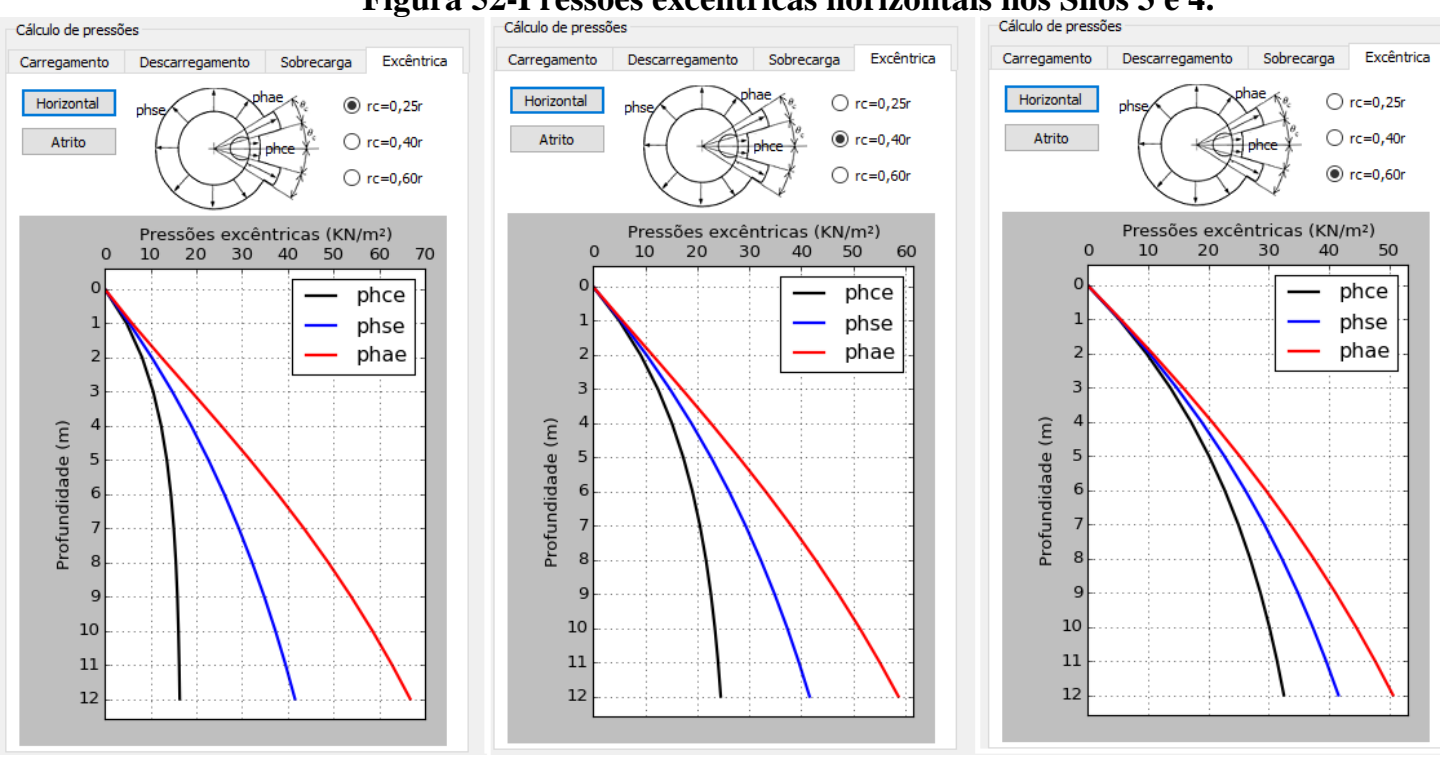

Fonte: A autora.

Figura 53- Pressões excêntricas de atrito nos Silos 3 e 4.
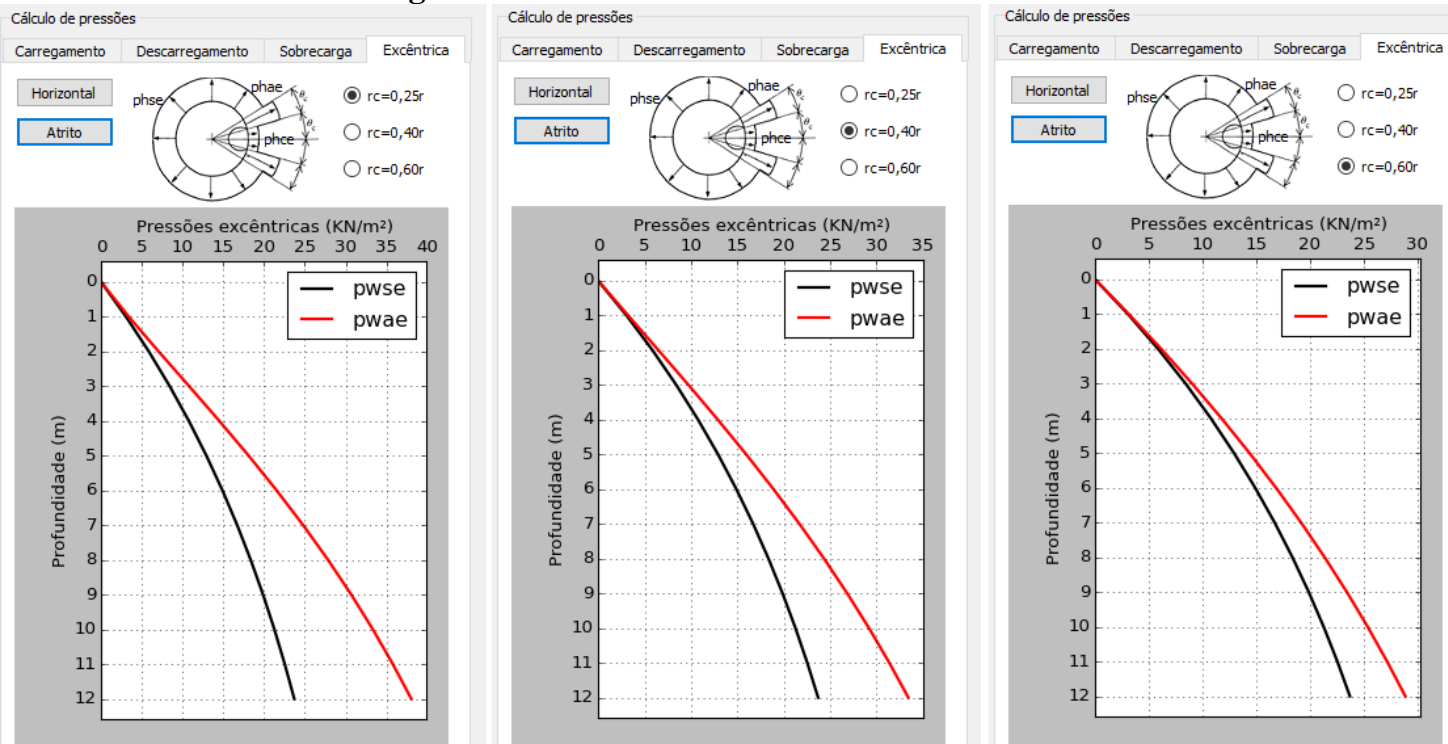

Fonte: A autora. 
- Pressões no fundo do silo:

São as mesmas para os casos de silos 1 e 2, pois elas dependem das pressões de Janssen (1985), ângulo de inclinação da tremonha $(\beta)$ e coeficiente de atrito da tremonha que neste caso foram adotadas 0,20 .

\subsection{Comentários do capítulo}

Torna-se válido ressaltar que o resultado dessa dissertação corresponde às etapas para a criação do software Os exemplos deste capítulo foram utilizados para exemplificar ilustrar a utilização do software Eurosilo.

Após análise dos resultados obtidos, pode-se perceber que as pressões variam significativamente considerando o descarregamento excêntrico. Por isso, silos projetados para serem concêntricos não devem ser utilizados com excentricidades de descarregamento. Esses podem não apresentar segurança satisfatória e causar sérios danos à estrutura. 


\section{CONCLUSÕES}

Após realizar uma significativa revisão bibliográfica quanto às teorias de pressões em silos e considerando os documentos normativos existentes, foi possível desenvolver um software capaz de calcular o fluxo e as pressões de produtos armazenados em silos metálicos cilíndricos: o Eurosilo.

Tal software apresenta as seguintes funcionalidades, em silos cilíndricos metálicos:

- Determinação do tipo de fluxo;

- Cálculo das pressões simétricas e assimétricas no corpo do silo;

- Cálculo das pressões de carregamento e descarregamento atuantes no fundo do silo.

Os estudos das pressões em silos metálicos, principalmente com descarregamento excêntrico, são imprescindíveis para um projeto estrutural seguro. Os exemplos realizados mostraram que o software Eurosilo, apresentou resultados satisfatórios para auxiliar o projetista através dos valores obtidos de pressão, fazer o dimensionamento da estrutura, além de ser uma proposta para uma futura norma brasileira de ações em silos.

\subsection{Sugestões para trabalhos futuros}

A principal sugestão é dar continuidade na programação deste software admitindo as mesmas hipóteses simplificadoras, fazendo também o dimensionamento de silos metálicos cilíndricos.

Sugere-se implementar valores das propriedades físicas de mais tipos de produtos armazenados, de preferência através de determinação com ensaios no aparelho de cisalhamento direto. 


\section{REFERÊNCIAS}

ALVES, V. Análise e dimensionamento de silos de concreto armado: desenvolvimento de um programa computacional. 98 p. Dissertação (Mestrado) - Universidade Estadual de Campinas. Campinas. 2001.

AMERICAN CONCRETO INSTITUTE ACI-313: Standard Practice for Design and Construction of Concrete Silos and Stracking Tubes for Storing Granular Materials. EUA, 1977.

ANDRADE Jr, L. J. Análise Estrutural das Chapas Metálicas de Silos e de Reservatórios Cilíndricos. 208p. Dissertação (Mestrado) - Escola de Engenharia de São Carlos. Universidade de São Paulo. 1998.

Ação do Vento em Silos Cilíndricos de baixa relação altura/diâmetro. 151p. Tese (Doutorado) - Escola de Engenharia de São Carlos. São Carlos. Universidade de São Paulo. 2002.

ARAÚJO, E.C.. Estudo Teórico e Experimental de Tremonhas Piramidais para Silos Metálicos Elevados. 317p. Tese (Doutorado) - Escola de Engenharia de São Carlos. Universidade de São Paulo. 1997.

AUATRALIAN STANDARD. AS 3774: Loads on bulk containers. Sydney, 1996.

BENINK, E. J. Flow and stress analysis of cohesionless bulk materials in silos related to codes. University of Twente. ISBN 90-9002704-1. Enschede. The Netherlands. 1989.

CALIL Jr., C. Silos de Madeira. 198 p. Dissertação (Mestrado) - Escola de Engenharia de São Carlos. Universidade de São Paulo. São Carlos. 1978.

Sobrepresiones en las paredes de los silos para almacenamiento de productos pulverulentos cohesivos. 184p. Tese (Doutorado). Escola Politécnica de Barcelona. Espanha. 
Publicação do Departamento de Estruturas da Escola de Engenharia de São Carlos. USP. 1982.

. Recomendações de Fluxo e de Cargas para o Projeto de Silos Verticais. 198p. Tese de Livre Docência. EESC - USP. 1990

CALIL Jr., C.; CHEUNG, A.B. Silos: Pressões, fluxo, recomendações para projeto e exemplos de cálculo. 240 p. Serviço gráfico - EESC/USP - São Carlos - SP. 2007.

CHEUNG, A. B. Modelo estocástico de pressões de produtos armazenados para a estimativa da confiabilidade estrutural de silos esbeltos. 252 p. Tese (Doutorado) - Escola de Engenharia de São Carlos. USP. São Carlos. 2007.

COMPANHIA NACIONAL DE ABASTECIMENTO (CONAB). Acompanhamento da safra brasileira de grãos. V.3, n.10, 183p. Brasília. 2015.

COUTO, L.G. Contribuição ao Estudo dos Silos de Argamassa Armada para Armazenamento de Cereais. 147p. Dissertação (Mestrado) - Escola de Engenharia de São Carlos. Universidade de São Paulo. 1989.

DEUTSCHE NORM - DIN 1055-6: Basis of design and actions on structures - Part 6: design loads for building and loads in silo bins. Berlin, Verlaz, 2005.

EUROPEAN COMMITTEE OF STANDARDIZATION. PrEN 1991-4:Actions on Silos and tanks. CEN. United Kingdom. 2006.

ESTEVES Jr., P. Silos Metálicos de Chapa Corrugada. 118p. . Dissertação (Mestrado) Escola de Engenharia de São Carlos. Universidade de São Paulo. 1989.

FASSONI, D. P. Sistema Construtivo Modular em Madeira para Silos Horizontais. 150p. Dissertação (Mestrado) - Escola de Engenharia de São Carlos. Universidade de São Paulo. 1994. 
FORTES FILHO, J. Uma introdução ao estudo de silos. 427 p. Dissertação (Mestrado) Escola de Engenharia de São Carlos. USP. São Carlos. 1985.

FREITAS, E.G. Estudo teórico e experimental das pressões em silos cilíndricos de baixa relação altura/diâmetro e fundo plano. 175 p. Tese (Doutorado) - Escola de Engenharia de São Carlos. USP. São Carlos. 2001.

GALLEGO, E; GONZÁLEZ-MONTELLANO, C; RAMÍREZ, A.; AYUGA, F. A simplified analytical procedure for assessing the worst patch load location on circular steel silos with corrugated walls. Engineering Structures 33. 1940-1954. 2011

GOMES, F. C. Silos para armazenamento de laranjas. 107 p. Dissertação (Mestrado) Escola de Engenharia de São Carlos. USP. São Carlos. 1994.

GOMES, C. G. Estudo teórico e experimental das ações em silos horizontais. 182 p. Tese (Doutorado)- Escola de Engenharia de São Carlos. USP, São Carlos. 2000.

INTERNACIONAL ORGAZNIZATION FOR STANDART ISO 11697: Bases for design of structures: Loads due bulk materials. London, 1995.

JANSSEN, H. A. Versuche Über Gestreindedruck in Silozellen. Zeitschrift. Verein Deustscher Ingeniure. v. 39. 1895.

JENIKE, A. W. Storage and flow of solids. Salt Lake City: University of Utah, 1964.

JENIKE, A.W.; JOHANSON, J. R. Bin Loads. Journal of the Structural Division, ASCE, v.95, 1968.

JENIKE, A.W.; JOHANSON, J. R; CARSON, J. W. Bins loads in 3 parts. Journal of engineering for Industry, ASCE, v.95. p. 1-5, 6-12, 13-20, 1973.

MADRONA, F. S. Pressões em Silos Esbeltos com descarga excêntrica. 119 p. Dissertação (Mestrado) - Escola de Engenharia de São Carlos. USP. São Carlos. 2008. 
MARTINS, G.C.A. Estudo teórico e experimental de esforços devidos a cabos de termometria fixados em estruturas de coberturas de silos cilíndricos para armazenamento de grãos. 2012. 84 p. Dissertação (Mestrado) - Escola de Engenharia de São Carlos, Universidade de São Paulo, 2012.

MILANI, A.P. Determinação das propriedades de produtos armazenados para o projeto de pressões e fluxo em silos. 272 p. Tese (Doutorado) - Escola de Engenharia de São Carlos. USP. São Carlos. 1993.

NASCIMENTO, F.C. A relação entre as pressões horizontais e verticais em silos elevados: o parâmetro K. 119 p. Dissertação (Mestrado) - Escola de Engenharia de São Carlos. USP. São Carlos. 2008.

NASCIMENTO, J. W. Estudo de silos metálicos prismáticos para fábricas de ração. 152 p. Tese (Doutorado) - Escola de Engenharia de São Carlos. USP. São Carlos. 1996.

PALMA, G. Pressões e fluxo em silos esbeltos (h/d $\geq \mathbf{1 , 5}) .109$ p. Tese (Mestrado) - Escola de Engenharia de São Carlos. USP, São Carlos. 2005.

PIEPER,K; WENZEL,F. Druckverhältnisse in Silozellen, Wilhelm Ernst und Sohn, Berlin, 1964.

ROTTER, J.M. The Analysis of Steel Bins Subject to Eccentric Discharge. Proc., Second Int. Conf. Bulk Material Storage Handling and Transportation. IEAust. 264-271p (1986).

SADOWSKI, A.J.; ROTTER, J.M. Steel silos with different aspect ratios: II - behaviour under eccentric discharge. Journal of Constructional Steel Research 67. 9 p. 2011.

SILVA, M. C. A. T. Estudo da Variabilidade pressões em silos. 192 p. Tese (Doutorado) Escola de Engenharia de São Carlos. USP. São Carlos. 1993.

SPERL, M. Experiments on corn pressure in silo cells - translation and comment of Janssen's paper from 1895. Granular Matter, V.8(2), p. 59-65. 2006. 
WALKER, D. M. An Appoximate Theory for Pressures and Arching in Hoppers. Chem. Eng. Sci.. V.21. 1966.

WALTER, J.K. A theoretical analysis of stresses in silos with vertical walls. Chemical Engineering Science. v. 28. 1973.

VAZ, J. Silos verticais de madeira compensada. 346 p. Dissertação (Mestrado) - Escola de Engenharia de São Carlos. USP. São Carlos. 1987. 